Universidad Autónoma Metropolitana Unidad - Iztapalapa

División de Ciencias Básicas e Ingeniería Departamento de Ingeniería Eléctrica Posgrado en Ingeniería Biomédica

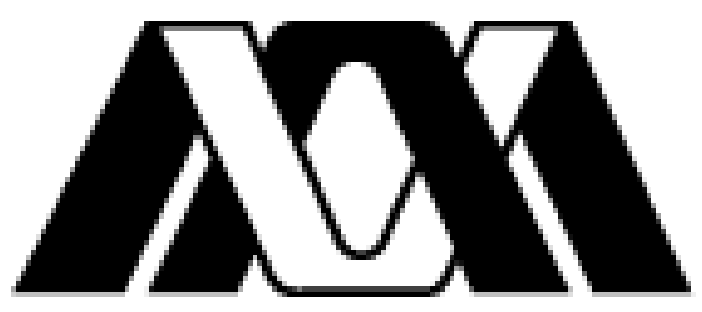

Tesis para obtener el grado de Maestro en Ciencias (Ingeniería Biomédica)

\title{
"Estudio del efecto del polipirrol dopado con yodo, sintetizado por plasma, en ratas con lesión crónica de médula espinal, por medio de MRI"
}

Presenta:

Ing. Arturo Hernández Medina

Asesores:

Dr. J. C. Axayacatl Morales Guadarrama

Dr. Roberto Olayo González 


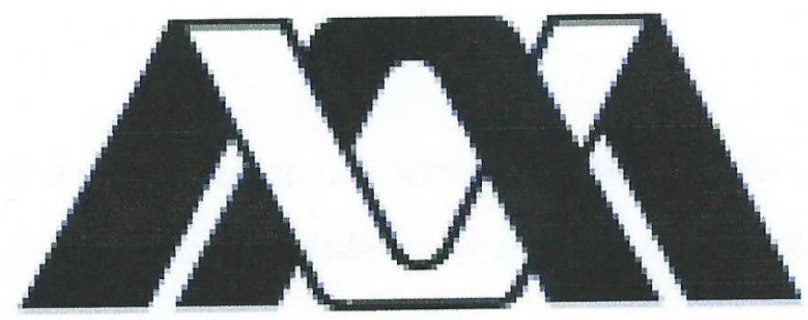

Universidad Autónoma Metropolitana

Unidad - Iztapalapa

División de Ciencias Básicas e Ingeniería

Departamento de Ingeniería Eléctrica

Posgrado en Ingeniería Biomédica

Tesis para obtener el grado de Maestro en Ciencias (Ingeniería Biomédica)

"Estudio del efecto del polipirrol dopado con yodo, sintetizado por plasma, en ratas con lesión crónica de médula espinal, por medio de MRI"

Presenta: Ing. Arturo Hernández Medina

Directores de tesis:

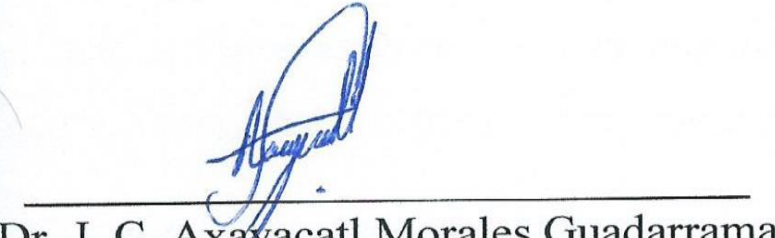

Dr. J. C. Axayacatl Morales Guadarrama

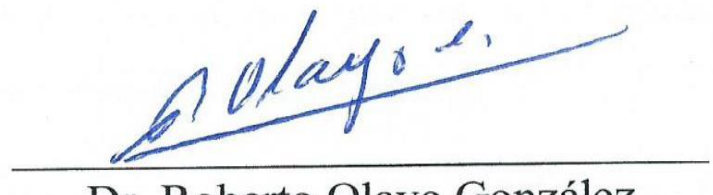

Dr. Roberto Olayo González

Sinodales:

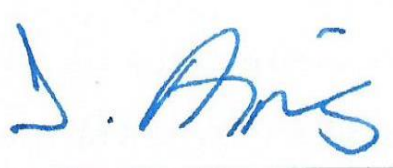

Dr. José Joaquín Azpiroz Leehan SECRETARIO

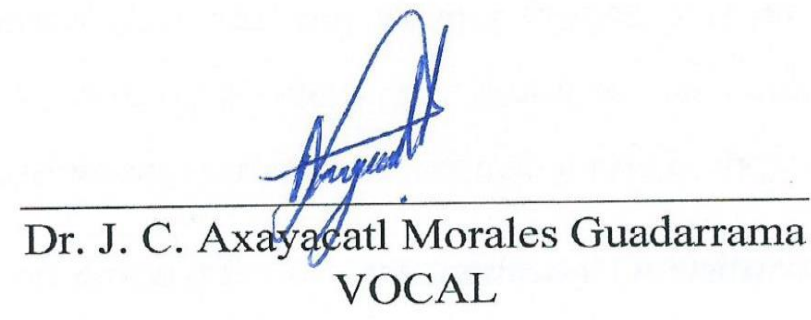

VOCAL

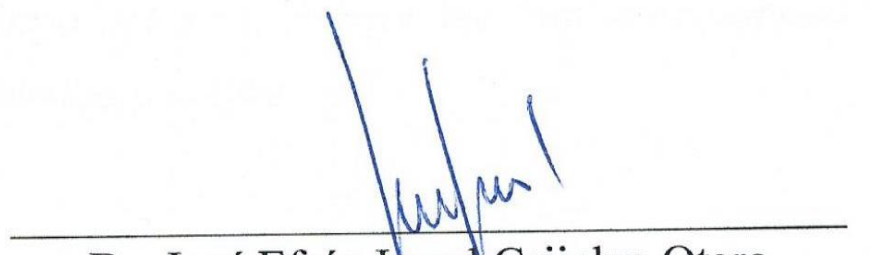

Dr. José Efrén Israel Grijalva Otero

PRESIDENTE 
Quiero dedicar esta tesis a cada una de las personas que estuvieron presentes en esta etapa, que me han acompañado y que, con palabras de aliento o recomendaciones, me han hecho una mejor persona.

A mi papá, Arturo, por siempre estar ahí; con un carácter singular y representativo que cualquier persona que lo conoce sabe a qué me refiero. Pero, al mismo tiempo, tan cariñoso y protector con sus hijos que sería irreconocible para el resto. Por siempre apoyarme e incentivarme a no conformarme y dar lo mejor de mí.

A mi mamá, Susana. Con su forma de ser cariñosa, empática, amigable y protectora nos ha sabido complementar, a través de ejemplos, para ser mejores personas desde un punto de vista más humanitario.

Gracias por mantener a nuestra familia y brindarnos todo lo necesario a sus dos hijos.

A mi hermana, Elizabeth, por ser la mejor maestra y ejemplo para mí desde hace mucho tiempo. En conjunto con Irving, por su carácter sobreprotector a su hermano menor, porque sé que siempre estarán ahí con cualquier duda y problema. Por ser la mejor balanza durante este crecimiento y formación profesional que han impulsado en mí.

A Mariana, por estar presente en más de estos dos años de diferentes experiencias. Por compartir los buenos y malos momentos. Así como por apoyarme en todas las ideas de vida y por darme motivación para ser mejor día con día.

A todos mis profesores, que son parte fundamental de cada uno de mis logros, y a mis asesores en esta última etapa; por compartir su conocimiento y por guiarme en cada momento de trabajo. A Miguel por su valioso conocimiento y tiempo invertido en mi trabajo. A todos mis compañeros y amigos del posgrado, así como a los de Guanajuato y Querétaro, entre otro que están fuera del país. Porque me han acompañado y han hecho todo este camino mucho más divertido y alegre. 


\section{Agradecimientos}

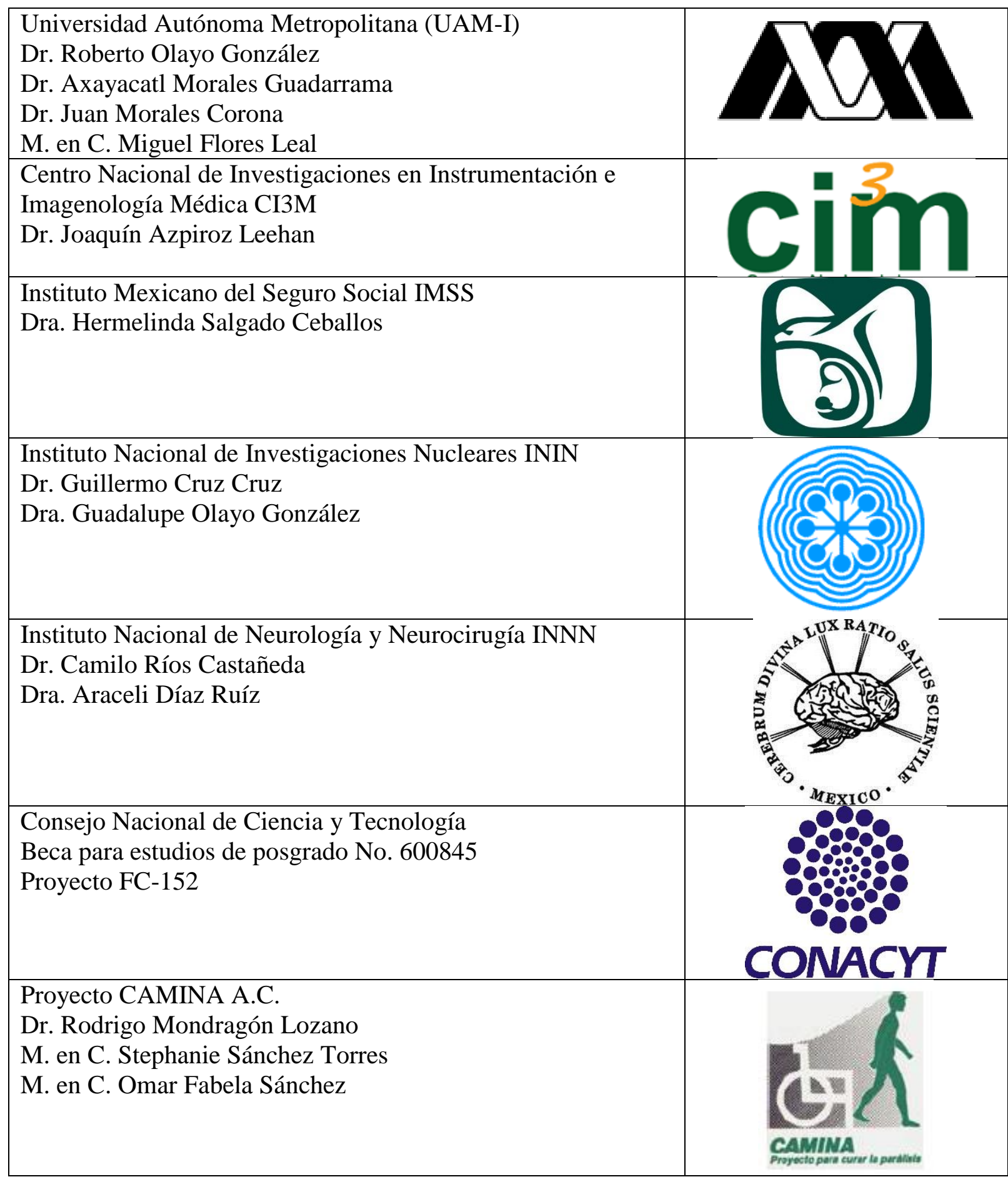




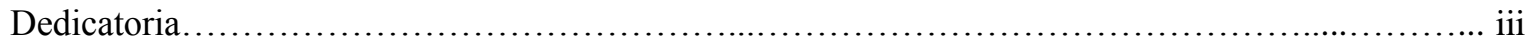

Agradecimientos....................

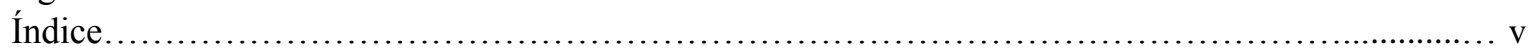

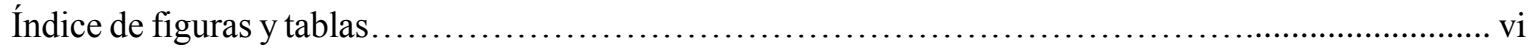

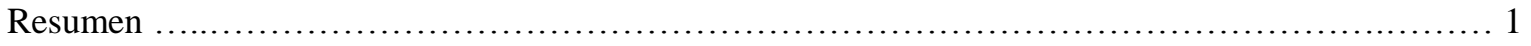

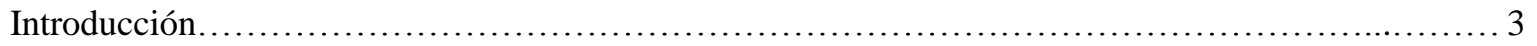

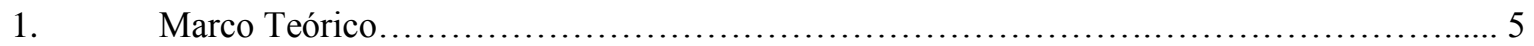

1.1 Lesión Traumática de Médula Espinal........................................................... 6

1.1.1 Efectos secundarios de la Lesión Traumática de Médula Espinal.......................... 7

1.1.2 Anatomía y fisiología de la médula espinal..................................... 10

1.1.3 Epidemiología de la lesión de médula espinal..................................... 15

1.1.4 Estrategias terapéuticas en lesión de médula espinal................................. 17

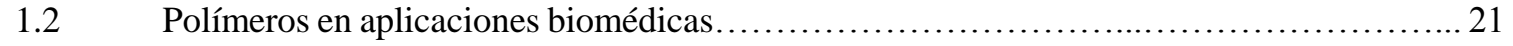

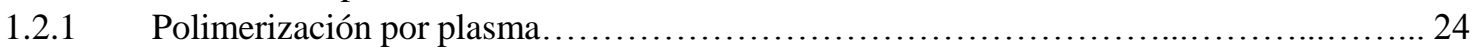

1.2.2 Polímero Polipirrol dopado con yodo en lesión de médula espinal........................ 26

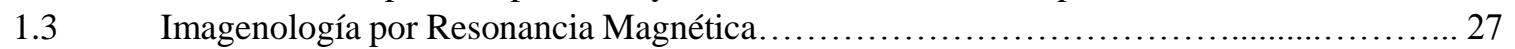

1.3.1 Resonancia Magnética en lesiones de médula espinal....................................... 34

1.3.2 Imagen por Tensor de Difusión y Tractografía por Resonancia Magnética................. 36

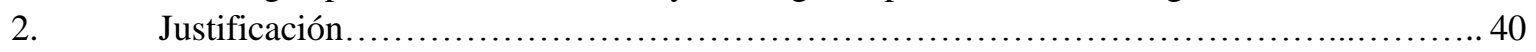

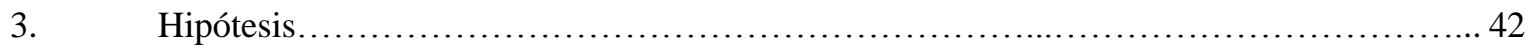

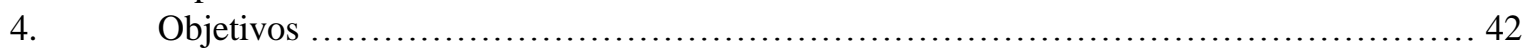

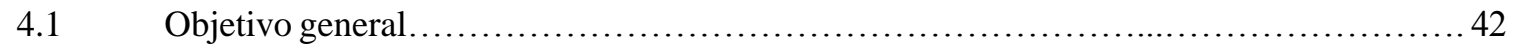

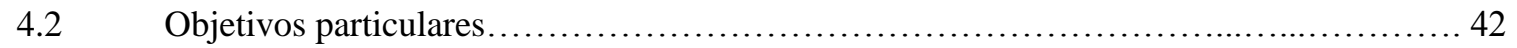

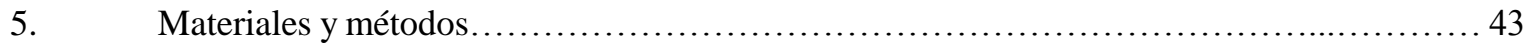

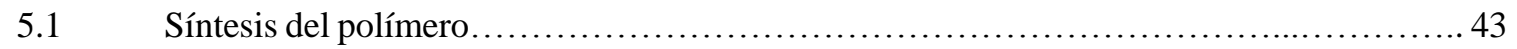

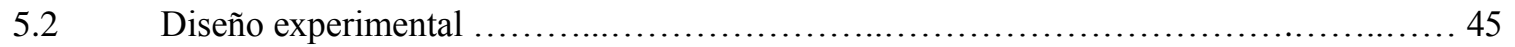

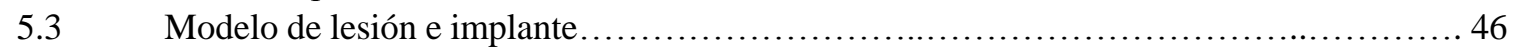

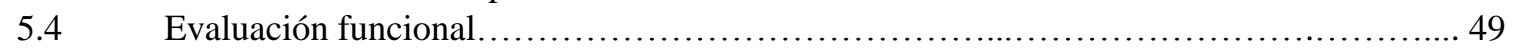

5.5 Estudio de Imagenología por Resonancia Magnética................................... 50

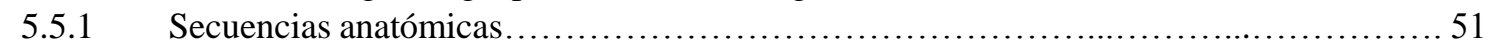

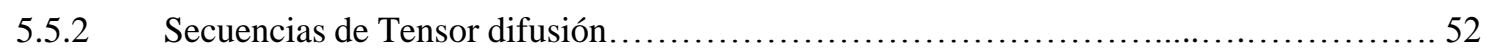

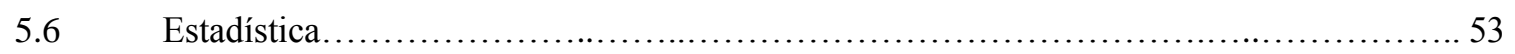

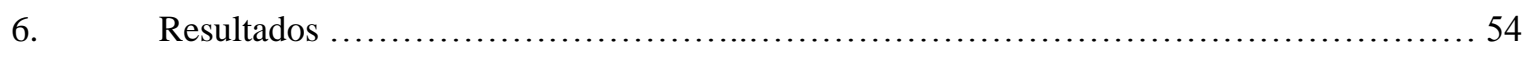

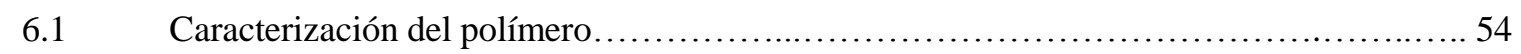

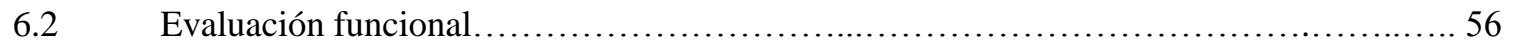

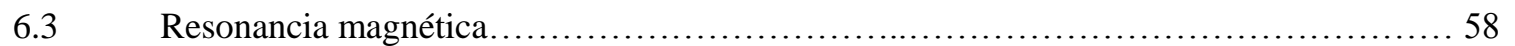

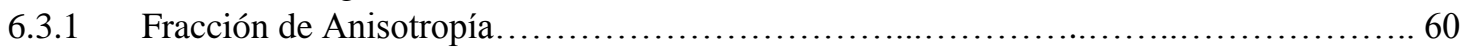

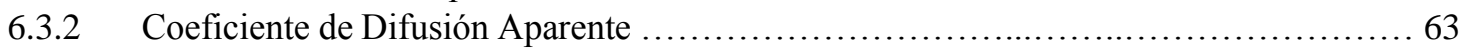

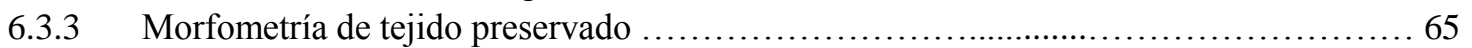

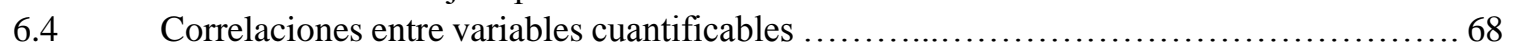

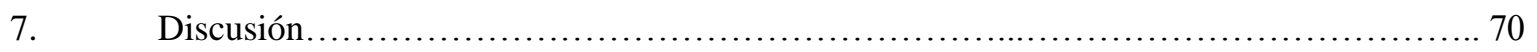

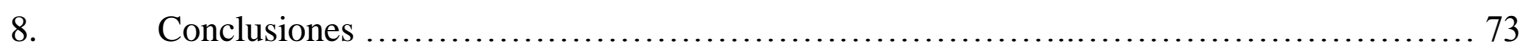

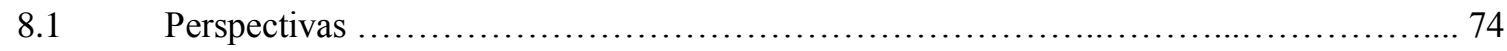

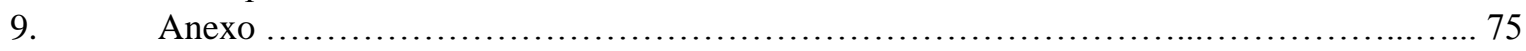

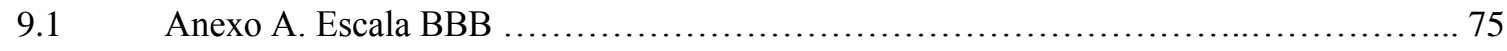

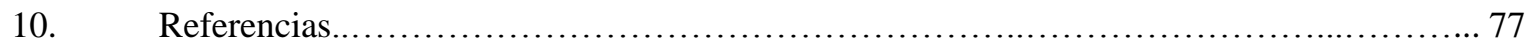




\section{Índice de figuras y tablas}

Figura 1.1 Daño ocurrido después de LTME. Representación del trauma inicial y daño secundario. Fase aguda: compromete los vasos sanguíneos, reduciendo la entrega local de oxígeno, lo que decrementa la producción de ATP e incrementa la producción de especies reactivas de oxígeno. En los daños secundarios se comienza a ver muerte neuronal, desmielinización de los axones, activación de la microglia y llegada de astrocitos que formarán la cicatriz glial (Scholpa 2017).

Tabla 1.1 Principales acontecimientos ocurridos en la fase aguda de la lesión traumática de médula espinal. Se remarcan en azul las casillas de los padecimientos que se repiten en fase sub-aguda. Modificado de Oyinbo, 2011

Tabla 1.2 Principales acontecimientos ocurridos en la fase sub-aguda de la lesión traumática de médula espinal. Se remarcan en azul las casillas de los padecimientos que se repiten en fase aguda y en verde aquellos que también aparecen en fase crónica. Modificado de Oyinbo, 2011

Tabla 1.3 Principales acontecimientos ocurridos en la fase crónica de la lesión traumática de médula espinal. Se remarcan en verde aquellos padecimientos que también aparecen en fase sub-aguda. Modificado de Oyinbo, 2011

Figura 1.2: Estructura de una neurona grande perteneciente al encéfalo (Guyton 2011).

Figura 1.3: Anatomía fisiológica de la sinapsis (Guyton 2011).

Figura 1.4: Organización longitudinal de la médula espinal, con una breve descripción de las mayores funciones de cada nivel (Bickenbach 2013).

Figura 1.5: Corte axial de la médula espinal. Disponible el 27 de noviembre de 2017

http://www.efn.uncor.edu/departamentos/divbioeco/anatocom/Biologia/Los\%

20Sistemas/Nervioso/Central/Medula.htm

Figura 1.6: Médula espinal con meninges. Disponible el 2 de diciembre de 2017 en:http://accessmedicine.mhmedical.com/content.aspx?bookid=574\&sectionid $=42524595$

Tabla 1.4 Principales polímeros naturales en aplicaciones biomédicas. Modificado de (Angelova 1999)

Tabla 1.5 Principales polímeros sintéticos en aplicaciones biomédicas. Modificado de (Angelova 1999)

Figura 1.7 Diagrama ejemplo de polimerización por plasma. La entrada de monómero, la bomba de vacío y una salida para medición de presión en la parte inferior. Los dos electrodos en el centro con la reacción y el plasma entre ellos; uno a tierra y el otro a la fuente de energía. (Wydeven 1976)

Figura 1.8 Protones alinados de forma de baja o alta energía con respecto al campo estacionario (Grover 2015).

Figura 1.9 Protones sin y con aplicación de un campo magnético externo (Pooley 2005). 
Figura 1.10 Inducción de RF sobre el tejido que desalinea los núcleos por absorción de energía. Disponible el 17 de noviembre de 2017 en: http://onoimaging.blogspot.mx/2008/07/basic-principles-of-magneticresonance.html

Figura 1.11 Tensión proporcional FID. Disponible el 17 de noviembre de 2017 en: http://onoimaging.blogspot.mx/2008/07/basic-principles-of-magneticresonance.html

Figura 1.12 Transformación de la FID para obtención de información (Grover 2015).

Figura 1.13 Relajación longitudinal (T1) (Pooley 2005).

Figura 1.14 Relajación Transversal (T2) (Pooley 2005).

Tabla 1.6 valores de tiempo para relajaciones $\mathrm{T}_{1}$ y $\mathrm{T}_{2}$, de algunos de los principales tejidos y sustancias del SNC

Figura 1.15 Relajación longitudinal y transversal cerebral (Pooley 2005).

Figura 1.16 Movimiento isotrópico (A) Difusión restringida, se eleva el valor de FA (B y C) (Grover 2015).

Figura 1.17 Ecuaciones para los índices FA y ADC (Vedantam 2013).

Figura 1.18 Ejemplos de Tractografías: Haz de fibras corticoespinales en azul con un poco de fibras dispersas (A). Haz de fibras cortico espinales con cuerpo calloso en rojo (B). Tracto cortico espinal, con parte del tronco del cuerpo calloso y tracto córtico-bulbar, en azul por la dirección (C).

Figura 5.1 Reactor durante polimerización de PPy/I

Figura 5.2 Paredes de reactor recubiertas por polímero PPy/I

Figura 5.3 Mesopartículas de PPy/I obtenidas en mortero de Agatha

Figura 5.4 Cronograma del estudio experimental que se siguió para cada una de las ratas.

Figura 5.5 Rata colocada en instrumento NYU impactor para realizar la LTME Figura 5.6 Médula espinal de rata expuesta a la altura de la vértebra T9

Figura 5.7 Rata durante evaluación BBB

Figura 5.8 Resonador Magnético Varian de 7T utilizado para los estudios de los sujetos experimentales. Ubicado en las instalaciones del CI3M (Centro Nacional de Investigaciones en Instrumentación e Imagenología Médica)

Figura 6.1 Espectroscopía por infrarrojo del polímero polipirrol sintetizado por plasma

Tabla 6.1 Principales puntos de absorción encontrados en el espectro por IR del PPy/I

Figura 6.2 Gráfica de valores BBB promedio, para evaluar la recuperación locomotora, de los dos diferentes grupos de estudio. Expresado como la media de las evaluaciones por grupo de estudio \pm error estándar $(n=10$, previo al implante $4 ; n=3$ grupo control, después del momento del implante; $n=6$ grupo implante, después del implante). ANOVA de medidas repetidas. *Diferencia significativa entre grupo implante con respecto al grupo control $(\mathrm{p}<0.05)$

Figura 6.3 Imágenes sagitales, longitudinales, de resonancia magnética, ponderadas en T1, de rata con lesión traumática de médula espinal. Obtenidas con secuencia GE3D. Se remarca la zona de la lesión con un círculo. 
Figura 6.4 Imágenes sagitales, longitudinales, de resonancia magnética, ponderadas en T2, de rata con lesión traumática de médula espinal. Obtenidas con secuencia FSEMS. Se remarca la zona de la lesión con un círculo.

Figura 6.5 Imágenes sagitales de resonancia magnética, ponderadas en T1, de la zona de la lesión traumática de médula espinal en ratas. Se realiza comparativa entre sujeto control y sujeto implante en las semanas 0 y 11 , después de la lesión y 7 semanas después del implante, respectivamente.

Figura 6.6 Imágenes sagitales de resonancia magnética, ponderadas en T2, de la zona de la lesión traumática de médula espinal en ratas. Se realiza comparativa entre sujeto control y sujeto implante en las semanas 0 y 11 , después de la lesión y 7 semanas después del implante, respectivamente.

Figura 6.7 Gráfica de valores FA promedio, de los dos diferentes grupos de estudio. Expresado como la media de las evaluaciones por grupo de estudio \pm error estándar ( $n=3$ grupo control; $n=6$ grupo implante). ANOVA de medidas repetidas. *Diferencia significativa entre grupo implante con respecto al grupo control $(\mathrm{p}<0.05)$

Figura 6.8 Gráfica de valores ADC promedio, de los dos diferentes grupos de estudio. Expresado como la media de las evaluaciones por grupo de estudio \pm error estándar ( $n=3$ grupo control; $n=6$ grupo implante). ANOVA de medidas repetidas. *Diferencia significativa entre las semanas de estudio para ambos grupos $(\mathrm{p}<0.05)$

Figura 6.9 Comparativa morfológica entre grupos de investigación. Se muestra la médula segmentada entre T8-T10. En verde se encuentra todo el tejido nervioso, en azul se muestran los quistes y en color amarillo los voxeles hipointesos de la región de interés.

Figura 6.10 Gráfica con los porcentajes de preservación de tejido en la médula espinal para cada uno de los grupos de investigación en las diferentes semanas que fueron evaluadas.

Tabla 6.2 Porcentajes de volúmenes de los dos grupos de investigación con respecto al tiempo del experimento en que fueron evaluados.

Figura 6.11 Correlación de valores FA con ADC para cada uno de los estudios (5 estudios en total) realizados a cada sujeto experimental $(n=9), 45$ muestras en total. Cálculo del coeficiente de correlación de Pearson, se encontró relación significativa $(\mathrm{r} 2=0.3153, \mathrm{p}<0.01)$

Figura 6.12 Correlación de los puntajes FA (rojo) y ADC (azul), con respecto a las evaluaciones BBB de la semana en la cual se realizó cada estudio de resonancia magnética, 5 estudios en total realizados a cada sujeto experimental $(n=9), 45$ muestras en total. Cálculo del coeficiente de correlación de Pearson, no se encontró relación significativa para $\mathrm{FA}-\mathrm{BBB}(\mathrm{r} 2=0.0511, \mathrm{p}=0.135)$, ni para $\mathrm{ADC}-\mathrm{BBB}(\mathrm{r} 2=0.026, \mathrm{p}=0.208)$ 


\section{Resumen}

Introducción. En diversos estudios se ha mostrado un eficiente uso del implante de polipirrol dopado con yodo (PPyI), sintetizado por plasma, para la recuperación funcional, en sujetos experimentales, como tratamiento después de una Lesión Traumática de la Médula Espinal (LTME). Este trabajo muestra los resultados de la aplicación del implante de polímero PPyI como tratamiento después de una LTME, en fase crónica, mediante Imagenología de Resonancia Magnética (MRI).

Objetivo. Estudiar el efecto del polímero polipirrol dopado con yodo en un modelo de lesión crónica de médula espinal a la altura de la novena vértebra torácica en sujetos experimentales, ratas, por medio de imágenes de resonancia magnética.

Materiales y métodos. Se ocuparon 12 ratas, Long Evans, hembras adultas, con peso entre los 215-240g, dividas en 2 grupos, implante y control. Se provocó una LTME a la altura de la $9^{\mathrm{a}}$ vertebra torácica, colocando PPyI al grupo implante, 4 semanas después de la lesión. Semanalmente, con dos evaluadores en ciego, se midió la recuperación de la función locomotora, bajo la escala de evaluación Basso, Beattie y Bresnahan (BBB).

Se realizó un estudio longitudinal de MRI 7T después de la lesión. Los valores de Fracción de Anisotropía (FA) y Coeficiente de Difusión Aparente (ADC) se obtuvieron por procesamiento en el software DSI Studio. Los valores del porcentaje de tejido preservado se obtuvieron por procesamiento en el software Amira. Se realizaron pruebas estadísticas a las medias de las variables dependientes (FA, ADC, BBB y porcentaje de tejido preservado) del tiempo y tratamiento ocupado, por medio de ANOVA de muestras repetidas $(\mathrm{p}<0.05)$. También se realizaron cálculos del coeficiente de correlación de Pearson entre las variables mencionadas. Todo el análisis fue realizado con el software RKWard.

Resultados. Se encontraron diferencias significativas entre las medias de ambos grupos para FA y BBB, evidenciando una mejor recuperación después de una LTME para el grupo implante con respecto al grupo control. En cuanto a la variable ADC se tuvieron diferencias significativas, con respecto a la semana de evaluación, entre medias de los grupos. También se encontró significancia estadística en la correlación de las variables ADC y FA para todo el conjunto de datos. Se muestra que cuando aumenta el valor de la variable ADC, disminuye el valor de FA.

El estudio morfológico in-vivo, por Resonancia Magnética, permitió apreciar ligeras diferencias fisiológicas entre ambos grupos; entre ellas la formación de quistes menores para el grupo implante, así como mejor preservación de la arquitectura de la zona lesionada. Estas apreciaciones se corroboraron con el estudio morfométrico; el porcentaje de quistes fue mayor para el grupo control, mientras que el porcentaje de tejido preservado, después de la semana de implante fue mayor para el grupo con implante de polímero.

Conclusiones. Este trabajo muestra la viabilidad del uso de PPyI como tratamiento de LTME en fase crónica. Además, se presentan datos que podrían ampliar el uso de variables cuantificables de MRI (FA, ADC y porcentaje de tejido preservado) como una herramienta complementaria en el diagnóstico de la lesión previamente mencionada.

Es importante continuar este tipo de estudios ya que amplían las opciones de evaluación en LTME, y ofrecen propuestas de mejora para el tratamiento de estas lesiones. 


\begin{abstract}
Introduction. The efficient use of the plasma polymerization polypyrrol-iodine (PPyI) implant have been shown in different studies, improving the motor functional outcome in the animal subjects, after a Traumatic Spinal Cord Injury (SCI). In this theses are shown the results after the application of the PPyI implant as a treatment in the chronic phase of SCI, evaluated by Magnetic Resonance Imaging (MRI).

Purpose. This study was conducted to evaluate the effect of PPyI in vivo, in a chronic SCI model, at the level of the ninth thoracic vertebra, in rats, using Magnetic Resonance Imaging.

Materials and methods. Adult female Long Evans rats $(n=11), 215-240 \mathrm{~g}$, were randomly assigned to one of both groups, control and implant. The implant group received PPyI particles in a chronic phase, 4 weeks after applying a moderate contusion SCI model. The control group comprises animals with SCI following the same injury model. Weekly, the motor function of the hind limbs was assessed with the BBB scale.

A longitudinal MRI 7T study was followed after the SCI. The Fractional Anisotropy and Apparent Diffusion Coefficient were obtained after data processing in DSI Studio Software. The percentage of spared tissue was obtained by data processing in Amira Software. The statistical analysis include a repeated measures ANOVA, searching significant differences in MRI parameters (FA, ADC and spared tissue) and BBB scores. The Spearman coefficient correlation was calculated for FA, ADC and BBB. All the analysis were performed in RKWard Software. Differences were considered statistically significant at $\mathrm{p}<0.05$.

Results. Significant differences in FA and BBB was found between both groups (control and implant), showing a better recovery of motor function, after chronic SCI, for the implant group over the control group. In ADC, just the difference between evaluation weeks, was significally different. Also, significant negative correlation was found between ADC and FA for all the acquired data during the experiment. ADC increased, whereas FA decreased in all groups.

The in vivo morphological study, generated by MRI, showed lightly physiological differences between the experimental groups; included the smaller cysts formation in the implant group than the control group. The architecture surrounding the injury epicenter, was better preserved in the implant group compared with the control group. This results were supported by the morphometric study; the volume percentage of cysts was higher in the control group than the implant group. And, finally, the percentage of preserved tissue, after the implantation week, was higher in the implant group, than the control group.

Conclusions. This theses shown the feasibility in the treatment using PPyI after a chronic SCI. Besides, some quantitative MRI data are presented as biomarkers in SCI, it could amplify the use of the MRI technologies in the SCI diagnosis and treatment.

It is important to continue this kind of experiments because enlarges the SCI evaluation options, furthermore it propose some ideas to improve the treatment after the chronic spinal cord injuries.
\end{abstract}




\section{Introducción}

La lesión Traumática de médula espinal (LTME) es una condición muy complicada, tanto médica como socialmente, se le ha considerado como una de las discapacidades más trágicas que le pueden acontecer a una persona. Esto se debe a diversos factores, siendo dos de ellos los principales. Primero, es un padecimiento que, en la mayoría de los casos, aparece de la nada. Sin previo aviso y con un efecto devastador desde el inicio. Nadie de nosotros es inmune a este riesgo.

Segundo, las consecuencias de la lesión son mortalidad prematura o, en el mejor de los casos, exclusión social. Esto se debe a que los cuidados de este padecimiento son inadecuados en un gran número de países (principalmente aquellos en vías de desarrollo), y/o situaciones específicas en cualquier clínica. De esta forma una persona con lesión en médula espinal puede sufrir diversos padecimientos asociados, algunos de ellos son infecciones en vías urinarias, úlceras en la piel y muchos otros. Estos provocan un alto índice de muertes en los primeros años posteriores a la lesión.

Incluso cuando el paciente recibe la atención médica correcta y rehabilitación necesaria, es probable que se le sea negado el acceso a educación y empleo; repercutiendo directamente en su independencia, atacando su vida familiar y social.

Por esta razón, los esfuerzos realizados en la búsqueda de optimizar, perfeccionar y mejorar la rehabilitación de personas con LTME son extensos, así como variados. Muchos de ellos están enfocados en estudiar todos los padecimientos que desencadenan los procesos secundarios, ya que al comprenderlos de mejor forma podría ayudar a contrarrestarlos desde el inicio, logrando una mejor recuperación. Otro de los tópicos en los cuales se centran los estudios actualmente, es en regenerar y favorecer el crecimiento de las células para volver a tener conexiones sinápticas en la zona dañada.

En el presente estudio se muestra una opción experimental para la rehabilitación después de una LTME; en estudios previos del grupo de investigación se ha mostrado que el implante del polímero polipirrol dopado con yodo (PPy/I), sintetizado por plasma, sobre la zona 
lesionada, mejora la función locomotora. Esto cuando es implantado en etapas agudas y sub agudas de la lesión. Siendo relevante ir un paso más adelante con la investigación, analizando qué ocurre en la etapa crónica de la lesión antes mencionada.

Otra herramienta que se está utilizando para rehabilitación de la médula espinal son las Imágenes por Resonancia Magnética (MRI, por sus siglas en inglés Magnetic Resonance Imaging). Éstas nos permiten conocer dónde y con qué gravedad está dañada la médula espinal, sin ser dañinas ni invasivas para el paciente. Dentro de las técnicas que se muestran con mayor futuro es la de imagen por tensor de difusión (DTI, por sus siglas en inglés Diffusion Tensor Imaging). Ésta se muestra promisora en las lesiones traumáticas de la médula, debido a su capacidad de medir la magnitud y dirección de la difusión de moléculas de agua en varios tejidos.

Con ayuda de esta herramienta se pudo evaluar la zona lesionada de la médula espinal, con un seguimiento longitudinal, in-vivo, de nuestros sujetos experimentales. Los cuales llegaron hasta una etapa crónica de la lesión para posteriormente implantarles, a un grupo de estudio, el polímero polipirrol dopado con yodo (PPy/I) obtenido por síntesis por plasma, mencionado anteriormente.

Los resultados del experimento comentado en los párrafos anteriores se encuentran en el capítulo sexto de la presente tesis; la metodología utilizada para llegar a todos estos resultados es comentada en el capítulo quinto. Por otro lado, en el primer párrafo se podrá encontrar un marco teórico con toda la información mínima necesaria para comenzar a comprender el tema y adentrarse en la línea de investigación. Posterior a este capítulo se encuentran la justificación del trabajo, la hipótesis y los objetivos; ubicados en los capítulos segundo, tercero y cuarto, respectivamente.

Para concluir se presenta una discusión de los resultados, una conclusión de los datos encontrados y algunas perspectivas que ampliarían el trabajo presentado. Ya que lo que se presenta en este documento es poco comparado con toda la investigación y datos que se podrían obtener a partir de esto. 


\title{
1 Marco Teórico
}

\author{
"Tener una Lesión de Medula Espinal puede cambiar \\ profundamente la vida de una persona, esto puede afectar \\ de manera directa todos los sistemas del cuerpo. También \\ afecta la percepción ante otras personas"
}

Thomas N. Bryce, MD

\subsection{Lesión Traumática de Médula Espinal.}

La Lesión Medular (LM) es un proceso patológico que afecta diferentes funciones del ser humano, entre ellas la motora, sensitiva y autonómica. El modo en cómo va a alterar depende del origen, completitud y nivel en cual se produce la LM; otros factores importantes son la extensión transversal o longitudinal de tejido lesionado y su afectación sobre la sustancia blanca o gris (Montoto, 2006, p. 500-519, citado en Henao-Lema, 2010). La etiología de estas lesiones es muy variado, incluyendo causas de origen congénito, traumático, infeccioso, tumoral o secundario a enfermedades sistémicas. (M. e. DeVivo 2006)

Se indica que la primera causa de lesiones medulares es el trauma, ya que está asociado con los principales incidentes de LM, entre ellos tenemos a los accidentes de tránsito, heridas por arma de fuego, heridas con armas blancas, caídas de altura, accidentes laborales, inmersiones en aguas poco profundas, accidentes deportivos y algunos otros de menor incidencia (Henao-Lema 2010).

Como hemos visto, la Lesión Traumática de Médula Espinal (LTME) puede ocurrirle en cualquier momento a una persona, nadie está exento. Es una condición muy complicada, desde el punto de vista médico, así como del social. Se le ha considerado como una de las discapacidades más trágicas que a una persona le pudiera ocurrir. (Mazaira 1998)

Son dos factores, principalmente, los que influyen en el efecto devastador de este padecimiento. El primero de ellos es causado por la espontaneidad de la lesión, acompañada 
de un gran efecto destructor inmediato de las actividades y costumbres que los sujetos desarrollaban antes de que ocurriera la lesión. (Bickenbach 2013)

El segundo se debe a los padecimientos que pueden asociarse con este tipo de traumatismo; no sólo está presente la alta probabilidad de una complicada discapacidad, también pueden generar gran número de infección en vías urinarias, úlceras en la piel, daño en articulaciones, huesos y disfunción general de varios sistemas, incluyendo el respiratorio, gastrointestinal, urinario, y nervioso autónomo. (Chiu 2010)

Toda esta cadena de padecimientos asociados se debe a que cuando ocurre una LM no existe, hasta la fecha, una forma completa para la recuperación. Sucede lo contrario, se desarrolla una serie de eventos destructivos, algo que es denominado como los mecanismos secundarios de la lesión, los cuales agravan la situación después de los eventos primarios y pudieran explicar la dificultad de encontrar una terapia adecuada para la correcta rehabilitación después de una LTME. (Blesch 2008)

La LTME se podría dividir por etapas, las cuales pueden variar y traslaparse entre ellas, según los efectos que se determinen para cada una de las mismas. En primer lugar tenemos a la fase aguda, la cual acontece segundos o dentro de las dos primeras horas después de la lesión (Díaz-Ruíz 2013) y se deben a los mecanismos primarios; después está la etapa subaguda, que ocurre minutos a semanas después de la lesión (Tanhoffer AR 2007); finalmente, la etapa crónica, que se presenta meses a años después de que ocurre la lesión (Oyinbo 2011). En las últimas dos etapas se generan los efectos secundarios de la lesión, los cuales se deben a los efectos vasculares y bioquímicos implicados.

En la llamada fase aguda, ocurren los daños derivados puramente del trauma, cuando la estructura ha sido modificada a causa del impacto, la entrega local de oxígeno disminuye y provocará un decremento en la función mitocondrial. [Figura 1.1] 


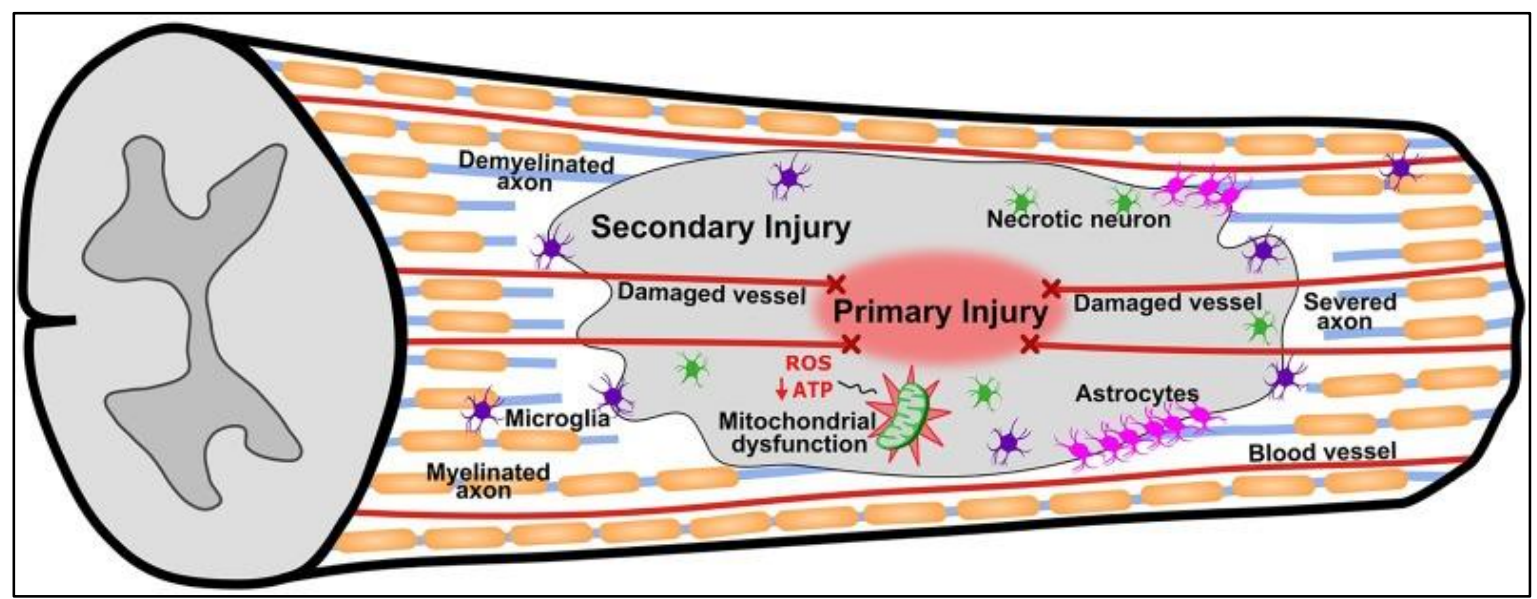

Figura 1.1 Daño ocurrido después de LTME. Representación del trauma inicial y daño secundario. Fase aguda: compromete los vasos sanguíneos, reduciendo la entrega local de oxígeno, lo que decrementa la producción de ATP e incrementa la producción de especies reactivas de oxígeno. En los daños secundarios se comienza a ver muerte neuronal, desmielinización de los axones, activación de la microglia y llegada de astrocitos que formarán la cicatriz glial. (Scholpa 2017)

La fase aguda comienza segundos después de la lesión e incluye eventos locales o sistémicos. Entre estos tenemos hipotensión sistémica, isquemia, vasoespasmos, daños sobre la membrana celular, acumulación de neurotransmisores, caidas en la homeostasis, entre otros. [Tabla 1.1] El primer paso para poder atacar estos padecimientos es estabilizar al paciente, ya que, generalmente, se encuentra en una situación que compromete de gran manera su vida.

Tabla 1.1 Principales acontecimientos ocurridos en la fase aguda de la lesión traumática de médula espinal. Se remarcan en azul las casillas de los padecimientos que se repiten en fase sub-aguda. Modificado de Oyinbo, 2011

\begin{tabular}{|c|c|c|c|}
\hline $\begin{array}{c}\text { Disminución del flujo } \\
\text { sanguíneo e hipotensión } \\
\text { arterial sistémica }\end{array}$ & $\begin{array}{c}\text { Transtornos en la } \\
\text { homeostasis }\end{array}$ & $\begin{array}{c}\text { Acumulación de } \\
\text { neurotransmisores }\end{array}$ & $\begin{array}{c}\text { Daños que } \\
\text { comprometen la } \\
\text { membrana celular }\end{array}$ \\
\hline Vasoespasmo & Isquemia & Edema & Muerte celular \\
\hline
\end{tabular}

\subsubsection{Efectos secundarios de la Lesión Traumática de Médula Espinal}

En la fase sub-aguda, que ocurre desde minutos hasta semanas o meses después de la lesión, se continúan presentando algunos de los efectos mostrados en la fase previa. Sin embargo 
también aparecen algunos nuevos [Tabla 1.2], entre ellos tenemos la formación de radicales libres y la respuesta inflamatoria que es altamente relevante en el proceso catabólico intracelular dentro de los mecanismos secundarios (Popovich 1997)

Tabla 1.2 Principales acontecimientos ocurridos en la fase sub-aguda de la lesión traumática de médula espinal. Se remarcan en azul las casillas de los padecimientos que se repiten en fase aguda y en verde aquellos que también aparecen en fase crónica. Modificado de Oyinbo, 2011

\begin{tabular}{|c|c|c|c|}
\hline $\begin{array}{l}\text { Disminución del flujo } \\
\text { sanguíneo e hipotensión } \\
\text { arterial sistémica }\end{array}$ & $\begin{array}{l}\text { Transtornos en la } \\
\text { homeostasis }\end{array}$ & $\begin{array}{l}\text { Excitotoxicidad causada } \\
\text { por neurotransmisores }\end{array}$ & $\begin{array}{c}\text { Daños que } \\
\text { comprometen la } \\
\text { membrana celular }\end{array}$ \\
\hline Vasoespasmo & Isquemia & Edema & Muerte celular \\
\hline $\begin{array}{l}\text { Producción de radicales } \\
\text { libres }\end{array}$ & Lipoperoxidación & Exceso de óxido nitroso & $\begin{array}{l}\text { Bloqueo en la } \\
\text { conducción }\end{array}$ \\
\hline $\begin{array}{c}\text { Exceso de } \\
\text { Norepinefrina }\end{array}$ & $\begin{array}{l}\text { Fallas en la función } \\
\text { mitocondrial, } \\
\text { disminución de ATP }\end{array}$ & $\begin{array}{l}\text { Invasión de células del } \\
\text { sistema inmune y } \\
\text { liberación de citoquinas }\end{array}$ & $\begin{array}{c}\text { Respuesta inflamatoria } \\
\text { debido a la muerte } \\
\text { celular }\end{array}$ \\
\hline $\begin{array}{c}\text { Inhibición de los } \\
\text { factores de crecimiento } \\
\text { neuronales }\end{array}$ & $\begin{array}{c}\text { Compresión vertebral/ } \\
\text { inestabilidad de la } \\
\text { columna }\end{array}$ & Cromatolisis central & \\
\hline $\begin{array}{c}\text { Desmielinización de los } \\
\text { axones sobrevivientes }\end{array}$ & Apoptosis & $\begin{array}{c}\text { Inicio de cavitación } \\
\text { central }\end{array}$ & $\begin{array}{l}\text { Emisión inicial de } \\
\text { cicatriz glial }\end{array}$ \\
\hline
\end{tabular}

Este proceso inflamatorio es pieza clave para entender los daños secundarios, persistentes hasta meses después de la lesión, esto es porque se genera una proliferación desmedida de astrocitos, los cuales van generando hipertrofia y una cicatriz glial que prohíbe la comunicación entre las neuronas sobrevivientes de los efectos primarios de la lesión (Fitch 1999).

Además, estas células del sistema inmune secretan citoquinas proinflamatorias que extienden el proceso inflamatorio, algunas de ellas son interleucina IL-1 $\beta$, IL-6 y Factor de Necrosis Tumoral- $\alpha$ (TNF- $\alpha$ ). Es cierto que estos efectos son una respuesta crítica para la limpieza y remoción de basura orgánica, una protección inmunológica que es contraproducente en este caso, ya que terminará con el proceso iniciado, la muerte neuronal (Dong 2001).

Entre otros procesos de la etapa sub-aguda, también tenemos a la excesiva entrada de calcio a la zona comprometida, fallas en la función mitocondrial y estrés oxidativo, inhibiendo la 
recuperación nerviosa y la regeneración de los axones (Warden 2001). Todo esto continúa incitando la apoptosis, situación que prevalece hasta la etapa crónica.

Finalmente, es pertinente mencionar que estos procesos van ligados unos con otros y pueden ocurrir en diferentes momentos alrededor de la zona comprometida, ya que ésta se extiende, los daños se van alargando.

Cuando se entra en la fase crónica de la lesión todavía se ven muchos de los procesos bioquímicos presentados en la fase sub-aguda [Tabla 1.3]. Por ejemplo, la cascada de apoptosis continúa en las neuronas, oligodendrocitos, microglia y astrocitos. La provocación más importante para la muerte neuronal después de la lesión está marcada por la inducción de calcio en las células (Xiong 2008), se comienzan a romper proteínas en el interior y se deriva en la muerte.

Tabla 1.3 Principales acontecimientos ocurridos en la fase crónica de la lesión traumática de médula espinal. Se remarcan en verde aquellos padecimientos que también aparecen en fase sub-aguda. Modificado de Oyinbo, 2011

\begin{tabular}{|c|c|c|c|}
\hline $\begin{array}{c}\text { La desmielinización } \\
\text { continúa }\end{array}$ & $\begin{array}{c}\text { Continuación de } \\
\text { apoptosis }\end{array}$ & Cavitación central & $\begin{array}{c}\text { Cicatriz glial / } \\
\text { Formación de quistes }\end{array}$ \\
\hline $\begin{array}{c}\text { Alteración de los } \\
\text { canales y receptores } \\
\text { iónicos }\end{array}$ & $\begin{array}{c}\text { Proceso regenerativo, } \\
\text { incluyendo brotes } \\
\text { generados por neuronas }\end{array}$ & $\begin{array}{c}\text { Alteración de los } \\
\text { neurocircuitos }\end{array}$ & Siringomielia \\
\hline
\end{tabular}

Otro de los ejemplos para esta fase es la cavitación central, un fenómeno progresivo que agrega complejidad al proceso de cura para una LTME, se comienza a presentar en la fase sub-aguda pero continúa evolucionando a lo largo del tiempo después de la lesión. Se trata de una cavidad encapsulada por cicatriz, puede ir aumentando de tamaño conforme pasa el tiempo, acompañado del proceso inflamatorio (Nguyen 2012).

Sobre la desmielinización, uno de los procesos relevantes en la fase crónica, se debe, principalmente, a la muerte, en el epicentro de la lesión, de los oligodendrocitos. Éstos mueren horas después de la LTME, pero su apoptosis continúa extendiéndose hasta por semanas. Esta desmielinización provoca retrasos y bloqueos en la comunicación neuronal, aumentando las limitaciones para curar la lesión (Oyinbo 2011). 
Uno de los pocos puntos a favor, para resaltar en esta fase, es el proceso regenerativo espontáneo, incluyendo la mielinización, el crecimiento y brote axonal. Se ha mostrado que en ratas, después de dos meses de la lesión se tuvo el punto más alto de desmielinización, pero éste fue bajando, de forma espontánea, hasta el décimo segundo mes de evaluación, último punto del estudio (Salgado-Ceballos 1998).

Pero sólo una cantidad limitada de esos axones logran recuperar sus funciones sinápticas por completo, una de las causas de esta falta de comunicación, entre otras, es la limitante de no tener un sitio propicio o guía para poder alcanzar el sitio adecuado (Cruz 2012). Y, debemos recordar, este tipo de regeneración tan prometedor es en ratas; en humanos se vuelve mucho más complicado.

Finalmente, la siringomielia es el término utilizado para describir la formación de quistes, rellenos de fluido cerebroespinal, en el interior de la médula espinal. Este trastorno crónico y progresivo, empeora a medida que los quistes crecen y generan una compresión sobre los nervios (Flores 2012). Los quistes pueden comenzar a formarse desde la etapa sub-aguda, pero es en la fase crónica cuando aparecen con mayor incidencia.

No se conoce completamente el proceso fisiopatológico que lleva a este padecimiento después de una LTME. Actualmente las imágenes por resonancia magnética son el método de diagnóstico para este padecimiento, debido a su capacidad de detección de flujo en el interior de la médula. (McIntyre A 2014).

\subsubsection{Anatomía y fisiología de la médula espinal}

El Sistema Nervioso es único en la gran complejidad de las reacciones de control que puede llevar en poco tiempo para mantener estable al cuerpo humano, se compone de un tejido especializado para regular las funciones más especializadas del organismo. Se divide en el Sistema Nervioso Central (SNC) y el Sistema Nervioso Periférico (SNP).

El tejido nervioso incluye dos tipos de células: las neuronas y la neuroglia (también llamadas células de sostén). Las primeras son las responsables de todas las funciones atribuidas al 
sistema nervioso. Son células excitables, capaces de conducir impulsos a modo de información e indicaciones para otras zonas del cuerpo. Aunque pueden tener variantes en tamaño y forma, todas las neuronas presentan una estructura básica que consta de tres partes esenciales: A) Soma neuronal; contiene el núcleo y citoplasma con todos los orgánulos intracelulares encargados del metabolismo celular. Desde este cuerpo neuronal se desprenden múltiples ramificaciones que componen las áreas receptoras y emisoras de señal. B) Dendritas; son prolongaciones ramificadas, a través de estas se reciben estímulos procedentes de neuronas vecinas con las cuales se establece la comunicación llamada sinapsis. C) Axón; es la prolongación que se desprende del soma, su función es enviar el impulso nervioso desde el cuerpo celular a otras células nerviosas u órganos efectores a través de la sinapsis. [Figura 1.2]

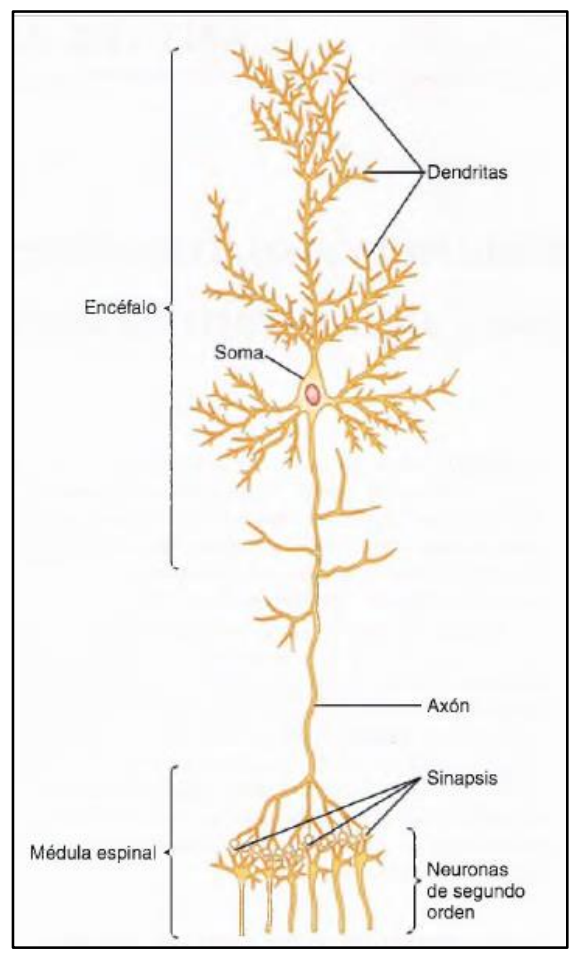

Figura 1.2 Estructura de una neurona grande perteneciente al encéfalo (Guyton 2011).

Para formar la sinapsis, el axón de la célula presináptica se ensancha formando la terminal presináptica con vesículas que almacenan un neurotransmisor químico. Por su parte, la célula postsináptica posee una terminal postsináptica. El espacio entre ambas terminales es conocido como hendidura sináptica. [Figura 1.3]. 


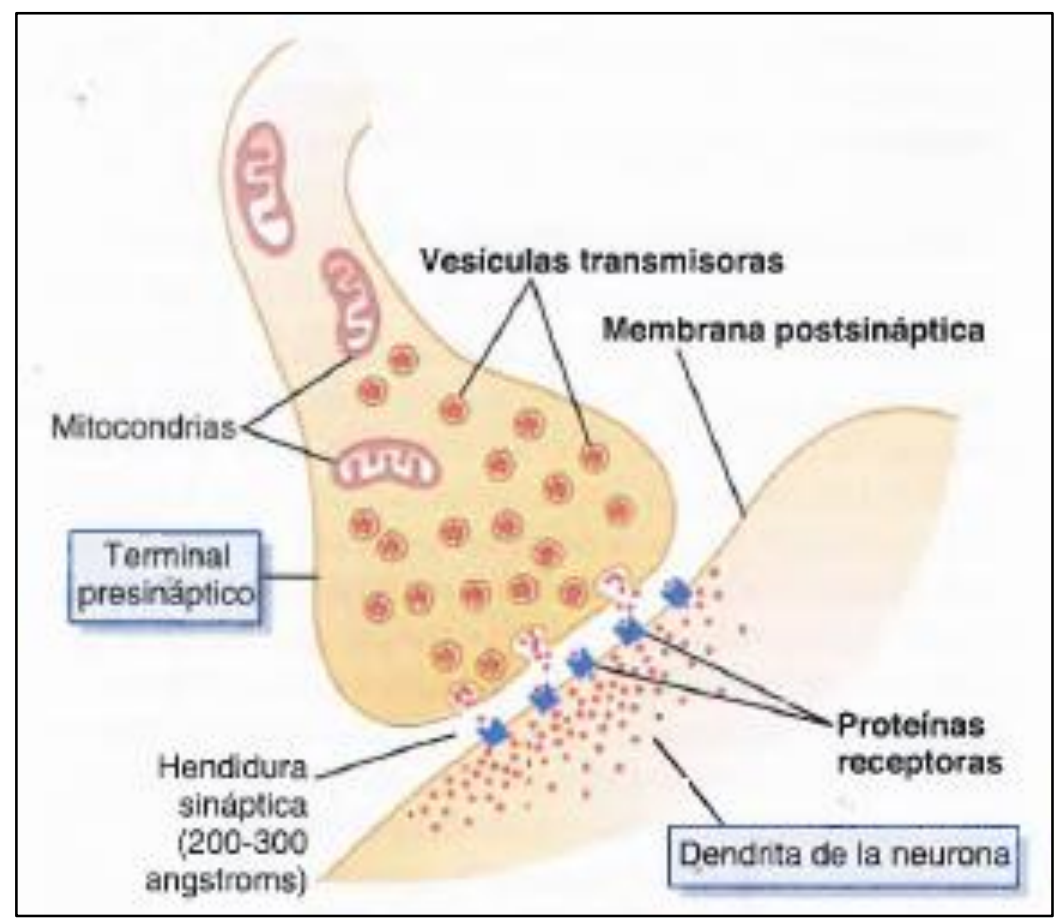

Figura 1.3. Anatomía fisiológica de la sinapsis (Guyton 2011).

Por otro lado, la neuroglia es un conjunto de células pequeñas, entre ellas tenemos a los astrocitos, oligodentrocitos, células de Schwann, células ependimarias, microglia, etc. Tienen funciones importantes; algunos ejemplos son: generación de una especie de andamio para estructura y soporte de las neuronas, metabolismo neuronal, síntesis de mielina y mielinización de los axones de las neuronas, la respuesta inmune con función fagocitaria, contribución al flujo del Líquido Cefalorraquídeo (LCR).

El sistema nervioso humano ha heredado características evolutivas específicas para cumplir con las funciones más complejas del cuerpo humano. De esta evolución se puede dividir en tres niveles con diferentes funciones significativas, entre estos tenemos: nivel medular, nivel encefálico bajo y nivel encefálico alto o cortical. (Guyton 1984)

En el nivel medular tenemos como principal actor a la medula espinal. Ésta se extiende desde el bulbo raquídeo hasta el borde superior de la segunda vértebra lumbar. Por su parte inferior acaba en forma de cono (cono medular) y luego viene la cola de caballo. [Figura $1.4]$. 


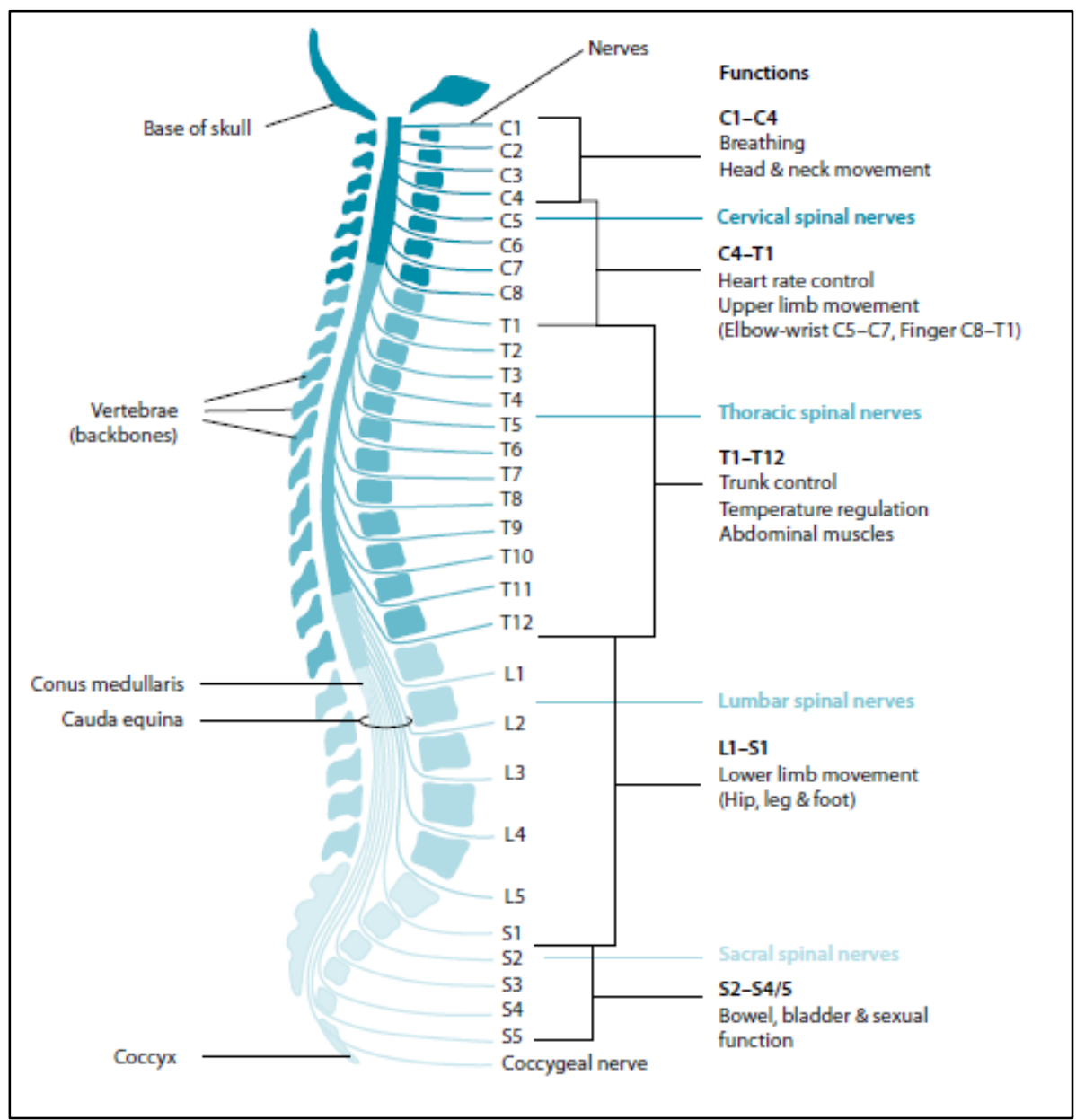

Figura 1.4 Organización longitudinal de la médula espinal, con una breve descripción de las mayores funciones de cada nivel (Bickenbach 2013).

La médula espinal está constituida por sustancia gris en la parte central y sustancia blanca, situada en la parte más externa. Por ambos lados de la médula espinal, la sustancia gris se subdivide en regiones conocidas como astas, las cuales se denominan por su localización, ya sea en anteriores, posteriores y laterales. En forma general, desde un corte axial, la sustancia gris tiene forma de hache mayúscula o de mariposa en el centro de la médula. La sustancia blanca está reunida en forma de cordones, anteriores, laterales y posteriores. En el centro de la médula existe un canal por el cual corre el LCR, llamado epéndimo. [Figura $1.5]$ 


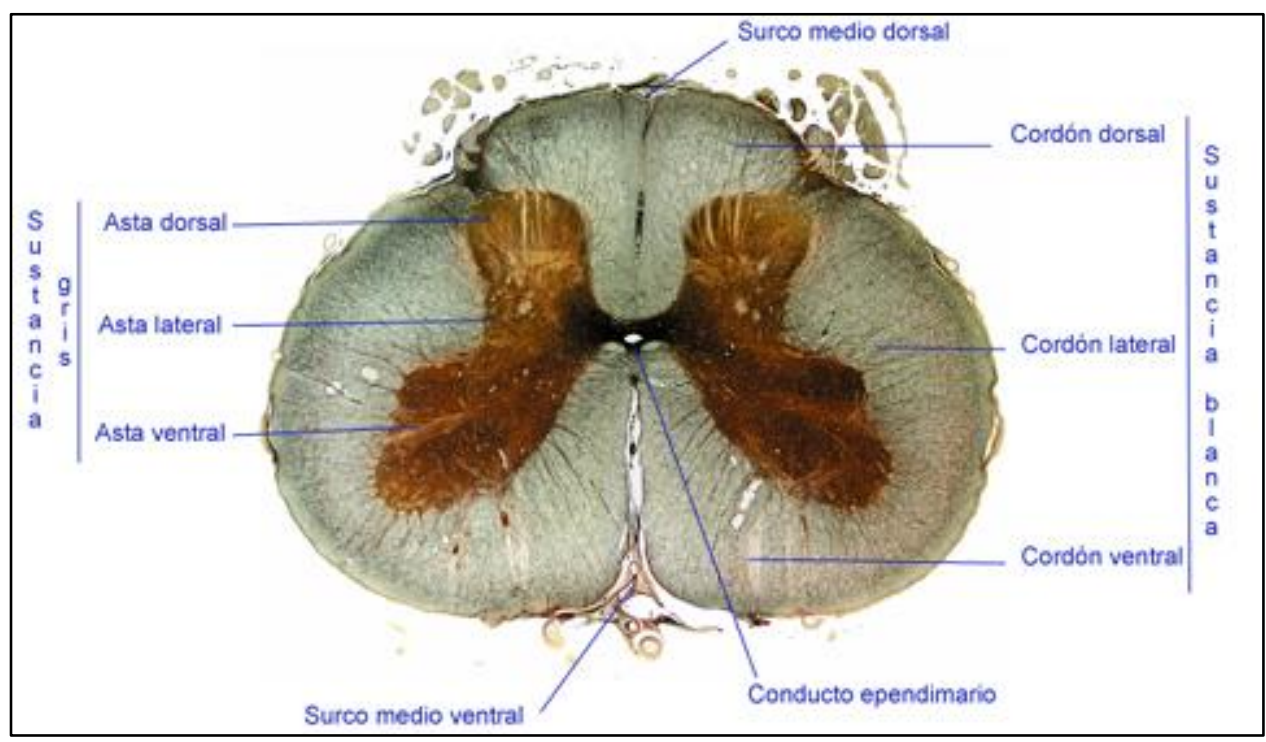

Figura 1.5 Corte axial de la médula espinal

En la médula espinal las señales sensoriales son transmitidas por los nervios raquídeos penetrando en cada segmento; éstas podrían generan respuestas motoras cercanas al lugar donde se generó la señal o en algún segmento cercano. Prácticamente todas las respuestas motoras de la médula son automáticas e inmediatas, ocurriendo a modo de reflejo. (Guyton 1984)

La médula espinal está rodeada por tres capas de tejido conjuntivo, conocido como meninges: duramadre, aracnoides y piamadre [Figura 1.6]. La primera es la más expuesta al resto del organismo, es una cubierta tubular, altamente resistente y fibrosa. La aracnoides es una membrana transparente, delgada. Entre ésta y la piamadre se encuentra el espacio subaracnoideo que contiene el LCR. (Tortosa 2009) 


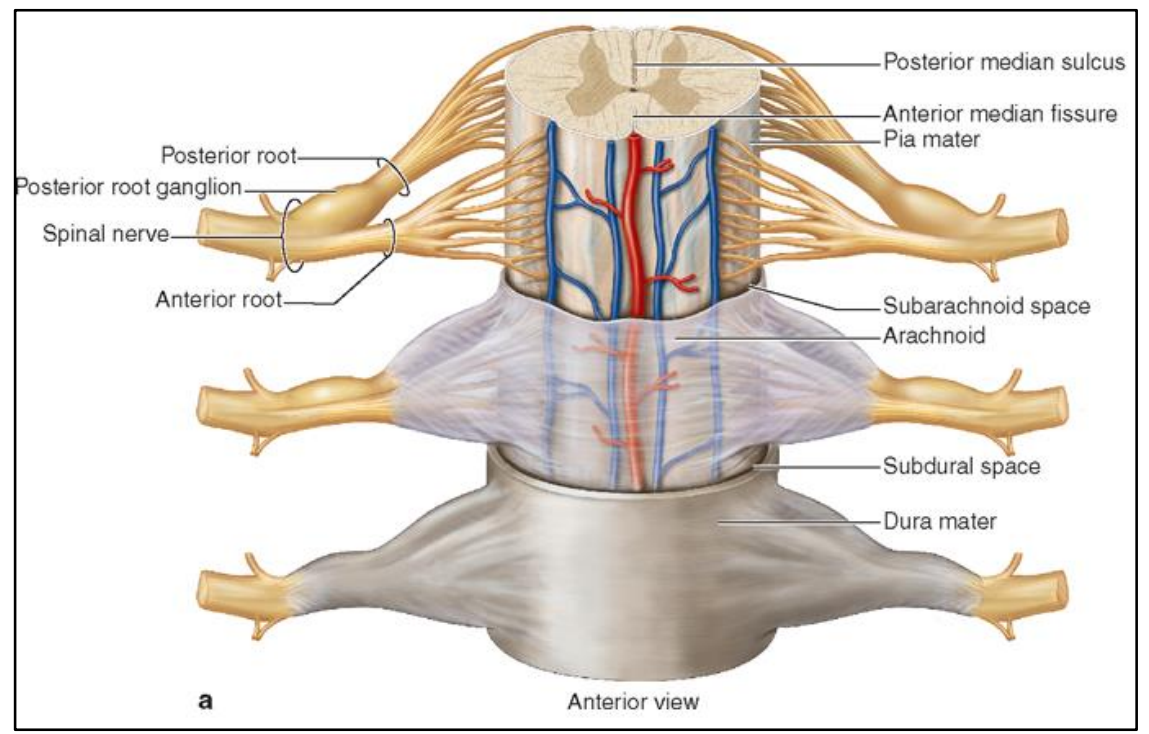

Figura 1.6 Médula espinal con meninges

\subsubsection{Epidemiología de la lesión de médula espinal}

El resultado de una LTME es una profunda discapacidad que en muchos casos puede llevar a la muerte. Es una patología que afecta biológica y socialmente a los individuos, ya que existe una gran incidencia en etapa productiva, resultando en una carga emocional, no sólo para él, también para su familia y la sociedad que lo rodea.

En la mayoría de los países en vías de desarrollo no existen sistemas estadísticos confiables para poder describir la patología, lo que sería de gran ayuda para abordar cada uno de los casos de diferente manera (Pérez 2008). Es por ello que Latinoamérica no registra una gran cantidad de estudios enfocados al tratamiento y cuidado de este tipo de padecimiento.

De entre los pocos datos que se encuentran en México, se puede decir que el promedio de edad en la cual acontece la LME (Lesión de Médula Espinal) es aproximadamente 33.1 y 33.6 para hombres y mujeres, respectivamente. Pero, en la incidencia no ocurre lo mismo entre géneros que con la edad; en este caso la relación de afectación hombre mujer es de 3.2 a 1 respectivamente. Entre otros datos, también se muestra que el accidente automovilístico 
representa el primer lugar de causas, seguido por caída de altura pero muy próximo a las heridas por arma de fuego, una causa que ha venido aumentando con los años, reflejando, probablemente, de alguna forma la situación social y política del país (Pérez 2008).

En Bogotá, bajo condiciones estadísticas poco confiables, similar a México, se reporta que la edad promedio de las personas con LME es de aproximadamente 36 años, con una relación hombre mujer de 4.1-1, respectivamente (Garzón 2005).

En Estados Unidos, con una base de datos mucho más robusta a lo que se presenta en México, los datos del National Spinal Cord Injury Statistical Center (NSCISC) arrojan que la incidencia anual, para 2015, fue de 54 casos nuevos por millón de habitantes, lo que deja un aproximado de 17,000 nuevos casos de LME cada año. Dentro de estos no se incluyen aquellos que mueren durante el accidente.

En el caso del Reino Unido, se pueden encontrar datos sobre LTME en menor prevalencia que en los mencionados previamente, este padecimiento le ocurre a un estimado de entre 10 y 15 personas por millón de población (Grundy D. 2002), una cantidad considerablemente menor, pero que se ve reflejado en los más de 40,000 habitantes en esta región con este padecimiento, según datos del 2008 otorgados por el Royal College of Physicians y cols. Y en información global, hay un estimado de 2.5 millones de personas que viven con una lesión de médula espinal, con más de 130,000 casos nuevos reportándose anualmente. (Thuret S 2006)

Sobre la prevalencia en Estados Unidos, se pensaba que era de 282,000 personas para el año 2016 y que el promedio de edad al cual ocurre la lesión es de 42 años, con un $80 \%$ de los nuevos casos para los hombres.

En cuanto a la etiología, se dice que el $38 \%$ corresponden a accidentes vehiculares, 30\% a caídas y el resto a otras causas como deportes, situaciones quirúrgicas, entre otras. Se puede denotar que, en contraste con otros datos que se han presentado, los casos por violencia disminuyen en gran número para este estudio.

Otros de los datos a resaltar son el estado civil, el nivel educativo y la ocupación de las personas. Para el primero de los casos, más de la mitad de los lesionados se encuentran 
solteros al momento de la lesión; del mismo modo, el porcentaje de personas con nivel educativo menor al bachillerato es superior al 50\% cuando ocurre la LME; por último, casi el $60 \%$ de los lesionados está empleado formalmente al momento de la lesión. (National Spinal Cord Injury Statistical Center 2016)

Hablando del costo de vida, estimado, para una persona que sufre paraplejia, derivada de LTME, a los 25 años de edad, es mayor a 2.3 millones de dólares. Para alguien con tetraplejia, con lesión ocurrida a la misma edad que el caso anterior, es mayor a 3.5 millones de dólares. (M. DeVivo 2002).

Finalmente, la esperanza de vida para una persona que sufre LTME, derivando en paraplejia, a los 20 años, se reduce en más de 15 años; mientras que para tetraplejia se reduce más de 20 años. Cuando se incrementa la gravedad, y hay dependencia de ventilador para suplir la función pulmonar, la esperanza de vida se reduce a menos de 40 años de edad. (National Spinal Cord Injury Statistical Center 2016)

\subsubsection{Estrategias terapéuticas en lesión de médula espinal}

Como previamente se mencionó, la LTME es un padecimiento inesperado que no permite tener ningún tipo de prevención capaz de evitar por completo los daños primarios en todas las personas. La ventana de tiempo para actuar durante estos daños es demasiado corta para muchos sistemas de salud; dar un diagnóstico efectivo del lugar de la lesión, estabilizar las vértebras del paciente y darle algún tratamiento efectivo, en corto tiempo, se vuelve una tarea imposible para todos los casos. Si bien es cierto que descomprimir la médula espinal y estabilizar las vértebras ayuda para no tener un daño continuo, sólo minimiza el efecto primario de la lesión.

Sin embargo, los efectos secundarios se pueden limitar; es decir, evitar que la lesión se extienda más, esto ayudará a tener mejores oportunidades para intentar prosperar a una recuperación. Pero, como bien se sabe, no existe actualmente un modo efectivo para curar este padecimiento en pacientes, ya que evitar los efectos de los daños secundarios está aún lejos del alcance de la ciencia. 
Se han hecho varios acercamientos, estrategias terapéuticas, para detener los daños secundarios. Entre ellos tenemos la entrega de factores de crecimiento, mejora de las propiedades conductivas, modulación de las interacciones con los inhibidores de mielina, modificaciones a la matriz extracelular y estimulación eléctrica, tratando de mejorar la conductividad de la zona a través de la reactivación de los nervios.

Uno de los primeros tratamientos utilizados después de una LTME fueron los esteroides glucocorticoides, se pensó en ellos por su habilidad de reducir edemas cerebrales en pacientes con tumor, el principal de ellos fue la metilprednisolona (MP). Se mostró que sus efectos son limitados para las funciones que se buscan, además se debe suministrar muy rápido. El verdadero problema no fue eso, radicó en los posibles efectos secundarios, ya que aumenta el riesgo de infecciones, de trombosis, neumonía y retraso en sanar heridas, entre otros efectos encontrados en dosis altas (Scholpa 2017). Por lo tanto, se le ha categorizado como inoperante para los propósitos deseados y como un factor riesgoso. (Hall 2004)

Algunas de estas estrategias terapéuticas, también se han enfocado a alterar la neuroinflamación, a través de fármacos antinflamatorios la como minociclina, o inmunosupresores como la ciclosporina A (CsA). La minociclina, por ejemplo, es un antibiótico tipo tetraciclina con efecto neuroprotector y propiedades antiinflamatorias. Se mostró que a través de la reducción de la inflamación en la zona de la lesión, el puntaje motriz se mejoraba en pacientes con LTME a nivel cervical, sin dar beneficios a nivel torácico (Ulndreaj 2017).

Por otro lado, la ciclosporina, con la cual se buscaba inhibir la permeabilidad mitocondrial después de la lesión, para mejorar su función y disminuir la muerte celular en el SNC, ya se ha probado que sus resultados, para tratamiento clínico, son inconsistentes para la función deseada. (McMahon 2009)

Otro antibiótico que se ha usado para estos fines, con buenos resultados preclínicos es AntiNogo-A. Se ha mostrado que promueve el brote axonal y mejora la recuperación funcional después de una LTME. Actualmente también se encuentra en pruebas clínicas. Otro producto que se ha utilizado en pruebas clínicas es la dapsona; se busca utilizar sus efectos 
antioxidantes, antinflamatorios y antiapoptóticos en LTME. Se ha mostrado que este producto, en las primeras horas después de la lesión, a través de la inhibición de la enzima mieloperoxidasa tiene una protección significativa de la médula espinal. (Diaz-Ruiz 2011) Otros de los acercamientos importantes, en cuanto a desinflamatorios, se refiere a la inmunoglobulina intravenosa G (IVIG, por sus siglas en inglés), la cual es tomada de donadores sanos, y es suministrada a modo de suero. Los modelos preclínicos han mostrado que, a través de la disminución inflamatoria, se mejora la recuperación (Brennan 2016).

También se ha probado con la reducción del daño por radicales libres, mediante la administración de glucocorticoides, quelantes de hierro y promotores de glutationes. Por reducción del daño neuronal por excitotoxicidad, administrando N-metil-D-Aspartato (NMDA) o Riluzole, los cuales funcionan como receptores antagonistas (Oyinbo 2011).

Riluzole, es un benzotiazol que inhibe los canales de sodio y, con ello, la liberación de glutamato, reduciendo la excitotoxicidad. Se han mostrado buenos resultados del Riluzole para algunos padecimientos del SNC, como esclerosis lateral, Parkinson, Huntington y Alzheimer.

En estudios preclínicos se ha mostrado que este tratamiento reduce la espasticidad y promueve la preservación neuronal en ratas con lesión medular por hemisección a nivel cervical. (Satkunendrarajah 2016) En situación clínica se ha mostrado que mejora el puntaje motriz en pacientes con lesión incompleta a nivel cervical, no así en pacientes con lesión a nivel torácico (Grossman 2014).

Algunos otros intentos consisten en fármacos hipoglucemiantes o que detengan la hemorragia de la zona lesionada, como la Glibenclamida. Aprobada por la FDA (Food and Drug Administration) para su uso contra la diabetes. Se encontró que bloqueando la deformación de los capilares, con este fármaco, se contribuía a disminuir la hemorragia en la zona de la lesión. Estudios en ratas permitieron observar un decremento en el volumen de la lesión y preservación de materia blanca. (Simard JM 2007)

También se debe poner atención a una de las corrientes más fuertes en la ingeniería de tejidos, el trasplante de células progenitoras. Esta idea comenzó con trasplante de otro tipo 
de células, para tratar de reponer o unir a las células muertas o sobrevivientes, respectivamente. Esto buscando crear un ambiente más favorecedor para la regeneración neuronal. Se comenzó con trasplante de nervio periférico, células de Schwann (Papastefanaki 2007), células progenitoras embrionarias y de adulto. (Jablonska 2010)

Sin embargo, las que se muestran más atractivas son las células progenitoras mesenquimales, una célula madre multipotencial. Queda mucho por entender sobre este tipo de célula, cómo actúa y su eficacia a diferentes zonas, pero se ha mostrado que en tratamiento de LTME reducen la inflamación, modulan la respuesta inmune y secretan factores neuroprotectores.

Tal vez la preferencia en este tipo de célula se deba a que se encuentra en muchos tejidos de los adultos, tales como médula ósea, cartílago, tejido adiposo, entre otros, y que es la célula progenitora más estudiada en medicina regenerativa; por lo tanto existen muchos métodos bien conocidos para su extracción, cultivo, purificación, etc. Que aumentan cada vez la cantidad de estudios clínicos. (Ulndreaj 2017)

Muchos de los intentos terapéuticos tienen buenos resultados en ensayos preclínicos pero tienen muchos problemas para hacer la traslación clínica, incluso los que se han llegado a probar clínicamente, tienen menores efectos que lo mostrado previamente. De acuerdo con lo expuesto por (Ulndreaj 2017) hay poco énfasis en las necesidades clínicas con respecto a lo que se hace en lo experimental. Se sabe que arriba del 50\% de los casos de LTME son a nivel cervical pero la gran mayoría de los casos preclínicos son realizados a nivel torácico.

Solo basta recordar que hay grandes diferencias entre la médula en los diferentes niveles, tanto anatómica como fisiológicamente y de respuesta inmune, estos factores hacen que los resultados neuroprotectores se vean afectados al momento de querer probarlos clínicamente.

Se debe mencionar que se han hecho esfuerzos de otro tipo para mejorar la rehabilitación y calidad de vida para los pacientes con LTME; por ejemplo, mediante asistencia con dispositivos robóticos para caminar durante las terapias físicas de rehabilitación. Se ha logrado reducir la percepción del dolor, el nivel de espasticidad, incrementar la velocidad y longitud de paso al caminar, así como mejorar la postura (Varoqui 2014). 
Estos resultados fomentan una mejora en las funciones intestinales, cardiorrespiratorias, urinarias y metabólicas, entre otras. Como se sabe, la robótica es un campo en continuo avance; por ello se espera que en un futuro estos dispositivos puedan utilizarse no sólo durante la terapia, sino en las actividades de la vida diaria (Holanda 2017). Se espera que, en unión con otra terapia de neuroregeneración, se puedan hacer mejoras en los dispositivos robóticos de asistencia al paciente con LTME para que puedan ser de uso continuo y devolver la función locomotora.

Por último, no nos podemos olvidar de los implantes de biomateriales en el área de la lesión, que trabajan como un andamio en el espacio perdido o lastimado por la lesión, para recuperar la comunicación y la regeneración del tejido que se ha perdido. Los biomateriales más estudiados han sido los polímeros compatibles con el SNC. Se espera que con un material biocompatible, implantado en la lesión, puedan reducirse los daños secundarios y, mejor aún, proveer un espacio que facilite el contacto entre ambos lados del epicentro de la lesión (Cruz 2010). En el siguiente apartado se detallarán más estos polímeros.

\subsection{Polímeros en aplicaciones biomédicas}

Los biomateriales se han usado de forma recurrente para beneficio en varias aplicaciones terapéuticas, desde las aplicaciones en liberación controlada de fármacos, hasta dispositivos quirúrgicos, implantes, equipo ortopédico y materiales de soporte (Liang 2017).

Algunas otras aplicaciones, ya más enfocadas a biopolímeros son los andamios para crecimiento, funcionalización y adaptación celular (Wang 2015, Fan 2014), inmovilización de enzimas, biosensores (Tahara 2013), bioadhesivos y dispositivos oculares. La importancia central de los polímeros como biomateriales funcionales se debe, en gran parte, al avance en las técnicas de síntesis y la gran versatilidad de producción de polímeros para la ayuda en diferentes procesos fisiológicos. La capacidad de producción y modificación 
hace a los biopolímeros más deseables para muchas aplicaciones específicas; comparado con otros biomateriales como cerámicas o metales (Angelova 1999).

Por ejemplo, los hidrogeles son polímeros hidrofílicos entrecruzados que tienen un alto contenido de agua pero que proveen una estructura con poros de tamaño controlable. Son un tipo de polímero con una importancia creciente en el campo biomédico; en lesión de médula espinal se cree que ellos sirven en la recuperación, funcionando como un puente para el crecimiento axonal y a modo de protección para el crecimiento de cicatriz, permitiendo crear un ambiente más próspero para la recuperación del SNC. (Hejcl 2008) Otros de los polímeros atractivos para la recuperación de LTME son aquellos biopolímeros conductores sintetizados por plasma, entre ellos el PPy/I (Polipirrol/ Yodo) que se verá con detalle más adelante.

Se debe recordar que los polímeros usados como biomateriales también pueden ser naturales, sintéticos o una combinación de ambos. En la Tabla 1.4 se encuentran algunos de los principales polímeros naturales que se han utilizado. Éstos son normalmente biodegradables, pero tienen una gran desventaja; la falta de reproducibilidad para obtener el producto con estructura similar. Aunado a esto se encuentra la dificultad en los procesos para purificarlo y modificarlo cuando es necesario.

Tabla 1.4 Principales polímeros naturales en aplicaciones biomédicas. Modificado de (Angelova 1999)

\begin{tabular}{|c|l|}
\hline Colágena & $\begin{array}{l}\text { Basada en proteínas. Reabsorbible, biocompatible, no tóxico, elástico, usado } \\
\text { como implante en ingeniería de tejidos. Se usa en suturas, microesferas } \\
\text { liberadoras de fármacos, drenador de heridas. }\end{array}$ \\
\hline Albúmina & $\begin{array}{l}\text { Basada en proteínas. Reabsorbible, biocompatible, no tóxico, elástico, usado } \\
\text { como implante en ingeniería de tejidos. Usada como transportadora para } \\
\text { liberación de fármacos. (Cao 2015) }\end{array}$ \\
\hline $\begin{array}{c}\text { Poli } \\
\text { (aminoácidos) })\end{array}$ & $\begin{array}{l}\text { Entre algunos ejemplos tenemos la poli( } \alpha, \text { L-lisina), poli ( } \alpha, \text { L-ácido } \\
\text { glutámico), poli(ácido aspártico). Son no tóxicos, biocompatibles; son } \\
\text { ocupados como transportadores de fármacos. }\end{array}$ \\
\hline Alginato & $\begin{array}{l}\text { Extraído de fuente vegetal (algas marinas). Excelentes propiedades de } \\
\text { formación en gel. La estructura y viscosidad depende de la composición } \\
\text { química de formación. Es ocupado en inmovilización de matrices para células } \\
\text { y enzimas, microcápsulas inyectables para tratamientos neurodegenerativo y } \\
\text { padecimientos hormonales, así como para liberación controlada de sustancias } \\
\text { bioactivas (Tran 2014). }\end{array}$ \\
\hline
\end{tabular}




\begin{tabular}{|c|l|}
\hline $\begin{array}{c}\text { Ácido } \\
\text { hialurónico }\end{array}$ & Extraído de origen animal. Excelente lubricante, potencial agente terapéutico. \\
\hline Heparina & $\begin{array}{l}\text { Extraído de origen animal. Propiedades antitrombóticas y anticoagulantes, } \\
\text { ampliamente usado en cirugía. }\end{array}$ \\
\hline Quitosan & $\begin{array}{l}\text { Extraído de origen animal. Biocompatible, no tóxico, excelente habilidad para } \\
\text { formación de geles. Usado en sistemas de liberación controlada y } \\
\text { encapsulamiento de sustancias; puede ser utilizado como gel, membrana o } \\
\text { microesfera. (Choi 2015) }\end{array}$ \\
\hline
\end{tabular}

En los polímeros sintéticos sucede lo contrario, el modo de producción para condiciones necesarias, específicas, es relativamente sencillo y reproducible, pero existe el problema de la biocompatibilidad, se suele asociar a los polímeros sintéticos con reacciones inflamatorias. Sin embargo, en la actualidad ya existe una larga lista de biopolímeros sintéticos compatibles con el cuerpo humano, en la Tabla 1.5 se presentan algunos de ellos.

Tabla 1.5 Principales polímeros sintéticos en aplicaciones biomédicas. Modificado de (Angelova 1999)

\begin{tabular}{|c|l|}
\hline $\begin{array}{c}\text { Poliésteres } \\
\text { alifáticos }\end{array}$ & $\begin{array}{l}\text { Algunos ejemplos son poliácido láctico (PLA), poliácido glicólico (PGA), } \\
\text { policaprolactona (PCL). Son usados en suturas, liberación de fármacos, } \\
\text { como andamios para crecimiento celular. Son biodegradables y sus } \\
\text { propiedades pueden variar dependiendo de su fabricación }\end{array}$ \\
\hline Polivinil alcohol & $\begin{array}{l}\text { Mejor conocido como PVC, se usa como gel y anclado en membranas para } \\
\text { entrega de fármacos e inmunoaislamiento celular. }\end{array}$ \\
\hline $\begin{array}{c}\text { Polimetil } \\
\text { metacrilato }\end{array}$ & $\begin{array}{l}\text { El PMMA, junto con sus copolímeros son usados en implantes dentales, } \\
\text { remplazo de hueso e instrumentación ocular. }\end{array}$ \\
\hline $\begin{array}{c}\text { Politetrafloruro- } \\
\text { etileno }\end{array}$ & $\begin{array}{l}\text { Teflon®, se utiliza como injerto vascular, en clips y suturas, así como } \\
\text { recubrimientos. }\end{array}$ \\
\hline $\begin{array}{c}\text { Polióxido de } \\
\text { etileno }\end{array}$ & $\begin{array}{l}\text { Es altamente biocompatible. Sus diferentes copolímeros se han usado en } \\
\text { diversas aplicaciones biomédicas }\end{array}$ \\
\hline $\begin{array}{c}\text { Polihidroxietilo } \\
\text { metacrilato }\end{array}$ & $\begin{array}{l}\text { Sus hidrogeles han sido utilizados como lentes de contacto suaves, así } \\
\text { como entrega de fármacos, recubrimiento para la piel e inmunoaislamiento } \\
\text { celular. }\end{array}$ \\
\hline $\begin{array}{c}\text { Poliuretanos } \\
\text { termoplásticos }\end{array}$ & $\begin{array}{l}\text { Usado en implantes médicos permanentes como prótesis o catéteres, y en } \\
\text { sistemas de liberación de drogas. }\end{array}$ \\
\hline
\end{tabular}

Existe una amplia gama de métodos para producir y mimetizar con biomateriales poliméricos; las opciones son muchas por lo cual se deben buscar las diferencias entre unas y otras, para ver cuál es el mejor método para el tipo de biopolímero, la fisiología de la región donde se piensa utilizar y las propiedades ideales a las que se desea llegar. 
Algunos métodos son: Unión de fibras, electrohilado, moldeado por fundición, separación entre fases, liofilización, lixiviación con sal (Thottappillil 2015), prototipado digital con impresión de tinta 3D, por microextrusión, por impresión mediada por láser, entre otros (Morsi 2014). Finalmente, en el siguiente apartado se mostrará con mayor precisión, otro de los métodos, polimerización por plasma.

\subsubsection{Polimerización por plasma}

El método de síntesis de un polímero es relevante para las propiedades de los polímeros. Más aún cuando se busca biocompatibilidad, ya que ciertos aceleradores, solventes o productos intermediarios, típicos en las reacciones químicas, podrían ser dañinos para ciertos tejidos, células o estructuras del cuerpo humano. Es ideal que cuando buscamos biocompatibilidad, en el método de polimerización, se encuentre sólo el monómero específico del polímero. Esto con la intención de reducir reacciones adversas o no deseadas en el organismo donde se colocará el implante (Cruz 2010).

Un método que cumple con esas características es la polimerización por plasma. La reacción química es llevada a cabo mediante un campo eléctrico que promueve una colisión continua entre los monómeros, los cuales se van uniendo poco a poco, acelerados por un potencial eléctrico.

Todo esto sucede en un reactor, el cual se encuentra conectado a una bomba que lo mantiene al vacío. [Figura 1.7] La energía cinética que los electrones pueden alcanzar durante esta polimerización es equivalente a más de $100,000^{\circ} \mathrm{C}$ en el campo de la termodinámica que conocemos (Hegemann 2006). 


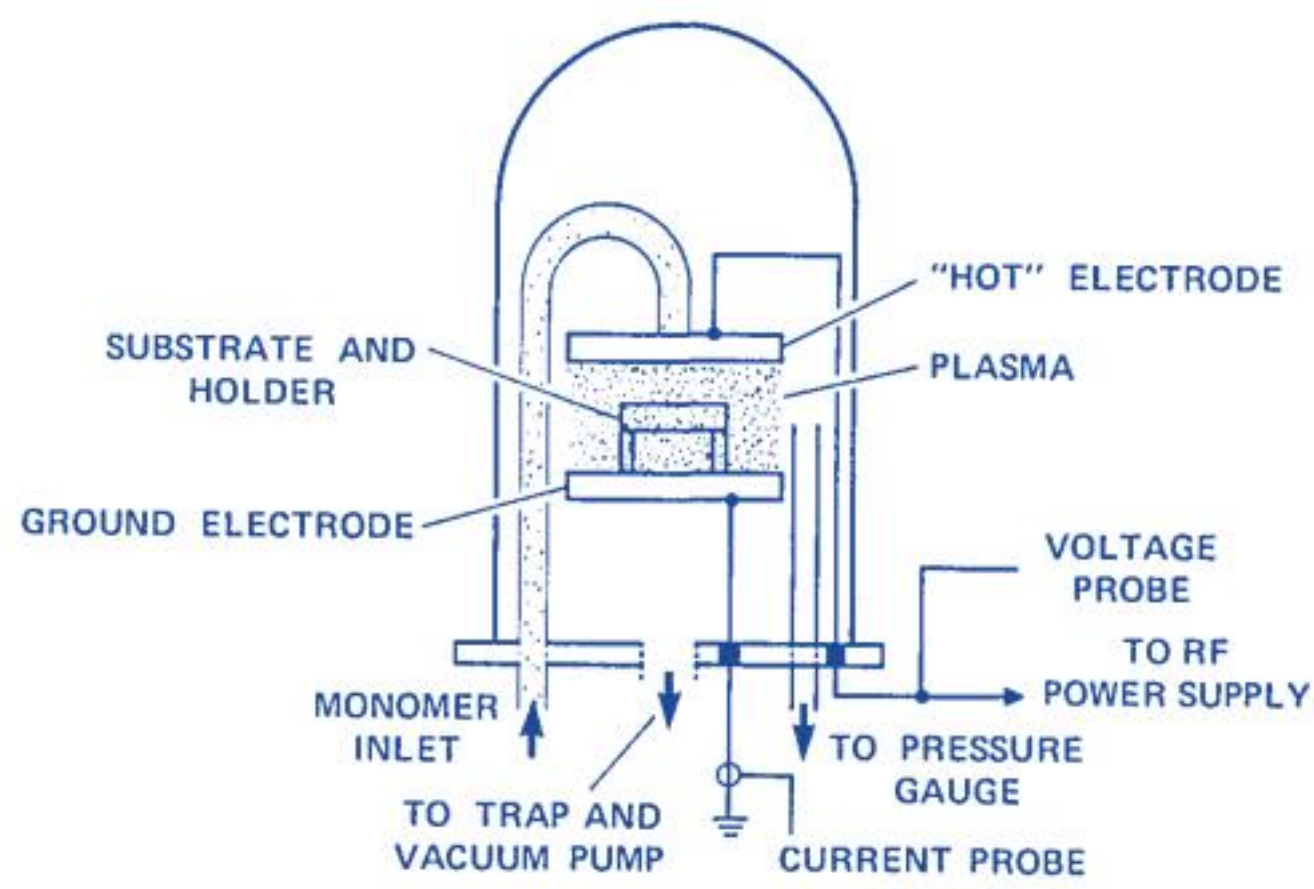

Figura 1.7 Diagrama ejemplo de polimerización por plasma. La entrada de monómero, la bomba de vacío y una salida para medición de presión en la parte inferior. Los dos electrodos en el centro con la reacción y el plasma entre ellos; uno a tierra y el otro a la fuente de energía. (Wydeven 1976)

Otras de las ventajas que obtenemos en la síntesis por plasma son que la reacción puede comenzar en estado gaseoso, que el polímero recubre cualquier superficie expuesta al plasma; para nuestro caso recubrirá ambas placas expuestas dentro del reactor. Además, este método de síntesis es medianamente reproducible, ya que el tiempo de reacción nos puede dar un aproximado del grosor y tamaño de la película de recubrimiento de los materiales expuestos. Finalmente, la energía electromagnética, las bajas presiones y altas energías del material producen un material estéril. Todas estas propiedades hacen que este tipo de síntesis sea el ideal para tratamientos en la LTME, tal como se verá en el siguiente apartado. 


\subsubsection{Polímero polipirrol dopado con yodo en lesión de médula espinal}

Como ya se ha visto en espacios previos, los polímeros son utilizados en muchas aplicaciones; con diferentes métodos de síntesis. En el caso específico de lesión de médula espinal, Álvarez-Mejía, en el 2008, demostró que los implantes poliméricos (PPy, PPy/I, PPy/PEG) utilizados en su trabajo tenían un posible beneficio en la recuperación funcional de sujetos experimentales, después de una lesión de médula espinal.

Se menciona que el posible beneficio pueda deberse al método de síntesis (por plasma) ya que los grupos nitrilos, de triples ligaduras, que aparecen con este método, pueden añadir a los radicales libres y actuar como antioxidantes, reduciendo procesos dañinos como la lipoperoxidación. Se debe mencionar que este efecto sólo se mostró en estos polímeros cuando eran sintetizados por plasma, otros métodos no presentaban dichos efectos. (Álvarez Mejía 2015)

También se demostró que al utilizar PPy/I en los implantes, la recuperación motora fue mayor que en los otros polímeros que también fueron sintetizados por plasma, esto se piensa que se puede deber a la absorción de nitrógeno, es más intensa que en los otros dos. Otro detalle importante a mencionar fue que también se presentaba una menor destrucción del tejido con el implante de PPy/I con respecto a los otros polímeros sintetizados por plasma. Cabe mencionar que otro factor importante que explique este fenómeno sea la conductividad eléctrica, ya que PPy/I mostró una mayor conductividad con respecto a los otros implantes poliméricos probados.

Con base en estos resultados se han hecho diferentes pruebas con algunas variantes en el tiempo de administración, etapa y tipo de lesión, método de aplicación del polímero y sujetos de experimentación (Morales-Guadarrama 2015, Alvarez-Mejía 2015, Cruz 2012, Mondragón-Lozano 2017). 


\subsection{Imagenología por Resonancia magnética.}

La obtención de imágenes, con fines médicos, por medio de Resonancia Magnética fueron realizadas por primera vez en el Reino Unido en 1980 (Grover 2015). Este tipo de técnica tiene una amplia aceptación actualmente, además de su reconocimiento a nivel mundial. De acuerdo con Nacher (2007), el gran reconocimiento de la Imagen por Resonancia Magnética (MRI, por sus siglas en inglés), en el campo médico, es debido a su variedad para obtener imágenes nítidaz del interior del cuerpo de una forma no invasiva e inofensiva.

Las imágenes por resonancia magnética son una importante herramienta para diagnosticar y evaluar la LTME, éstas permiten una visualización no invasiva de los cambios en la médula espinal. Imágenes convencionales, ponderadas en T1 y T2 son comúnmente usadas para identificar alteraciones vertebrales, compresiones de la médula y lesiones en general dentro de esta zona. (Oakden 2015)

La MRI emplea un campo magnético principal, llamado externo o estacionario $\left(\mathrm{B}_{0}\right)$, de gran potencia; se consigue a través de una gran corriente eléctrica generada por una bobina a temperaturas superconductivas, enfriadas con helio líquido. (Pooley 2005) Éste campo hace que los protones del sujeto analizado puedan alinearse con él, ya sea de forma paralela -también conocida como de baja energía- o antiparalela -también conocida como estado de alta energía-, tal como es mostrado en la Figura 1.8

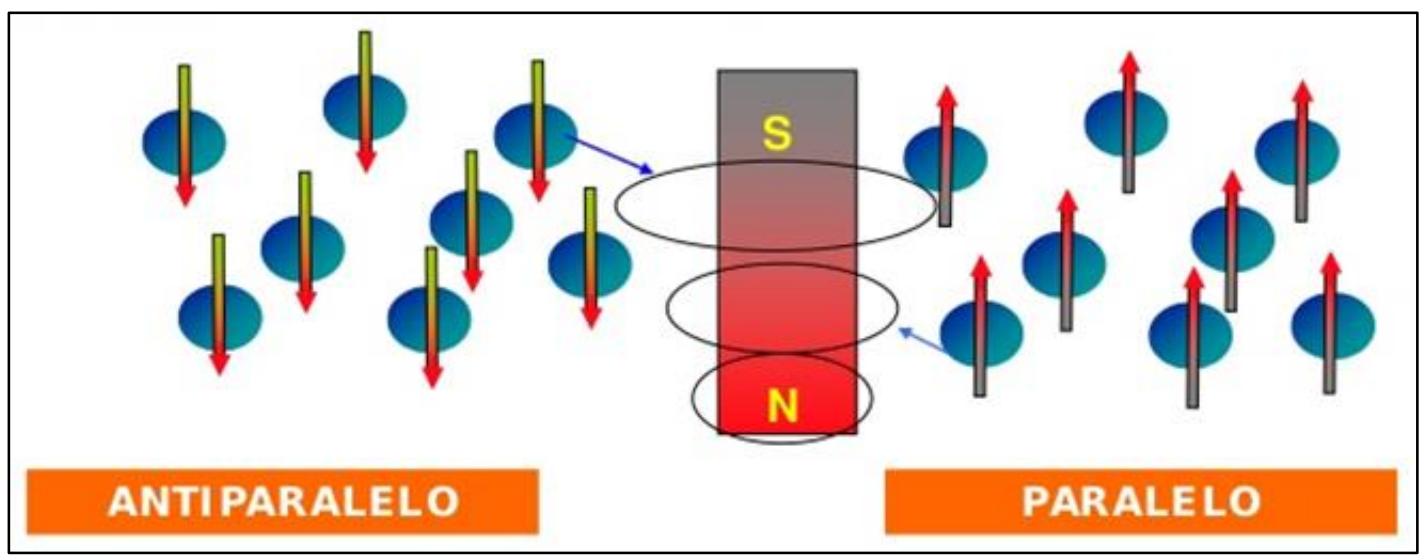

Figura 1.8 Protones alineados de forma de baja o alta energía con respecto al campo estacionario (Grover 2015). 
Los núcleos del sujeto que es sometido al campo externo se alinean en la misma dirección que el campo $\mathrm{B}_{0}$. [Figura 1.9] A pesar de que un objeto magnético se pueda orientar completamente de forma paralela al campo, los nucleos de éste tienen un momento angular debido a su precesión alrededor del eje del campo magnético externo.

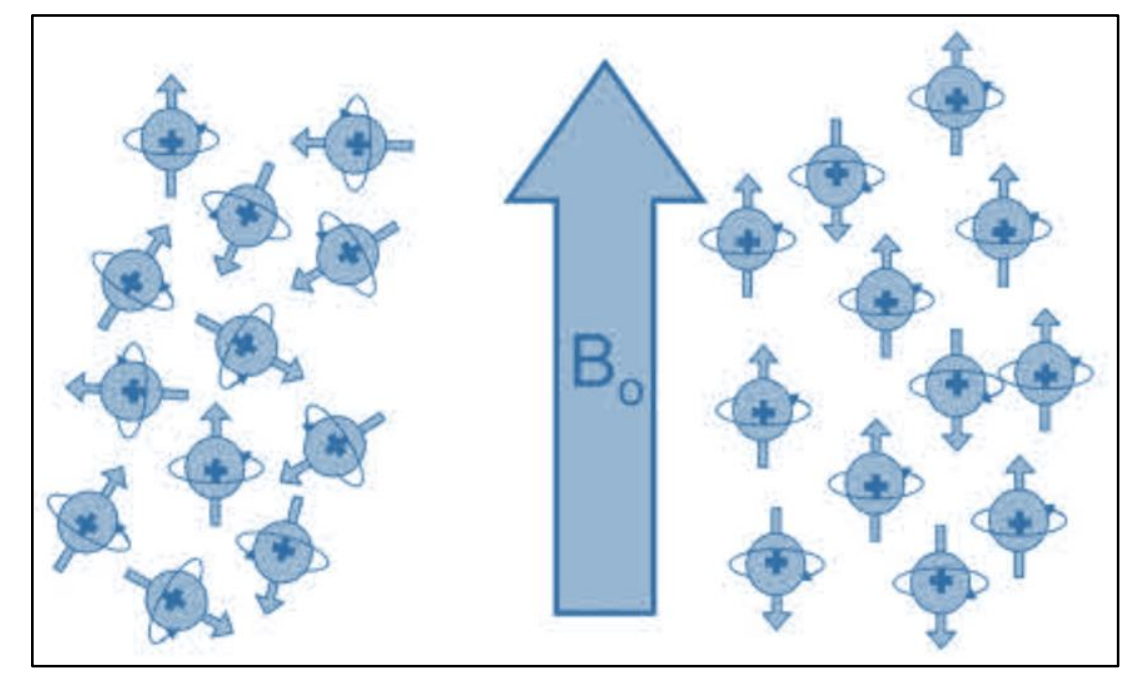

Figura 1.9 Protones sin y con aplicación de un campo magnético externo (Pooley 2005).

La velocidad de rotación alrededor del campo es conocida como la frecuencia de Larmor, la cual es directamente proporcional a la fuerza del campo magnético que se tenga (Stehling, Turner y Mansfield 1991), tal como se describe en la siguiente ecuación:

$$
\omega_{0}=\gamma B_{0}
$$

Donde el radio giromagnético $\gamma=42.58 \mathrm{MHz} / \mathrm{T}$, para hidrógeno, mientras que el campo $\left(B_{0}\right)$ varía según el equipo y la potencia que éste presente; para el caso de un resonador con campo estacionario de 7T, la frecuencia angular de los protones, sería $\omega=298 \mathrm{MHz}$.

Los núcleos que están alineados por el campo magnético pueden ser excitados por una señal de Radio Frecuencia (RF) externa, generando un segundo campo magnético $\left(\mathrm{B}_{1}\right)$ perpendicular al campo externo $B_{0}$. [Figura 1.10] Generalmente, la RF es aplicada a modo de pulsos; esto con la finalidad de que esa energía sea absorbida por los nucleos, causando una transición en su nivel de energía y el decaimiento de éste durante la relajación. 


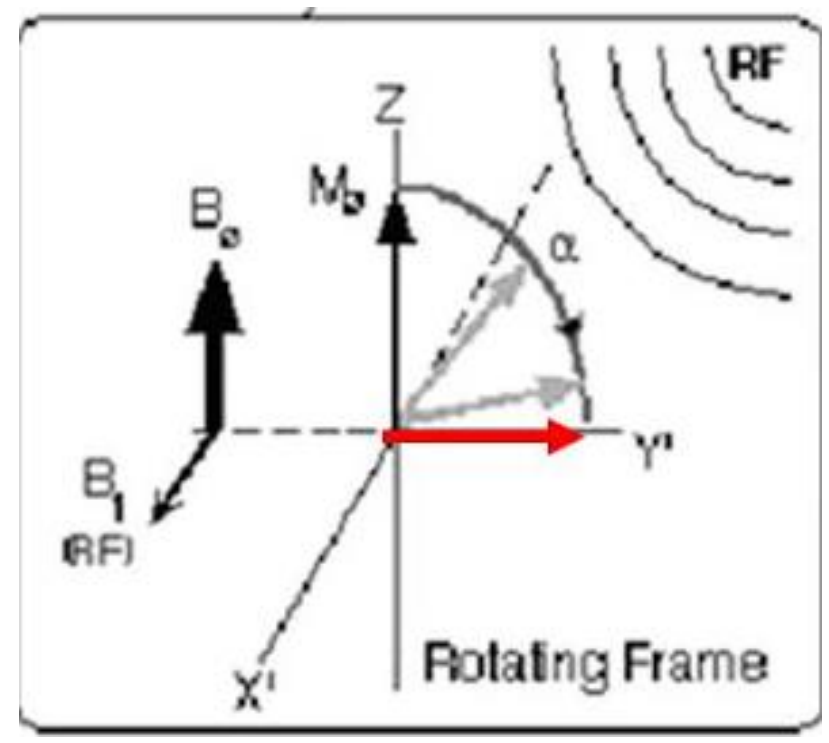

Figura 1.10 Inducción de RF sobre el tejido que desalinea los núcleos por absorción de energía

De acuerdo con Scherzinger (1985), la energía que es absorbidad induce un voltaje que puede ser detectado por una bobina y amplificado por una serie de circuitos electrónicos para ser mostrada como una tensión proporcional, conocida como Decaimiento de Inducción Libre (FID, por sus siglas en inglés). [Figura 1.11].

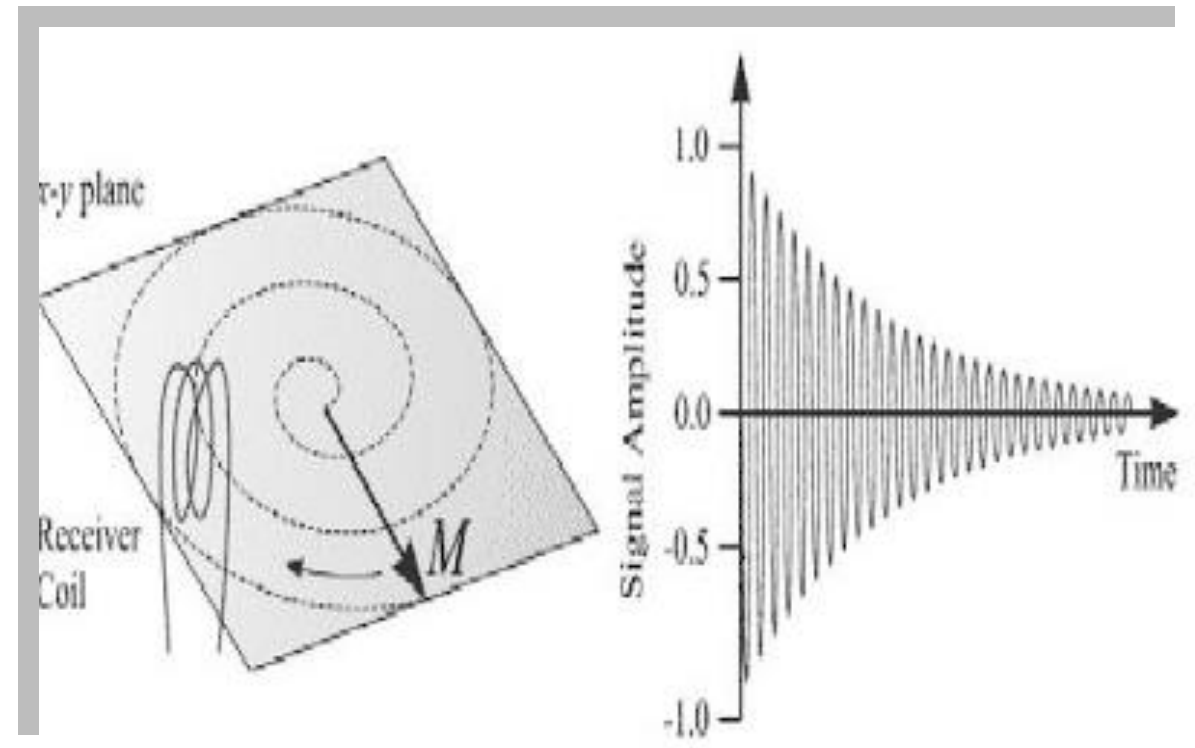

Figura 1.11 Tensión proporcional, FID 
La señal FID se obtiene en el dominio del tiempo, para poder simplificarla se utiliza la Transformada de Fourier, de la cual se puede arrojar información para generar una Imagen de Resonancia Magnética (MRI) o el espectro de la frecuencia, que otorga información bioquímica de los diferentes metabolitos presentes en la muestra dentro del campo externo a la cual se le induce la RF. [Figura 1.12]

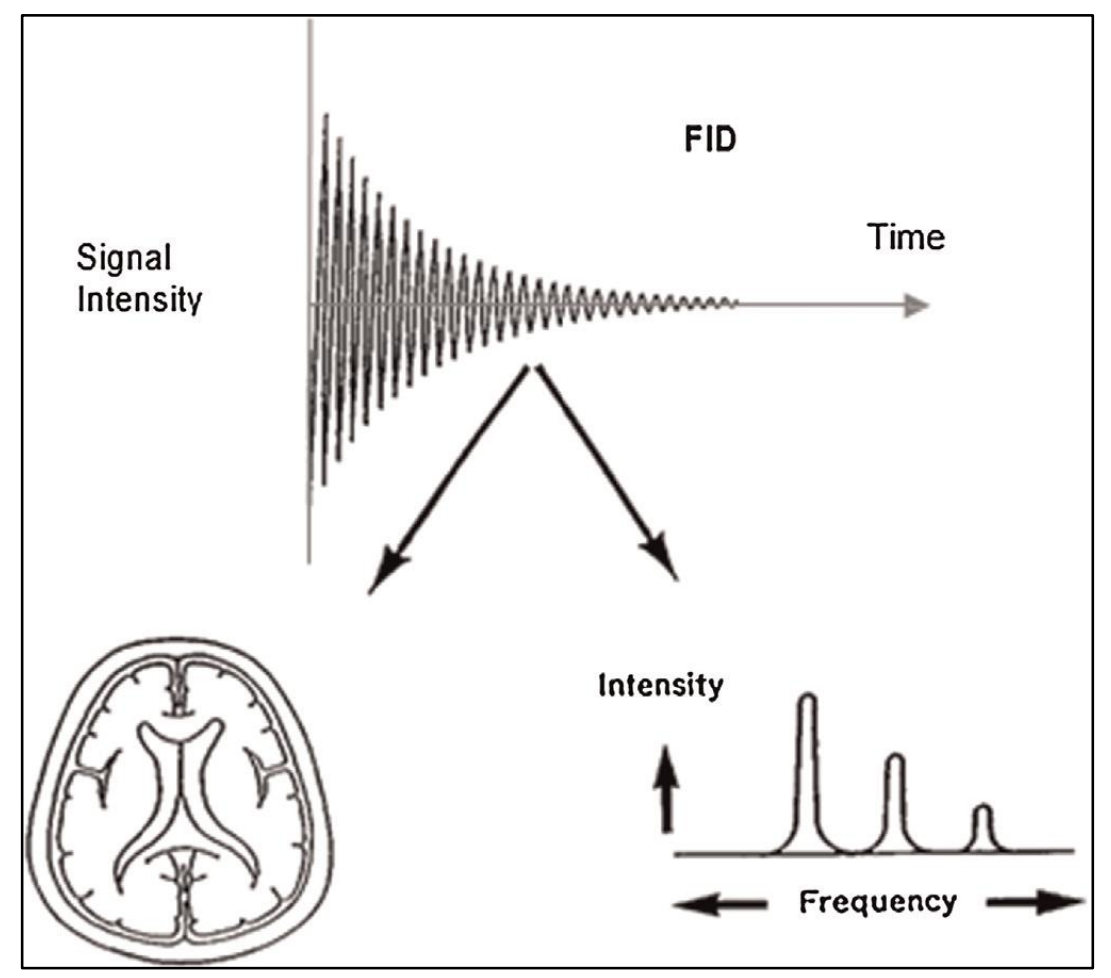

Figura 1.12. Transformación de la FID para obtención de información (Grover 2015).

Cuando los pulsos de RF han terminado, el sistema regresa a un equilibrio térmico mediante el proceso llamado relajación. Éste describe el retorno de los spins de los núcleos a un estado de equilibrio alineados al campo externo. Existen dos tipos de relajación; la primera de ellas es la longitudinal, la vemos expresada cuando la energía del núcleo es disipada a su alrededor en lo que regresa a alinearse al campo externo, éste tipo de relajación es medida por la constante de tiempo $\mathrm{T}_{1}$. [Figura 1.13] 


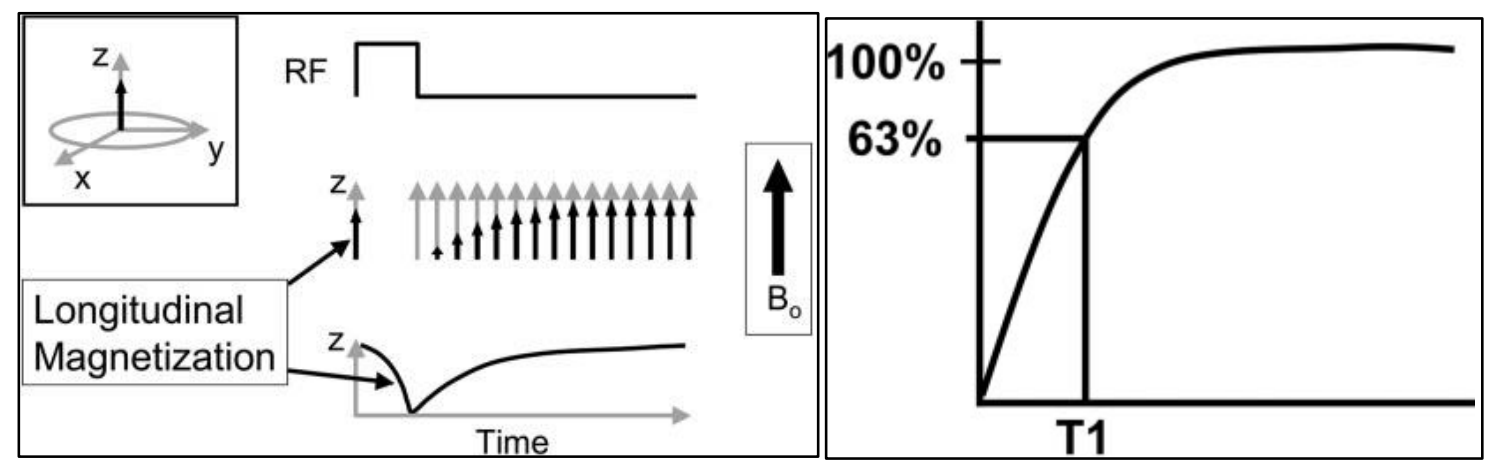

Figura 1.13. Relajación longitudinal (T1) (Pooley 2005).

Sin embargo, la energía también puede ser redistribuida en el núcleo sin desprenderse de ella, generando una desalinealición transversal al campo externo, conocida como relajación transersal, la cual es medida por la constante de tiempo T2. [Figura 1.14]

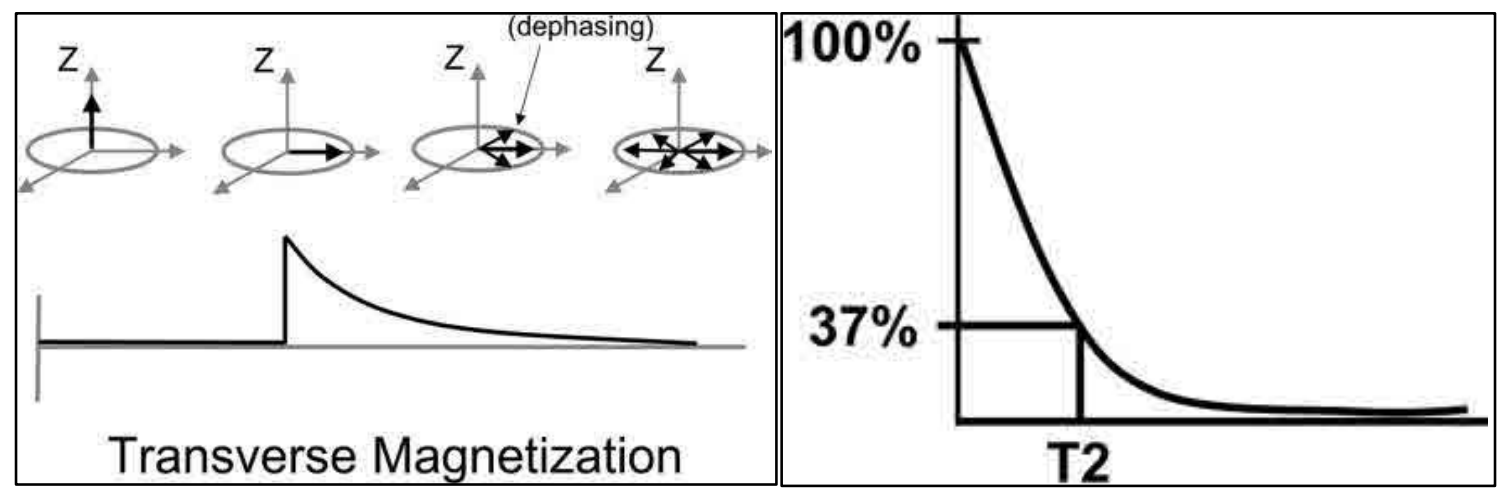

Figura 1.14. Relajación transversal (T2) (Pooley 2005).

$\mathrm{T}_{1}$ representa el tiempo que es tomado para que el sistema, sobre el cual se ejerce la energía, regrese al $63 \%$ de su equilibrio térmico después del pulso de RF. Por ejemplo, la materia blanca tiene un valor más bajo que la materia gris para $T_{1}$, aproximadamente $700 \mathrm{~ms}$ y $1000 \mathrm{~ms}$, respectivamente. Por lo tanto, la materia blanca aparecerá de tonos hipointensos, con respecto a la materia gris, cuando la imagen se pondere a $\mathrm{T}_{1}$. Por el contrario, la materia blanca aparecerá en tonos hiperintensos, con respecto a la materia gris cuando la ponderación sea en $\mathrm{T}_{2}$. Ya que esta última representa el tiempo cuando el 37\% de la energía se ha desalineado de forma transversal al campo externo; es decir, al plano "xy". Como se sabe que la materia blanca llega al $37 \%$ en $80 \mathrm{~ms}$ y la materia gris en $100 \mathrm{~ms}$., se puede decir 
que si la adquisición de la señal se toma en un tiempo específico, entre ambos, la materia gris será hipointensa, en ese caso, con respecto a la materia blanca.

Los diferentes tiempos a los cuales relajan los tejidos deben ser tomados en cuenta para la preparación de las diferentes secuencias de imágenes, ya que de ello dependerá qué se apreciará en cada una de ellas. A continuación se presenta en la imagen las curvas de algunos tejidos para ser localizados mediante imagenología de resonancia magnética [Figura 1.15], acompañados de la tabla 1.6 con más valores en segundos para los tiempos de relajación $\mathrm{T}_{1}$ y $\mathrm{T}_{2}$ en diferentes tejidos.

Tabla 1.6 valores de tiempo para relajaciones $\mathrm{T}_{1}$ y $\mathrm{T}_{2}$, de algunos de los principales tejidos $\mathrm{y}$ sustancias del SNC

\begin{tabular}{|c|c|c|}
\hline Tejido/ Sustancia & $\mathrm{T}_{1}(\mathrm{~s})$ & $\mathrm{T}_{2}(\mathrm{~s})$ \\
\hline Materia Gris & 1.0 & 0.10 \\
\hline Materia Blanca & 0.7 & 0.08 \\
\hline LCR & 2.0 & 0.25 \\
\hline Sangre & 1.2 & 0.25 \\
\hline Agua & 4.7 & 3.50 \\
\hline
\end{tabular}



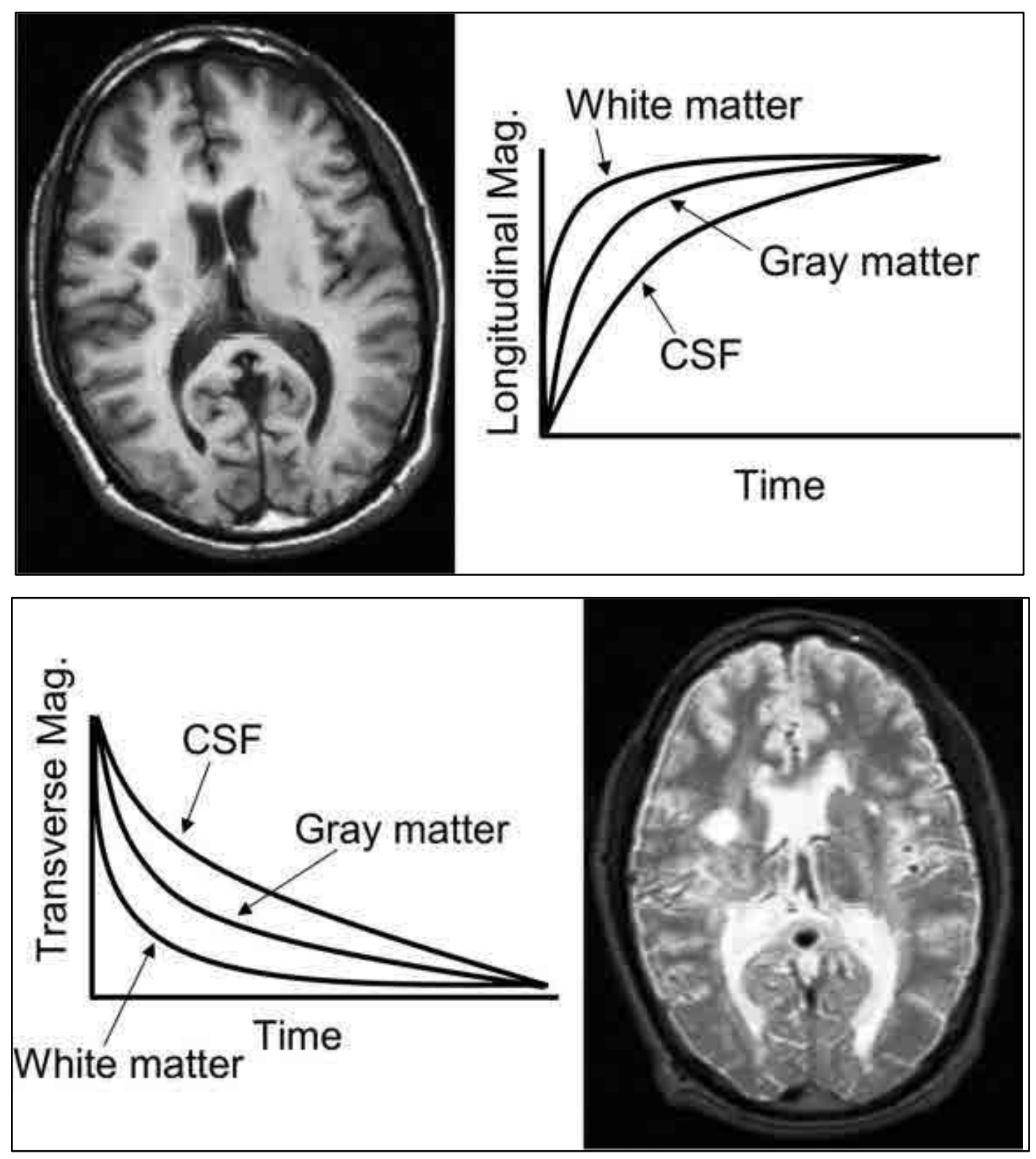

Figura 1.15 Relajación longitudinal y transversal cerebral (Pooley 2005).

En la Figura 1.15 se deben remarcar las diferencias entre ambas imágenes, a pesar de que se muestran cortes axiales similares para cerebros normales, es muy notorio el LCR, dentro de los ventrículos y alrededor de la corteza cerebral. Cuando se tiene relajación longitudinal, esto es remarcado con tonos hipointensos, contrario a lo que se tiene en la relajación transversal, en la que se aprecian en tonos hiperintensos. También se puede apreciar la gran 
diferencia que existe entre ambas relajaciones cuando hablamos de la sustancia gris y blanca.

Para localizar una región de interés de una señal de resonancia magnética se requiere el uso de gradientes. Los gradientes sirven para modificar ligeramente la uniformidad del campo magnético externo para que haya precesión a diferentes frecuencias a lo largo de la muestra (Rodríguez 2004). Así, una más rápida o lenta señal es detectada por el sistema de adquisición y se pueden validar distintas posiciones en el espacio, lo que permite reconstruir imágenes en tres dimensiones (Grover 2015).

\subsubsection{Resonancia Magnética en lesiones de médula espinal}

La MRI es una herramienta de suma importancia en la evaluación de la LTME, esto se debe a que nos permite visualizar los cambios en la médula espinal sin tener que ser invasivo o dañino para el cuerpo humano (Oakden 2015).

La MRI es una modalidad de imagenología, bien establecida, capaz de identificar la zona de la lesión de médula espinal, también puede ser usada para demostrar el grado de compresión después de una LTME, para encontrar hemorragias, laceraciones o contusiones en el parénquima, edemas y daños generales en etapas agudas y subagudas de la lesión. Puede contribuir a entender la severidad del daño y el pronóstico para mejoras neurológicas (Lammertse 2007, Chandra 2011).

Las ventajas que hacen a la MRI esta herramienta atractiva para evaluación de la LTME son su excelente resolución, la ausencia de artefactos generados por los huesos, la facilidad de tomar diferentes posiciones sin el movimiento del paciente, las diferentes secuencias que pueden ocuparse y la radiación no ionizante que es usada.

La MRI otorga un medio para seguir la evolución de la lesión, la formación de quistes alrededor del área de la lesión, la posible mejora después de un implante, la proliferación de tejido en la zona y la caracterización de las diferentes terapias que pudieran ser utilizadas 
para la regeneración del SNC, de una forma no invasiva, pudiendo prolongar estudios longitudinales con sujetos experimentales (Morales-Guadarrama 2013).

Existe la posibilidad de obtener perjuicios a las imágenes por dispositivos ferromagnéticos usados para la estabilización del paciente, pero, normalmente, no son lo suficientemente significativos para dañar la imagen. Sin importar cuál sea la causa de la lesión medular, la región de la mielomalacia contribuye a cambios en los tiempos de relajación ya mencionados, $\mathrm{T}_{1}$ y $\mathrm{T}_{2}$. Estos cambios pueden ser apreciados como un decremento en la intensidad de la señal de las imágenes ponderadas en $\mathrm{T}_{1}$, y como un área con brillo ligeramente superior cuando se trata de imágenes ponderadas en $\mathrm{T}_{2}$. Los quistes, por otro lado serán relativamente hipointensos en $\mathrm{T}_{1}$, pero realmente hiperintensos en $\mathrm{T}_{2}$.

Las estructuras que contengan LCR, incluyendo los quistes, serán siempre hiperintensas cuando se comparan con médulas espinales normales o con casos de mielomalacia. Estas características hacen, para muchos, a la MRI el único estudio capaz de distinguir diferentes tipos de lesión en pacientes, con síntomas neurológicos progresivos, que han pasado por un daño severo de la médula espinal (Saremi 1995).

Otras secuencias y técnicas de la MRI, fuera de las convencionales, como las imágenes ponderadas en difusión (MRI-DWI, por sus siglas en inglés), Imagen por Tensor de Difusión (DTI, por sus siglas en inglés) e Imagen de Resonancia Magnética funcional (fMRI, por sus siglas en inglés) ofrecen otras ideas y perspectivas para evaluar la LTME. Por ejemplo, cambios en la última indican actividad funcional de la médula espinal, esto basado en el nivel de dependencia de oxígeno en la sangre. Algunos estudios han mostrado que puede ser confiable en la detección motora y sensitiva después de una LTME (Lammertse 2007). Las imágenes de difusión se verán con mayor detalle en el siguiente apartado.

No debemos olvidar que también la resonancia magnética es capaz de otorgarnos una espectroscopía de la muestra que se esté evaluando, permitiendo dar una medida, no invasiva, de varios metabolitos bioquímicos por un análisis in-vivo. Se ha ocupado este tipo de estudio para ver diferentes componentes, entre ellos: colina, creatina, fosfocreatina, $\mathrm{N}-$ 
acetil aspartato, glutamato, glutamina y otros (Lammertse 2007). Algunos de estos metabolitos están seriamente implicados en el deterioro o recuperación del SNC. Se podrían considerar biomarcadores del sistema nervioso.

\subsubsection{Imagen por Tensor de Difusión y Tractografía por Resonancia Magnética}

La imagen por Tensor de Difusión es una técnica de resonancia magnética capaz de hacer mediciones sobre la magnitud y la dirección de la difusión de las moléculas de agua en diversos tejidos. Fue desarrollada de otra técnica para obtener imágenes, conocida como ponderada en difusión (DWI, por sus siglas en inglés), la cual mide la atenuación de las señales debido a la difusión. (Vedantam 2013).

La difusión es la propiedad física que describe el movimiento aleatorio de las moléculas en solución con concentración uniforme. Cuando las moléculas difunden igual en todas las direcciones se tiene una difusión isotrópica.

La difusión del agua tiene las propiedades del movimiento Browniano, cuando no es contenida tiende a moverse de forma equitativa en todas direcciones, por lo tanto es isotrópico. Pero cuando las mismas moléculas de agua se colocan en un sitio estructurado, adquieren la forma y movimiento de éste. [Figura 1.16]

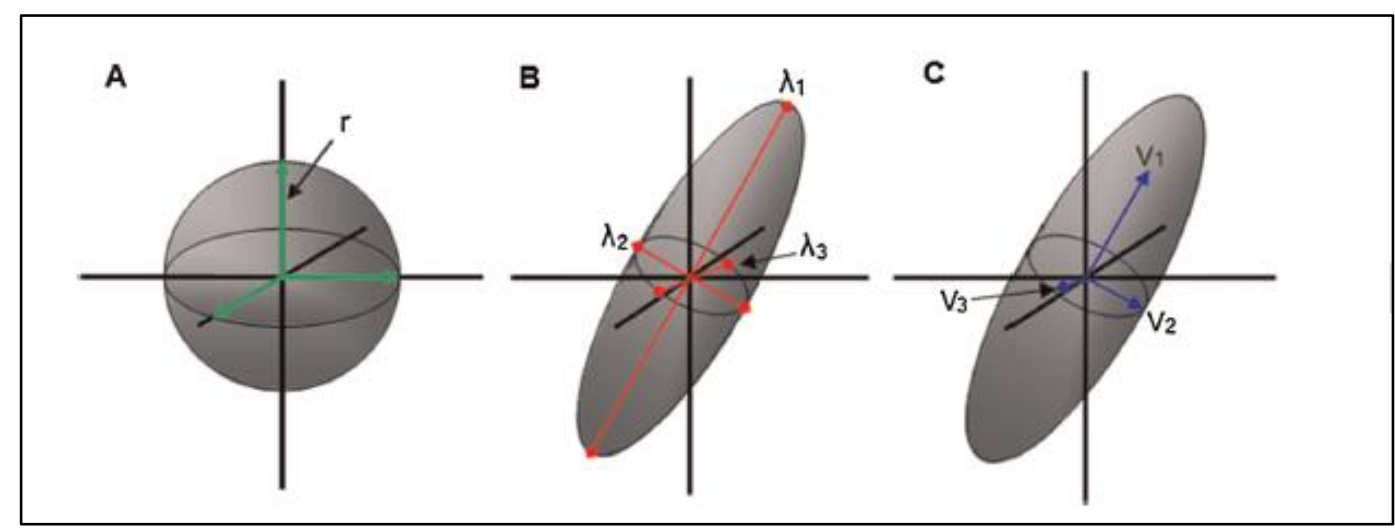

Figura 1.16 Movimiento isotrópico (A) Difusión restringida, anisotrópico (B y C) (Grover 2015). 
En la sustancia blanca cerebral existen barreras a la difusión, tales como la densidad, el diámetro de los axones, la integridad del axón, etc. En general, las moléculas del agua tienden a moverse de forma paralela a los tractos de materia blanca (Doran 1990). A este tipo de movimiento se le conoce como anisotrópico, ya que suele ser diferente para todas las direcciones, $\mathrm{y}$ al menos no igual para todas.

El movimiento de las moléculas en los planos puede ser reconstruido en un Tensor de difusión, definiendo el movimiento de las moléculas a cada uno de los planos en un elipsoide (Basser 2002). Para que un tensor pueda ser reconstruido se requieren, al menos, seis direcciones de difusión no colineares (Grover, 2015).

Con un entramado de este tipo de reconstrucción se obtiene una imagen por tensor de difusión, la cual es utilizada para caracterizar el movimiento molecular en múltiples direcciones dentro de un espacio tridimensional. Las difusiones en los tres principales ejes son definidas por eigenvectores, donde $\lambda_{1}$ es el eigenvector primario; representa la dirección y magnitud de la difusión longitudinal, mientras que $\lambda_{2}$ y $\lambda_{3}$ representan a los vectores alojados en los ejes restantes. (Vedantam 2013)

Las magnitudes de esos vectores son usadas para calcular algunos índices, permitiendo que la técnica DTI otorgue beneficios significativos sobre las tradicionales ponderaciones en T1 y T2. Las imágenes por difusor tensor pueden ser usadas para evaluar la extensión del daño axonal y su reparación (Martínez 2007), todo esto basado en los índices calculados con los vectores mencionados

La Fracción de Anisotropía (FA, por sus siglas en inglés), es un valor que va de 0 a 1 , éste define el grado de anisotropía; tejidos altamente anisotrópicos obtendrán un valor cercano a 1. El coeficiente de difusión aparente (ADC, por sus siglas en inglés) es el valor medio de los vectores previamente mencionados; es decir, la cantidad total de difusión sin importar la dirección en la cual se presenta. También se puede calcular este mismo valor, pero con respecto sólo al eje longitudinal o a los dos ejes restantes. En la Figura 1.17 se muestran las ecuaciones para los valores mencionados. 


$$
\begin{gathered}
F A=\sqrt{\frac{\left(\lambda_{1}-\lambda_{2}\right)^{2}+\left(\lambda_{2}-\lambda_{3}\right)^{2}+\left(\lambda_{1}-\lambda_{3}\right)^{2}}{2\left(\lambda_{1}{ }^{2}+\lambda_{2}{ }^{2}+\lambda_{3}{ }^{2}\right)}} \\
A D C=\frac{\lambda_{1}+\lambda_{2}+\lambda_{3}}{3}
\end{gathered}
$$

Figura 1.17 Ecuaciones para los índices FA y ADC (Vedantam 2013).

ADC y FA han sido fuertemente correlacionados con puntajes para la función locomotora, siendo valores cuantitativos de la evolución y recuperación luego de la LTME. (MondragónLozano, 2013)

Además, podemos obtener una tractografía, ésta es la imagen que se hace con base en el valor de FA de cada uno de los voxeles obtenidos durante el estudio, se puede seleccionar arriba de algún valor deseado para la anisotropía, en alguna región del cerebro para resaltar ciertas estructuras (Recio Rodríguez 2013).

Así, se obtendrán tractos de fibras en diferentes direcciones en el cerebro. Estas direcciones se representan con colores, tal como se muestra en las tractografías de la Figura 1.18. Entre laterales se le asigna color rojo, de ventral a dorsal se le otorga el color verde y azul para aquellos tractos en dirección caudal -rostral.

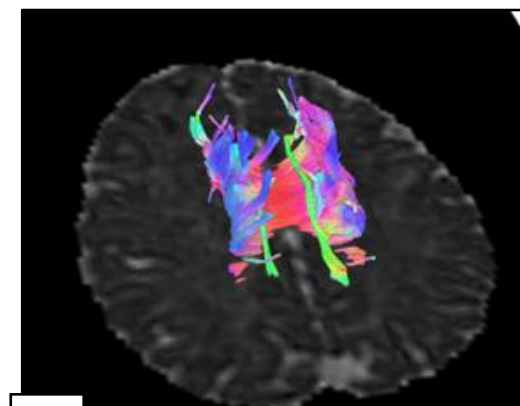

A
B

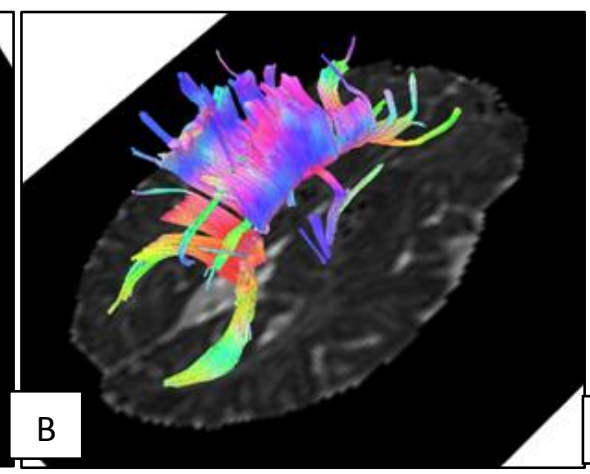

C

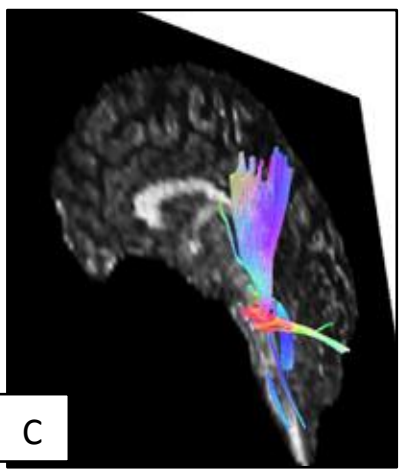

Figura 1.18 Ejemplos de Tractografías: Haz de fibras corticoespinales (azul) con un poco de fibras dispersas (A). Haz de fibras cortico espinales con cuerpo calloso en rojo (B). Tracto cortico espinal, con parte del tronco del cuerpo calloso y tracto córtico-bulbar, en azul por la dirección $(\mathrm{C})$ 
Se ha encontrado que la técnica DTI, gracias a los valores FA y ADC, es una buena medida para evaluar la integridad axonal. (Bazley 2012). El decremento en los valores FA evidencia la degeneración axonal en el sitio de la lesión, mientras que ADC incrementa luego de la lesión debido a la baja integridad del tejido (Zhang 2015). Estos valores tienen una correlación, y son una variable dependiente de la destrucción o regeneración en LTME. 


\section{Justificación}

\begin{abstract}
"Durante el terremoto de 2010 en Haití, fui golpeado y severamente lastimado por un muro. Mis lesiones fueron diagnosticadas como tetraplejia al nivel de C6. Cinco meses después del terremoto, fui readmitido en el hospital Appeal de Haití para rehabilitación. Ahí recibí mi primera silla de ruedas. Sin embargo, ésta no era de mi tamaño (soy muy alto) ni se ajustaba al nivel de mi lesión. En Haití, el sistema de salud no se preocupa por la provisión de sillas de ruedas, por lo tanto tú tienes que intentar conseguir una por tu cuenta-tienes que pagar por tu cuenta"
\end{abstract}

Samuel, Haití

Como bien se ha mencionado, estamos ante un problema médico y social de gran escala. Se estima que mundialmente entre 250000 y 500000 personas ven una modificación completa a su estilo de vida antiguo, ya que se suman a los casos de lesión en médula espinal (Bickenbach 2013). Esto sin mencionar aquellos casos en los cuales el paciente muere de forma prácticamente inmediata.

En Australia, se estima que el costo de vida por incidente es de 3.86 millones de dólares estadounidenses para paraplejia, mientras que 7.34 para tetraplejia. En Canadá los costos para el primer año de cada persona con lesión incompleta se estiman aproximadamente en 31,400 dólares estadounidenses y 2,000 para cada año subsecuente (Dryden 2005). Si estos números se multiplican por la cantidad de casos, se convierten en sumas de más de miles de millones de dólares estadounidenses, ocupados en este padecimiento. A esto se le deben sumar los costos económicos indirectos por bajas a la producción y afectación a las vidas de los responsables directos de los pacientes.

Cada una de las formas de disminuir todos los padecimientos relacionados con la LTME, se convierte en una manera de apoyar a este gran problema clínico. Esta línea de trabajo se encuentra en pleno desarrollo dentro de la UAM (Universidad Autónoma Metropolitana), incluyendo el posgrado en Ing. Biomédica.

Uno de los trabajos más recientes, dentro de la línea, ha mostrado que el polímero implantado en monos Rhesus, inmediatamente después de la lesión, crea una zona de 
conservación en la histoarquitectura cercana a la lesión. Además, promueve el crecimiento del tejido a través de él (Morales-Guadarrama 2015). Vislumbrando la posibilidad de traslación clínica; esto después de un análisis específico para cada caso y modelo de lesión. El análisis individual es necesario porque cada una de las lesiones es diferente; de esta forma el estudio y establecimiento del efecto del polímero en sujetos crónicos representa un gran avance para la línea de investigación, ya que se ampliaría de gran manera el rango de pacientes que podrían beneficiarse con desarrollos de esta línea. Una tendencia hacia el paciente.

Además, dentro del grupo de investigación, se ha generado el interés por encontrar más métodos para cuantificar el efecto del PPy/I en lesiones de médula espinal, en sujetos con padecimiento crónico; siendo una gran área de oportunidad para los estudios por medio de resonancia magnética. Esto se sumó al interés por la respuesta del polímero en una lesión crónica, lo que generó la posibilidad de aplicación de esta investigación, que derivó la presente tesis. 


\section{$3 \quad$ Hipótesis}

"Soy un tetrapléjico que tuvo una lesión de médula espinal muchos años atrás, en 1974, mientras jugaba rugby cuando tenía 15 años y medio"

Richard, Nueva Zelanda

Por medio de imágenes de resonancia magnética es posible estudiar y establecer el efecto del polipirrol dopado con yodo, sintetizado por plasma, en el tejido de una lesión medular crónica de sujetos experimentales, en la búsqueda de la recuperación locomotora.

\section{Objetivos}

"En 1998, sufrí una herida de bala que causó una lesión en la médula espinal al nivel torácico 6-7"

Robert, Uganda

\subsection{Objetivo general}

Estudiar el efecto del polímero polipirrol dopado con yodo en un modelo de lesión crónica de médula espinal a la altura de la novena vertebra torácica en sujetos experimentales, ratas, por medio de imágenes de resonancia magnética.

\subsection{Objetivos particulares}

Estudiar la morfometría del tejido de la zona lesionada de los sujetos experimentales por medio de imágenes de resonancia magnética.

> Analizar la evolución de la lesión mediante imágenes por tensor de difusión y tractografía.

$>$ Evaluar el efecto del polipirrol dopado con yodo en la recuperación locomotora de sujetos con lesión crónica de médula espinal mediante la escala BBB (Basso, Beattie y Bresnahan). 


\section{$5 \quad$ Materiales y métodos}

“Antes de la LME, yo era un persona muy independiente, con una vida social muy activa, muchos amigos, trabajando duro, viajando mucho, terminando mi curso de leyes, saliendo... Mi vida era idéntica a la de cualquier otra mujer joven, con muchos deseos de vivir. Después de la LME, todo cambió y se interrumpieron muchos sueños -vivir sola, terminar la universidad, empezar una familia"

Claudia, Brasil.

\subsection{Síntesis del polímero}

El polímero sintetizado por plasma a partir de monómeros de pirrol, fue creado en un reactor tubular de vidrio, tal como se muestra en la Figura 5.1.

Dicho reactor se encuentra disponible en las instalaciones de la UAM campus Iztapalapa. Los parámetros usados para la reacción fueron una potencia de $80 \mathrm{~W}$, un voltaje de $680 \mathrm{~V}$, una frecuencia de $13.5 \mathrm{MHz}$, con una temperatura equivalente a $365 \mathrm{~K}$ dentro del campo de la termodinámica conocida.

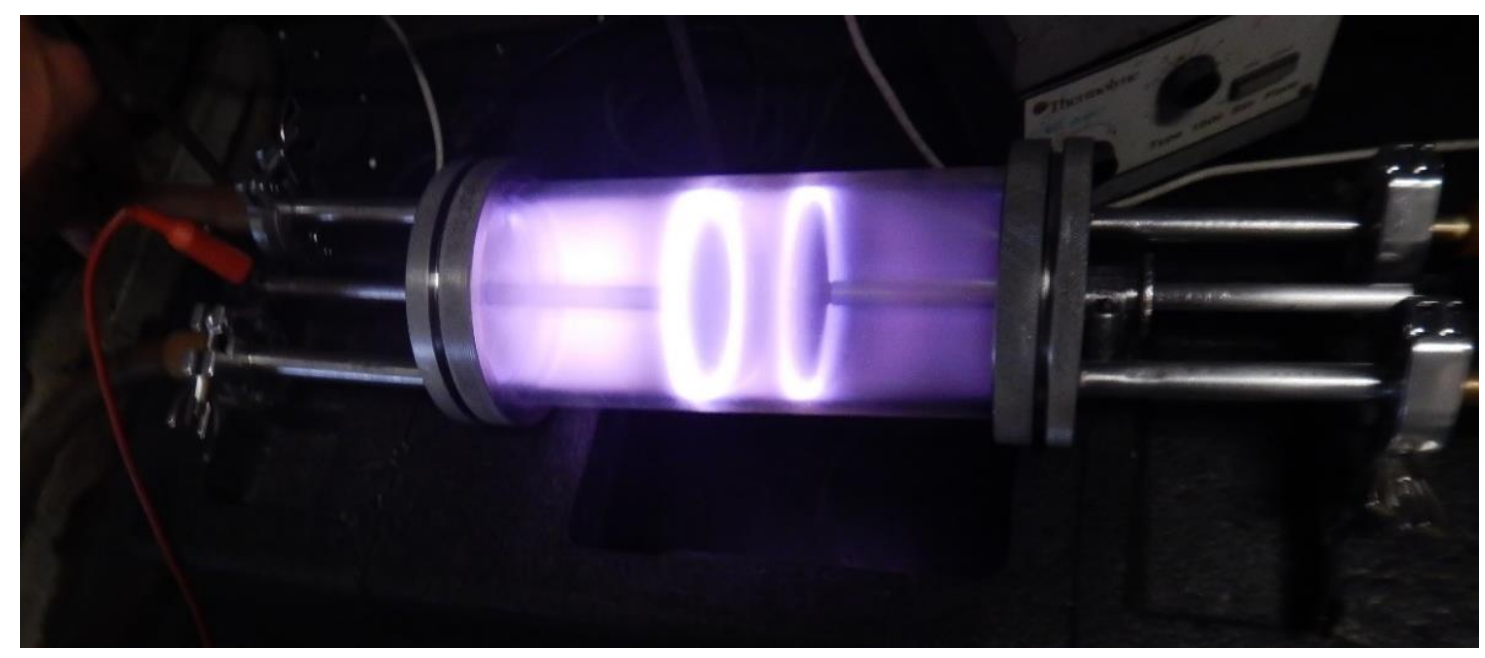

Figura 5.1 Reactor durante polimerización de PPy/I 
En la Figura 5.2 se muestra el reactor después de la reacción, se puede apreciar el ligero recubrimiento de material depositado sobre las paredes. Se debe resaltar que la mayor cantidad de material se encuentra sobre las placas internas, películas delgadas de material se extraen de éstas para posteriormente molerse en un mortero de Agatha, tal como se muestra en la Figura 5.3. Con este procedimiento se obtienen las mesopartículas de material que se implantó en los animales, con una dosis mencionada en el siguiente apartado.

El material obtenido de la polimerización por plasma está libre de agentes contaminantes; sólo se encuentran los monómeros implicados en la reacción. Sin embargo, durante el proceso de molienda para obtener mesopartículas, puede haber contaminación posterior; por esta razón se recomienda esterilizar el material en una cámara o cuarto con lámparas de radiación ultravioleta por al menos 3 minutos.

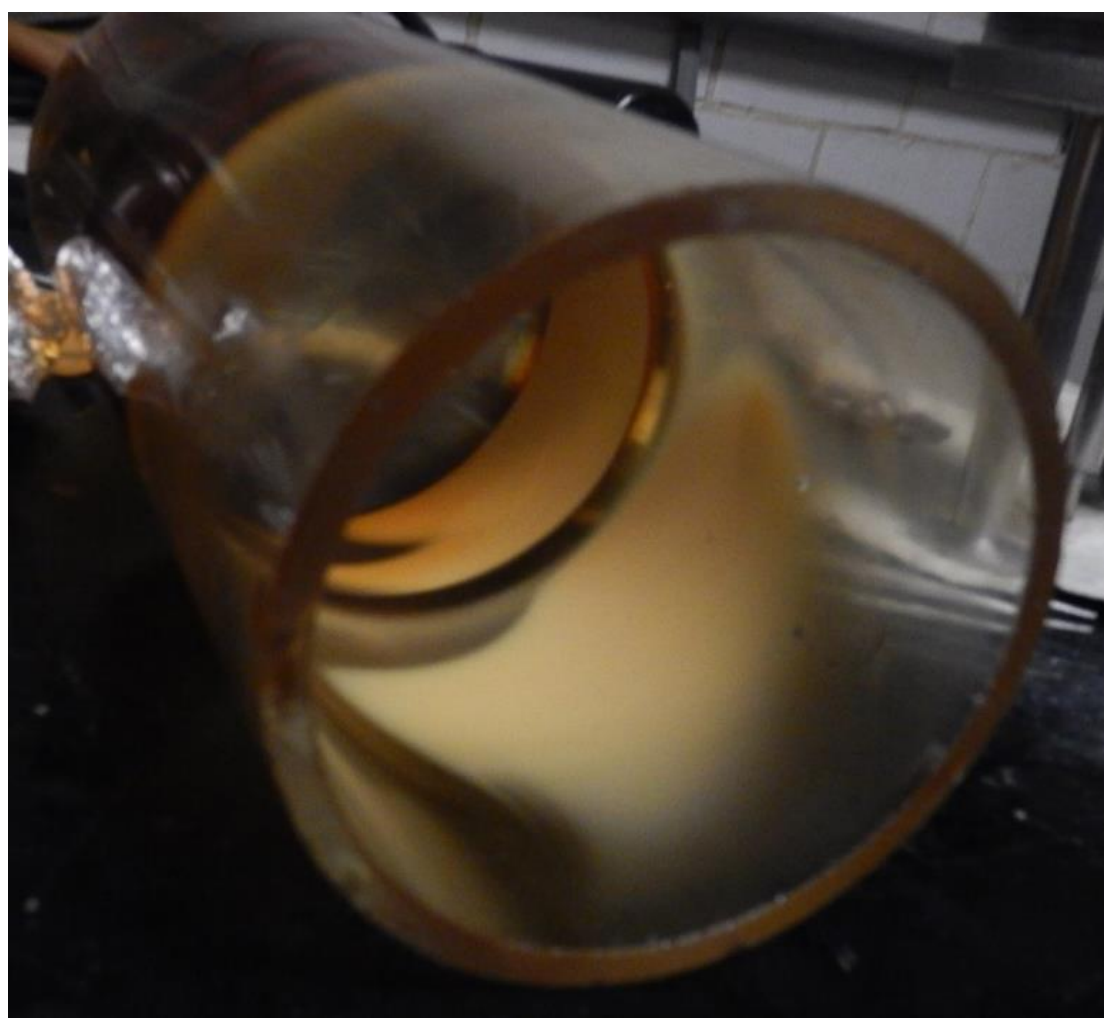

Figura 5.2 Paredes de reactor recubiertas por polímero PPy/I 


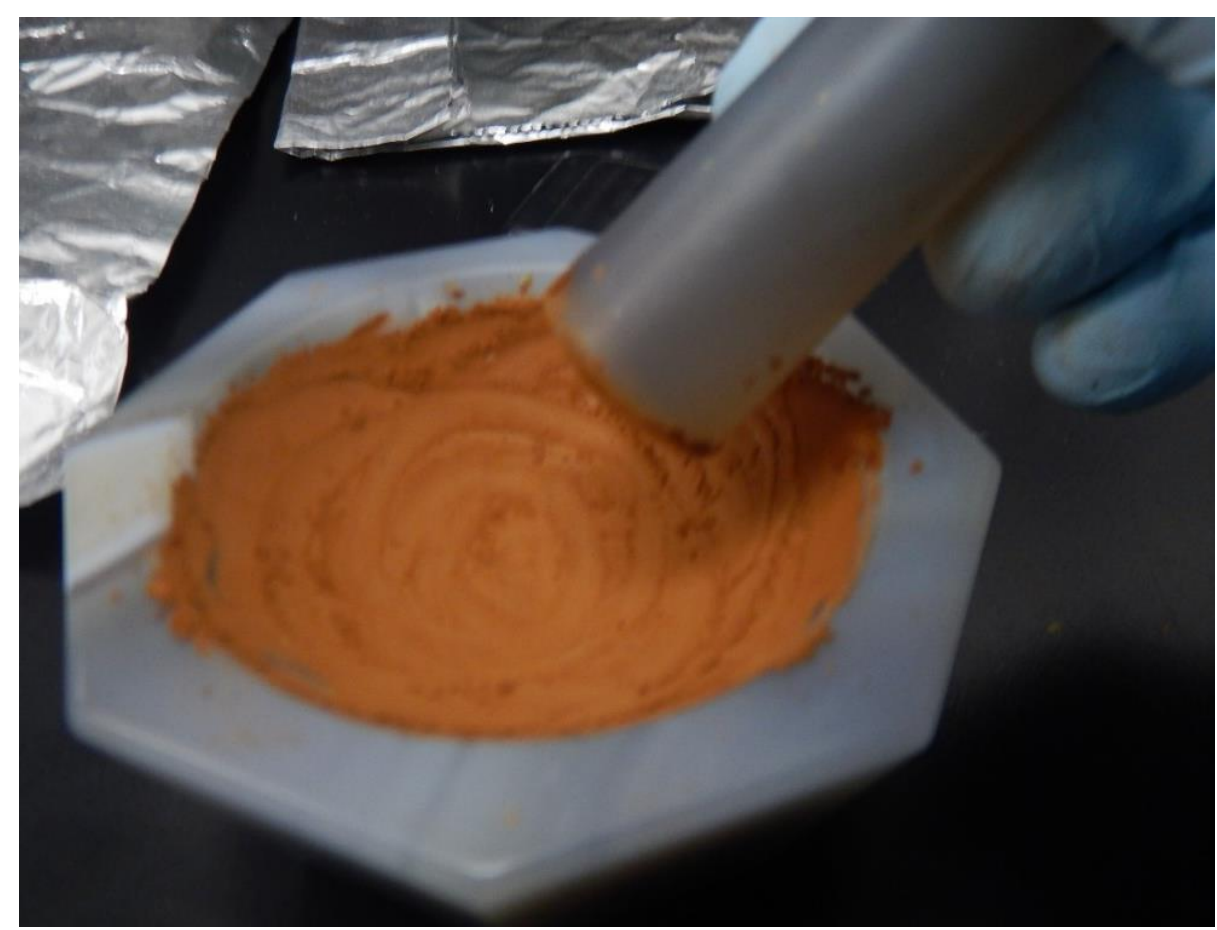

Figura 5.3 Mesopartículas de PPy/I obtenidas en mortero de Agatha

\subsection{Diseño experimental}

Se ocuparon 12 ratas sanas de la cepa Long Evans. Todas ellas hembras adultas, de la misma edad (8-9 semanas), con peso entre los 215-240g. Se les provocó una LTME a la altura de la $9^{a}$ vertebra torácica $(\mathrm{T} 9)$.

Todos los sujetos experimentales fueron tomados como sujetos control hasta la cuarta semana de estudio, cuando los sujetos hayan entrado a una fase crónica de la lesión. En esta etapa, de forma aleatoria, por insaculación, se generaron dos grupos experimentales:

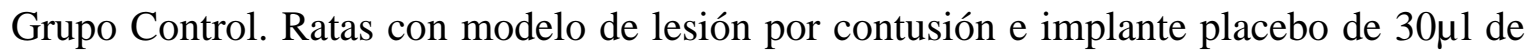
solución fisiológica $(n=3)$

Grupo Implante. Ratas con modelo de lesión por contusión e implante de 30 4 l solución de mesopartículas de PPy/I a una concentración de 5mg/ml (n=6). 
A cada una de las ratas se les realizó una evaluación funcional semanal (tal como se menciona en el apartado 5.4), con dos evaluadores en ciego, midiéndose la recuperación de la función locomotora, bajo la escala de evaluación Basso, Beattie y Bresnahan (BBB). También, se realizó el estudio longitudinal de resonancia magnética 7T, con secuencias de imagenología en los siguientes tiempos después de la lesión: 2 días, 3 semanas (previo al implante), 5 semanas (después del implante), 8 y 11 semanas. El cronograma del estudio se muestra de forma completa en la Figura 5.4.

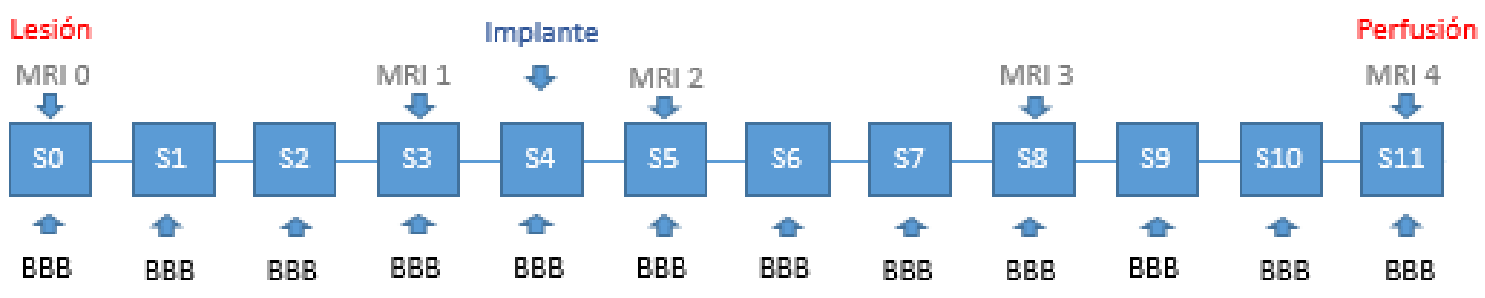

Figura 5.4 Cronograma del estudio experimental que se siguió para cada una de las ratas.

Al concluir el tiempo de estudio, las ratas fueron sacrificadas mediante perfusión vía intracardiaca con una bomba peristáltica $(30 \mathrm{ml} / \mathrm{min})$, fijándose con paraformaldehido y extrayéndose una muestra de médula $(1 \mathrm{~cm}$. Caudal y $1 \mathrm{~cm}$. cefálico) para posibles posteriores estudios. Todo el estudio se realizó siguiendo los lineamientos establecidos por la Norma Oficial Mexicana NOM-062-ZOO-1999 y las especificaciones técnicas para la reproducción, cuidado y uso de animales de laboratorio de la National Institutes of Health.

\subsection{Modelo de lesión e implante}

Todos los procedimientos quirúrgicos fueron realizados en las instalaciones del proyecto CAMINA A.C. Para poder practicar estos procedimientos se suministró anestesia general a todos los animales. La mezcla de anestesia consistió de $77.5 \mathrm{mg}$ de Ketamina y $12.5 \mathrm{mg}$ de hidrocloruro de xilacina por kg de peso corporal, suministrada vía intramuscular. 
La cirugía, para generar la lesión traumática de médula espinal incluye una incisión sagital en la piel, una disección de músculos paravertebrales de las apófisis espinosas (T9 y T10) y laminectomía en T9. (Morales 2008)

Posteriormente, se efectuó la lesión moderada de la médula espinal. Para ésta, los animales fueron colocados en el instrumento NYU (New York University) impactor [Figura 5.5], el cual deja caer un cilindro de acero inoxidable de $10 \mathrm{~g}$, desde una altura de $25 \mathrm{~mm}$, sobre la médula espinal expuesta al nivel de la vértebra T9 [Figura 5.6]. Este instrumento arroja un porcentaje de error, relativo a la deformación de la médula espinal al momento del impacto. En este estudio sólo se incluyeron los animales que presentaron un error $<7 \%$.

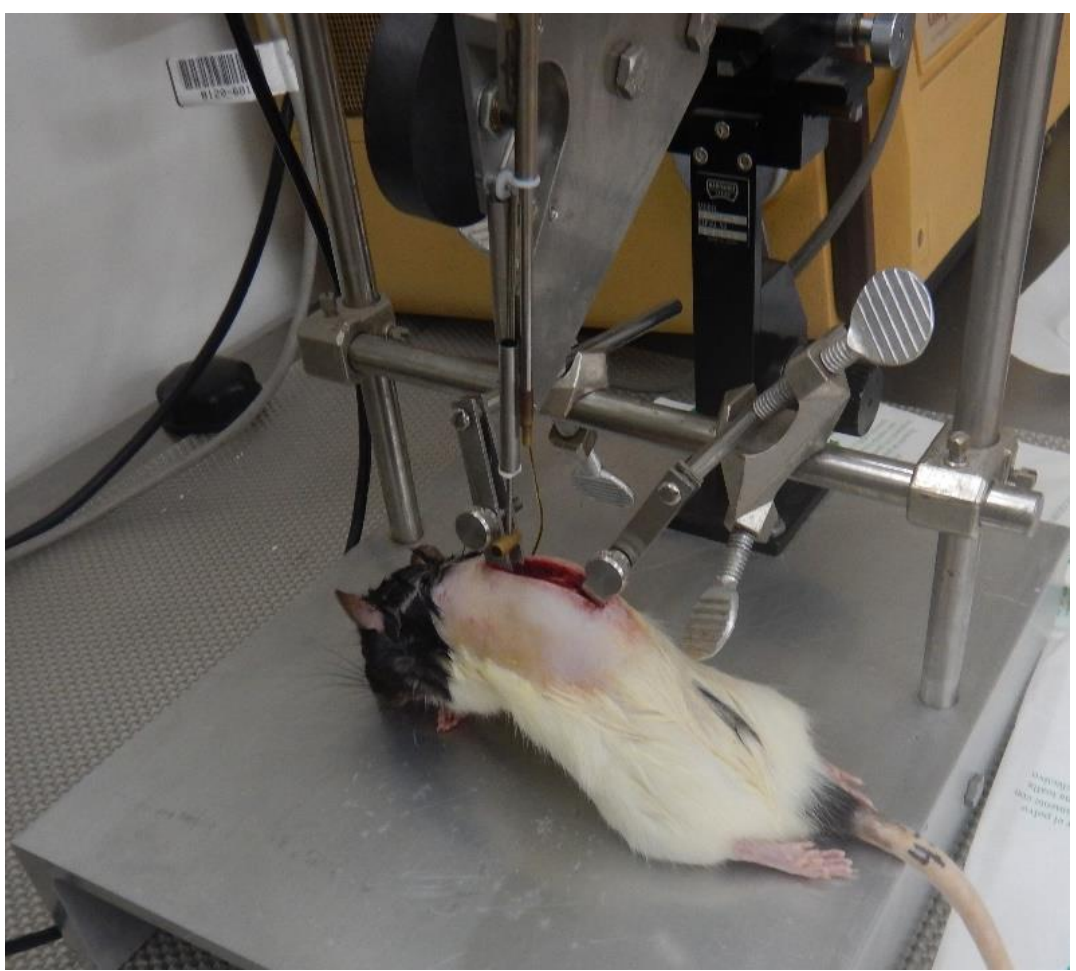

Figura 5.5 Rata colocada en instrumento NYU impactor para realizar la LTME 


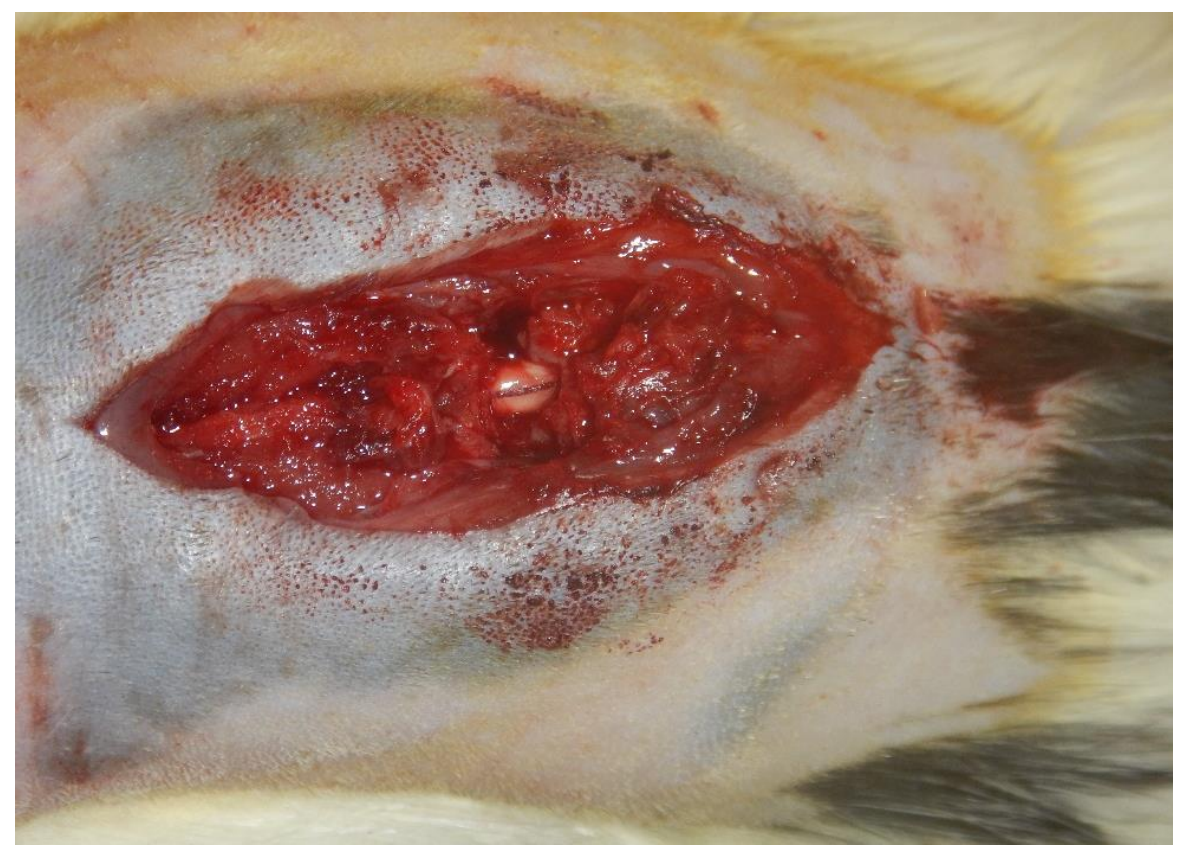

Figura 5.6 Médula espinal de rata expuesta a la altura de la vértebra T9

Para cerrar, músculo, fascia y piel de la incisión fueron suturados por planos. Se les suministró antibiótico y analgésicos a cada uno de los animales, se mantuvieron en cuidados extensivos para verificar su correcta recuperación.

Al finalizar cuatro semanas, etapa en la cual los sujetos ya entraron en una fase crónica, se les sometió a una cirugía similar a la primera. En ésta se volvió a abrir la zona lesionada, se inyectó solución fisiológica o con polímero, según correspondía el grupo. La inyección se colocó en tres diferentes puntos, el primero de éstos fue en el epicentro de la lesión, el segundo a $1 \mathrm{~cm}$. en dirección caudal al epicentro, y el último a $1 \mathrm{~cm}$. en dirección cefálica al epicentro. Para finalizar se suturó por planos y se siguieron cuidados similares a los practicados después del primer procedimiento quirúrgico.

Durante los primeros días posteriores a los procedimientos quirúrgicos, a cada sujeto, se le facilitó el acceso a agua y alimento. Cuando lograron establecer su estado de salud, estos mismos elementos fueron suministrados ad libitum. 


\subsection{Evaluación funcional}

Todos los sujetos fueron evaluados al día siguiente de la lesión para corroborar la ausencia de movimiento, posteriormente se realizó una evaluación semanal por un periodo de 12 semanas, utilizando la escala BBB (Basso, Beattie, Bresnahan), la cual está centrada en la evaluación de la función locomotora con base en las articulaciones de la cadera, rodilla y tobillo de cada una de las patas traseras.

Esta escala es no lineal y tiene 22 ponderaciones, donde el valor mínimo que se puede otorgar es 0 , representando una parálisis total, ausencia completa de movimiento en ambas patas traseras. Conforme avanza comienza a indicar movimientos aislados o más marcados en las 3 articulaciones que se analizan. Cuando llega a valores superiores a 8 nos indica que ya existe una colocación plantar sobre el suelo y cada uno de los siguientes valores indica mejor coordinación de los movimientos traseros con respecto a las patas delanteras, así como mayor soporte de peso sobre las patas traseras.

Al momento de llegar a valores superiores a 14 se comienza a indicar una mayor coordinación, una estabilidad del tronco, una mayor separación y acomodo para los dedos de las patas traseras, así como levantamiento y posicionamiento de la cola. Finalmente, la última ponderación de 21 indica un movimiento normal durante la marcha en las patas traseras. Se presentan cada uno de estos valores obtenidos de Molina. A, 2015. [Apéndice A]

Se utilizó un espacio abierto al movimiento de las ratas, pero limitado a $120 \mathrm{~cm} \times 120 \mathrm{~cm}$ [Figura 5.7] Se analizó, con dos evaluadores en ciego, el comportamiento de los animales por 3 minutos cada uno. Se realizó esta misma evaluación una vez por semana durante las 12 semanas de estudio. Se excluyó a todas aquellas ratas que tuvieran puntuaciones mayores a 1.5 en la escala BBB, después de 24 hrs; o mayores a 6 bajo esta misma escala, durante la primera semana de estudio. 


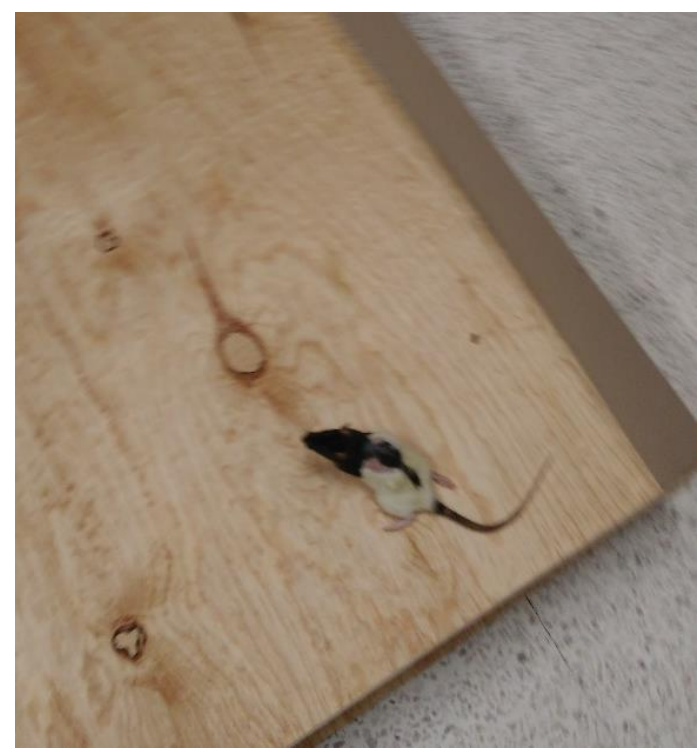

Figura 5.7 Rata durante evaluación BBB

\subsection{Estudio de Imagenología por Resonancia Magnética}

Para los estudios de cada una de las ratas se utilizó un Resonador Magnético para sujetos experimentales de la marca Varian de 7T, tal como se muestra en la Figura 5.8. Dicho resonador se encuentra disponible en las instalaciones del CI3M (Centro Nacional de Investigaciones en Instrumentación e Imagenología Médica) dentro de la UAM Iztapalapa. Las secuencias usadas se muestran más adelante, con los procesamientos correspondientes que se utilizaron para obtener variables cuantitativas. 


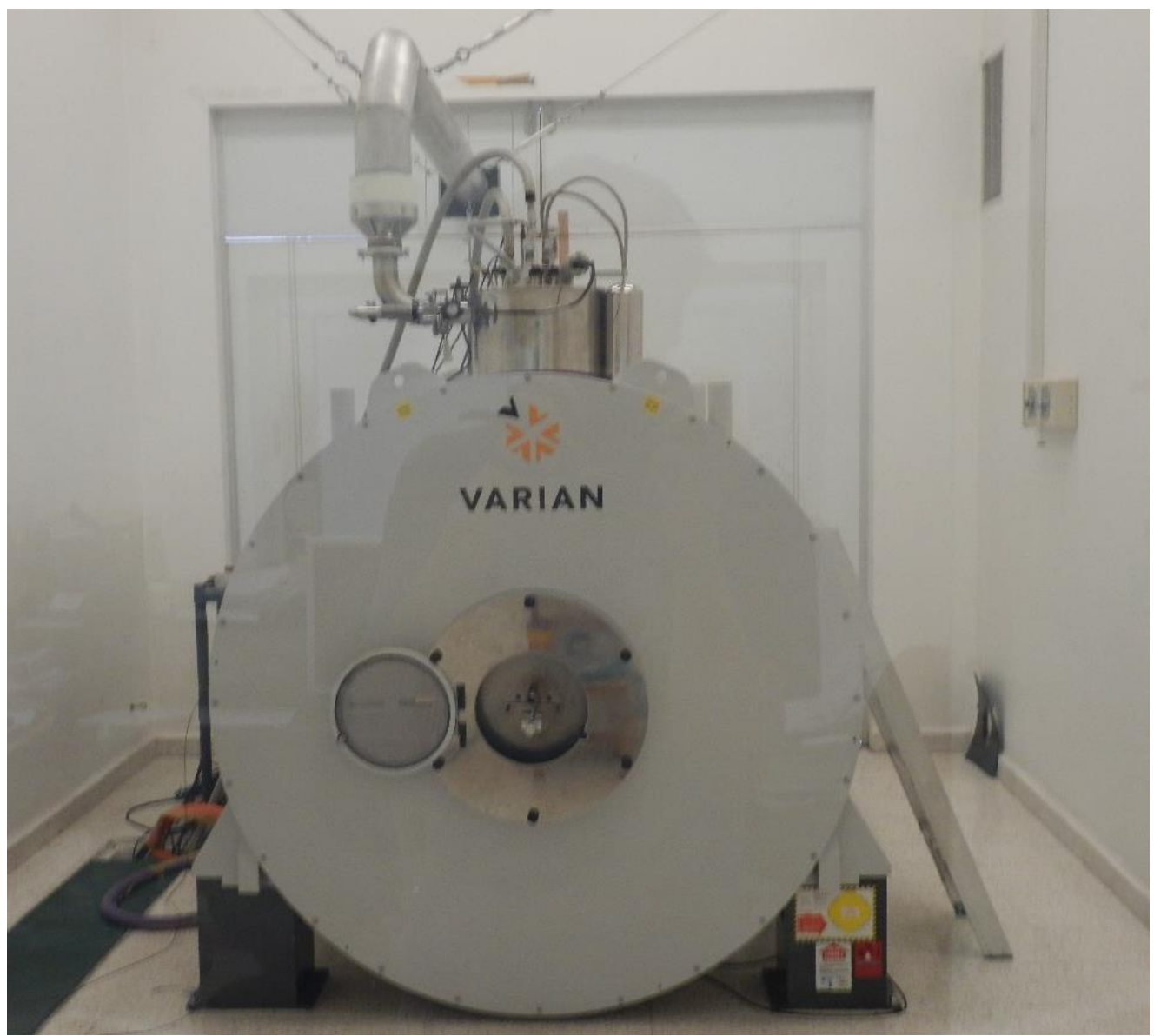

Figura 5.8 Resonador Magnético Varian de 7T utilizado para los estudios de los sujetos experimentales. Ubicado en las instalaciones del CI3M (Centro Nacional de Investigaciones en Instrumentación e Imagenología Médica)

\subsubsection{Secuencias anatómicas}

\section{GE3D (Gradient Echo 3D) ponderada a $T 1$}

Permite obtener imágenes ponderadas en T1 de una forma relativamente rápida, con tiempos TR cortos. Esta secuencia permite apreciar el alcance de la lesión en las primeras etapas, mostrando un decremento de energía, lo que se refleja en puntos hipointensos, en la señal de esta zona. Parámetros utilizados: $\mathrm{TR}=4.46 \mathrm{~ms}, \mathrm{TE}=2.25 \mathrm{~ms}$, Matriz=256x192x192, Promediaciones $=8$ (Tiempo de adquisición: 21 minutos y 55 segundos). 


\section{FSEMS (Fast Spin Echo Multi Slice) ponderada a T2}

Tiene la ventaja de obtener rápidamente imágenes en alta calidad T2. Esta secuencia mostró, de forma clara, los límites de la lesión en su etapa crónica, ya que aquellos puntos en los cuales se generan quistes se remarcan mucho debido a la gran cantidad de energía que presentan y se muestran hiperintensos en las imágenes. Parámetros utilizados: TR= $3508.38 \mathrm{~ms}$, TE-effective $-37.39 \mathrm{~ms}, \quad F O V=64, \quad$ Matriz $=256 \times 192, \quad$ Slices $=45$, Promediaciones $=7$ (Tiempo de adquisición: 8 minutos).

Las secuencias anatómicas fueron postprocesadas para obtener mayor información respecto a ellas. Se segmentó la región correspondiente a la médula espinal, con las diferentes variaciones que sufrió cada uno de los sujetos, a lo largo del experimento. Se seleccionaron los voxeles correspondientes entre las vértebras T8 a la T10, dejando el epicentro de la lesión en el centro de la región seleccionada. Se obtuvieron los volúmenes correspondientes a esta zona para cada una de las ratas en cada uno de los estudios realizados. Se segmentó entre tejido sano y zonas lesionadas para cada una de las etapas de experimentación, utilizando los contrastes de los voxeles como criterio de diferenciación entre uno y otro.

\subsubsection{Secuencias de Tensor difusor}

\section{EPI DTI (Echo Planar Imaging)}

Es una rutina de muy rápida adquisición, generalmente usada para fMRI (functional Magnetic Resonance Imaging). Puede detectar cambios ocurridos en una fracción de segundo y es menos sensible a artefactos de movimiento que otros métodos. Esta secuencia permitirá calcular el valor de Anisotropía Fraccional (FA), el Coeficiente de Difusión Aparente (ADC), observar el daño y regeneración axonal de la médula in-vivo y correlacionar la función locomotora de las ratas con los niveles de necrosis axonal, regeneración de células gliales y desmielinización en las microestructuras de la médula. Los parámetros a utilizar son los siguientes: $\mathrm{TR}=2500 \mathrm{~ms}$, TE $=30.5 \mathrm{~ms}$, Matriz $=64 \times 64 \times 32$, Promediaciones=10 (Tiempo de adquisición: 7 minutos 30 segundos). 
Las imágenes generadas por DTI fueron pre-procesadas y segmentadas mediante la suite DSI Studio (Carnegie Mellon University, EUA). Utilizando un modelo de reconstrucción basado en DTI para poder generar un mapa de tensores. De igual forma se obtuvieron los índices FA y ADC de la zona del epicentro de la lesión. Posteriormente, se creó una región de interés, representada únicamente por la médula espinal y la zona de la lesión; esto se realizó con el propósito de demarcar la región desde donde se comenzó el rastreo de fibras, tractos de SNC, a lo largo de todo el tejido seleccionado. Con esto se permitió visualizar la dirección y continuidad de las fibras neurales a lo largo de la médula, la interrupción de éstas en la zona de la lesión y las variaciones en los valores FA y ADC de ambos grupos.

\subsection{Estadística}

Se realizaron pruebas estadísticas a las medias de las variables dependientes (FA, ADC, BBB y tejido preservado) del tiempo y tratamiento ocupado, por medio de ANOVA de muestras repetidas $(\mathrm{p}<0.05)$. También se realizaron cálculos del coeficiente de correlación de Pearson, entre las variables mencionadas. Todo el análisis fue realizado con el software RKWard 0.6.5. 


\title{
6 Resultados
}

\begin{abstract}
"Mientras mi padre pedaleaba el triciclo mi madre me sostenía en sus brazos, un coche arrolló el triciclo. Ellos murieron. Yo sobreviví pero me convertí en parapléjico a la edad de 2 años. Mi abuelo me cuidaba en Bangkok. Después fui enviado a una escuela para niños con discapacidades. Ahora tengo 11 y estoy fuera de la escuela. Mi cerebro no está bien pero puedo mover mi silla

de ruedas sin dificultad. Afortunadamente $\mathrm{Mr}$. B, un hombre de negocios tetrapléjico y su esposa, me conocieron y acordaron hacerse cargo de mí, Ahora vivo con ellos. Ellos me dieron un silla para hacer deporte y planean convertirme en un atleta paralímpico en el futuro, yo creo que puedo serlo"
\end{abstract}

Anónimo, Tailandia.

\subsection{Caracterización del polímero}

El espectro por infrarrojo de las MPs del PPy/I sintetizado por plasma es mostrado en la Figura 6.1, con los puntos de absorción más significativos encerrados. Estos principales picos de absorción también se resumen en la Tabla 6.1.

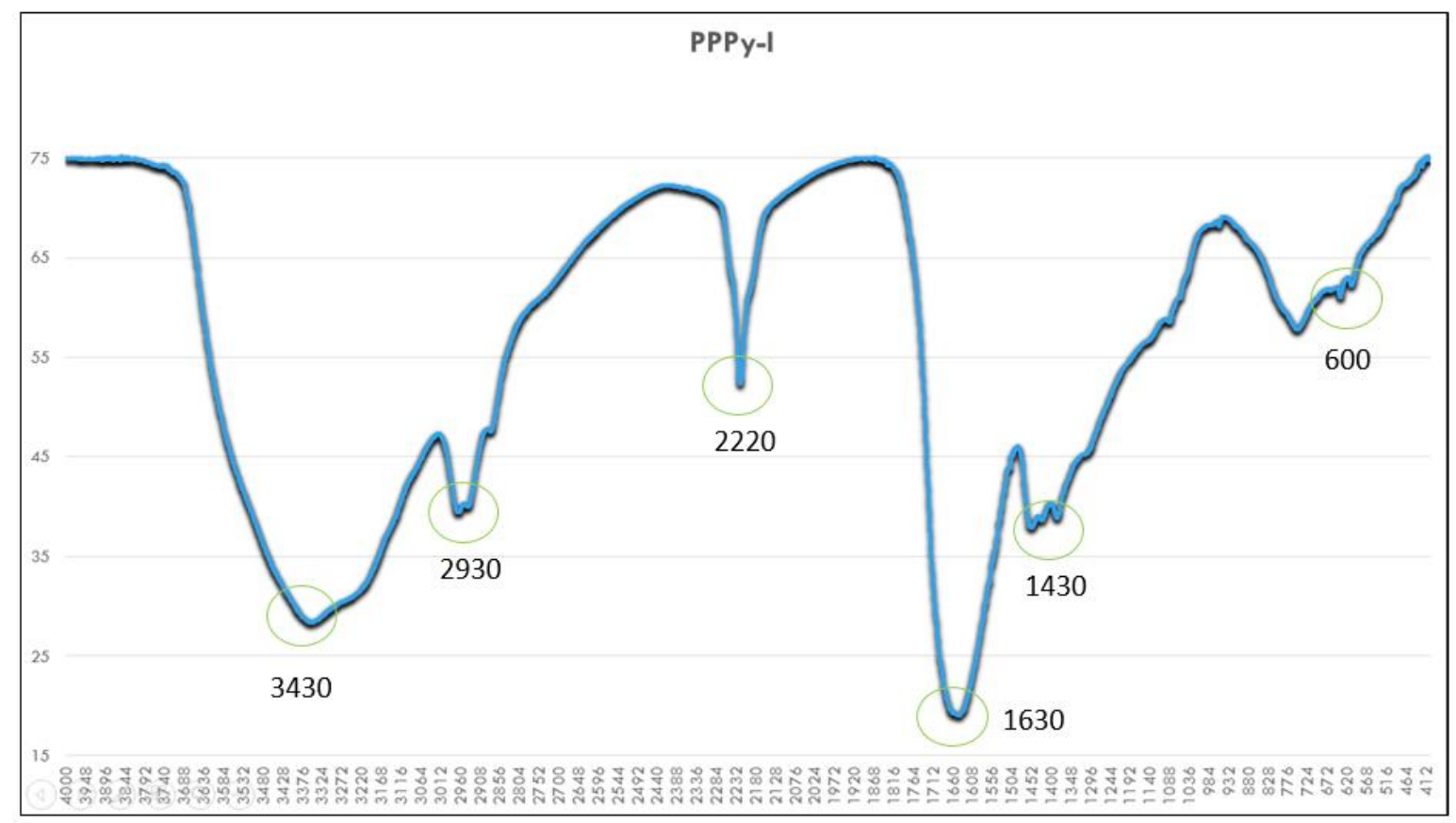

Figura 6.1. Espectroscopía por infrarrojo del polímero polipirrol sintetizado por plasma 
En este infrarrojo se pueden resaltar los enlaces $\mathrm{N}-\mathrm{H}$ y $\mathrm{O}-\mathrm{H}$ pertenecientes al pirrol, ubicados en $3430 \mathrm{~cm}^{-1}$. (Morales J., 2002) Alrededor de los $2930 \mathrm{~cm}^{-1}$ se presenta otra absorción importante que señala la presencia de grupos alifáticos $\mathrm{C}-\mathrm{H}$.

El pico que representa las absorciones generadas entre $2220 \mathrm{~cm}^{-1}$ y $2360 \mathrm{~cm}^{-1}$ se debe a la oxidación y deshidrogenación de las moléculas que promueven triples enlaces entre $\mathrm{C}$ y nitrógeno; tales como $\mathrm{C} \equiv \mathrm{N}$ y $\mathrm{C} \equiv \mathrm{C}$. También, se presentan dobles enlaces entre $\mathrm{N}, \mathrm{C}$ y $\mathrm{O}$ en diferentes combinaciones, entre las cuales tenemos: $\mathrm{O}=\mathrm{C}=\mathrm{C}, \mathrm{N}=\mathrm{C}=\mathrm{C}, \mathrm{C}=\mathrm{C}=\mathrm{C}$. Se podría interpretar a estos enlaces como extensiones de conjugación de enlaces dobles y sencillos alternados, los cuales generan una distribución electrónica a la mitad de ambas densidades en esos segmentos. (Mondragón-Lozano 2014)

Por otro lado, los enlaces dobles individuales entre $\mathrm{C}, \mathrm{O}$ y $\mathrm{N}$ pueden ser representados en $16300 \mathrm{~cm}^{-1}$, algunos de ellos son: $\mathrm{C}=\mathrm{C}, \mathrm{C}=\mathrm{O}, \mathrm{C}=\mathrm{N}$. El primero es parte de la estructura del polímero en estudio. Los dos siguientes son una posible representación de la deshidrogenación/ oxidación que se presenta durante la síntesis, ya que no está presente de forma natural en el pirrol. El pico presente en las cercanías a $1430 \mathrm{~cm}^{-1}$ se puede identificar como una posible sustitución de los hidrógenos en anillos heteroaromáticos. (AlvarezMejía, 2015)

Finalmente, se presenta la absorción cercana a $604 \mathrm{~cm}^{-1}$, ésta puede ser otra de las substituciones de los hidrógenos en los anillos. Es identificada en una porción pequeña, que podría estar representando la presencia del dopaje de Yodo en el polímero.

Tabla 6.1 Principales puntos de absorción encontrados en el espectro por IR del PPy/I

\begin{tabular}{|c|c|}
\hline 3430 & Enlaces N-H y O-H pertenecientes al pirrol \\
\hline 2930 & Presencia de grupos alifáticos $\mathrm{C}-\mathrm{H}$. \\
\hline $2360-2220$ & $\begin{array}{c}\text { Triples enlaces de } \mathrm{C} \text { con nitrógeno, como: } \mathrm{C} \equiv \mathrm{N} \text { y } \mathrm{C} \equiv \mathrm{C} \\
\text { Dobles enlaces entre } \mathrm{N}, \mathrm{C} \text { y O }\end{array}$ \\
\hline 1630 & Dobles enlaces individuales, como: $\mathrm{C}=\mathrm{O}, \mathrm{C}=\mathrm{C}, \mathrm{C}=\mathrm{N}$ \\
\hline
\end{tabular}




\begin{tabular}{|c|c|}
\hline 1430 & Sustitución de hidrógenos en anillos heteroaromáticos \\
\hline 600 & Posible sustitución por Yodo en las partículas poliméricas. \\
\hline
\end{tabular}

\subsection{Evaluación funcional}

Para este estudio se promediaron las evaluaciones de cada una de las patas traseras de las ratas, otorgadas por cada uno de los evaluadores. Se tomó la media de cada uno de los grupos de estudio, así como su desviación estándar y error estándar. Para la gráfica y exposición visual de los resultados, se tomaron a todas las ratas como sujetos control antes del implante (Semana 4), ya que todas tenían el mismo procedimiento quirúrgico y cuidados. Después del implante se tomaron como dos grupos completamente diferentes, tal como se muestra en la Figura 6.2.

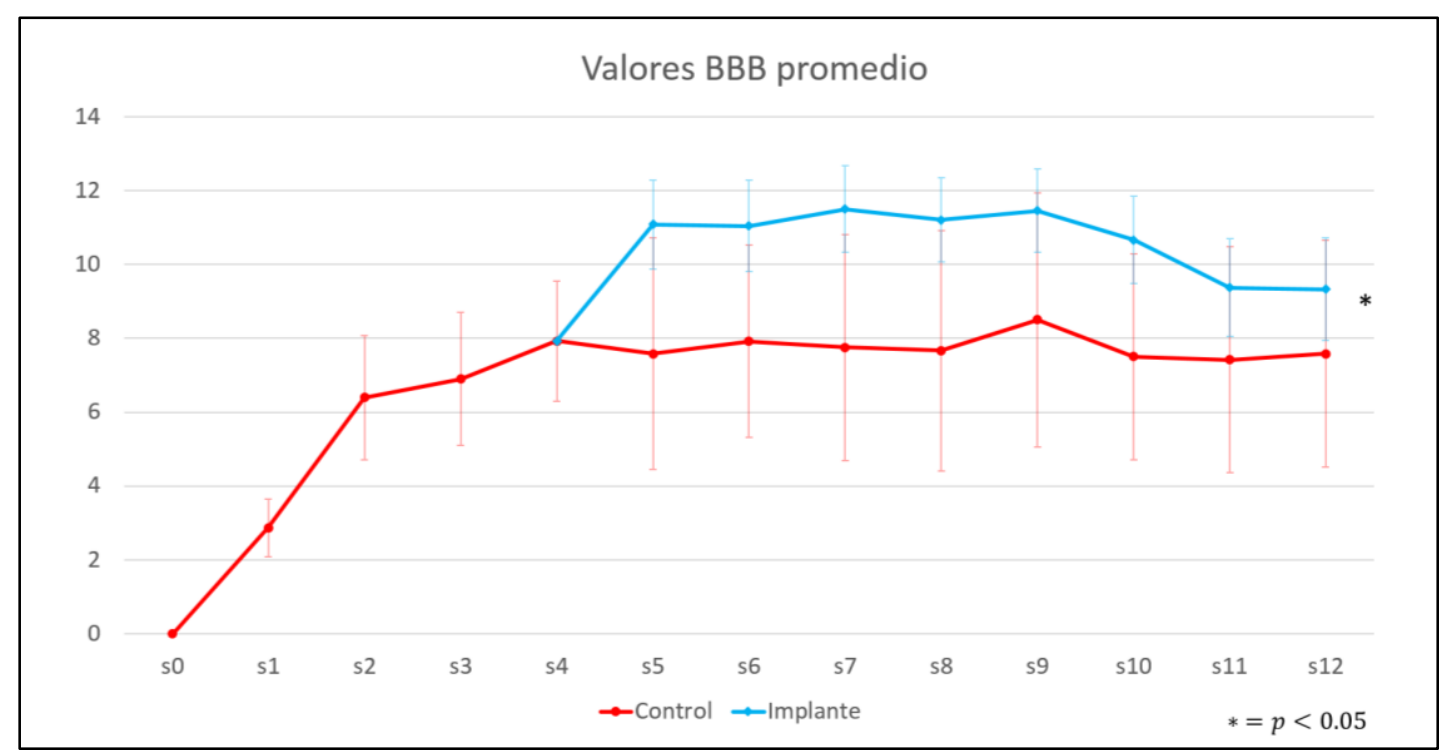

Figura 6.2 Gráfica de valores BBB promedio, para evaluar la recuperación locomotora, de los dos diferentes grupos de estudio. Expresado como la media de las evaluaciones por grupo de estudio \pm error estándar ( $n=10$, previo al implante $4 ; n=3$ grupo control, después del momento del implante; $\mathrm{n}=6$ grupo implante, después del implante).

ANOVA de medidas repetidas. *Diferencia significativa entre grupo implante con respecto al grupo control $(\mathrm{p}<0.05)$ 
Veinticuatro horas después de la lesión todos los animales obtuvieron puntaje de 0 . Al pasar la primera semana de estudio, la media del puntaje ( \pm error estándar) de todas las ratas fue equivalente a $2.87 \pm 0.78$. El día previo al implante, todo el conjunto de sujetos obtuvo $7.92 \pm 1.62$, a partir de aquí se dividieron de forma aleatoria para el implante. Después del implante, las puntuaciones para el grupo control fueron de: $7.58 \pm 3.13$ para la quinta semana de estudio; $7.66 \pm 3.43$ para la octava semana de estudio y $7.41 \pm 3.06$ para la décimo primera semana de estudio, representando desde movimientos aislados o extensos en cadera, rodilla y tobillo, llegando hasta pedaleo en ambas patas traseras, así como posible posición plantar sin soporte de peso. De acuerdo con la gráfica de la Figura 6.2, no hubo mucha variación después de la semana 4, comparada con la respuesta de las evaluaciones del grupo implante.

Para el grupo implante, después del proceso quirúrgico de colocación de implante, se obtuvieron las siguientes evaluaciones para la media de este grupo: 11.08 \pm 1.02 para la quinta semana de estudio; $11.20 \pm 1.14$ para la octava semana de estudio y $9.87 \pm 1.33$ para la décimo primera semana de estudio. Estos resultados nos representan desde pedaleo en ambas patas traseras o posición plantar, hasta pasos con posición plantar y frecuente soporte de peso con ocasional coordinación con las patas delanteras.

El cambio en los valores después de las cirugías correspondientes en el momento del implante, mostró una gran diferencia para ambos grupos. Hubo una mejoría notable para el grupo implante después del momento del implante, ésta diferencia en los valores de la evaluaciones se ve reflejada en la semana 4, donde la tendencia del grupo control deja de crecer y se mantiene alrededor del mismo valor durante el resto del estudio.

El análisis estadístico para estos dos grupos, ANOVA de medidas repetidas, evidenció diferencia significativa entre ambos grupos $(\mathrm{p}<0.05)$. Después de la semana nueve se observa un decremento en el valor de ambos grupos, sin embargo es más marcado en el grupo implante y continúa su tendencia por dos evaluaciones más, se desconoce la posible causa de este comportamiento. 


\subsection{Resonancia magnética}

Se obtuvieron todas las imágenes, de cada uno de los sujetos bajo estudio, especificadas en los diferentes tiempos para hacer una secuencia longitudinal y poder ver el avance de la lesión en cada una de las ratas. La Figura 6.3 muestra el avance de la lesión en una rata control, se puede apreciar la semana $0,3,5$ y 11; en la primera de ellas se aprecia una marca hipointensa en la zona encerrada (alrededor de la novena vértebra torácica), lo cual podría estar asociado con la lesión traumática.

En el estudio correspondiente a la semana 3; es decir, una semana antes del momento del implante, se puede apreciar que las zonas hipointensas en la región de interés disminuyen, sin embargo se comienza a perder la arquitectura previamente mostrada. Comienza un proceso de acinturamiento.

Para la semana 5, una semana después del implante, se muestra una gran degeneración de la región de interés, se pierde la arquitectura de la zona con respecto a la semana 0 . De igual modo, las marcas hipointensas en la imagen se vuelven a incrementar; una posible respuesta al proceso quirúrgico al cual se volvieron a someter para el implante.

Finalmente, para la semana 11 se muestra una gran pérdida de la arquitectura de la zona de interés cuando se le compara con la semana 0 . El tejido hipointenso se vuelve a disminuir a niveles similares a la semana 3; no obstante, la cantidad de tejido que se ha perdido desde el primer estudio de MRI es algo que se debe resaltar, situación que se mostrará detalladamente más adelante en un estudio del volumen de la región de interés. 


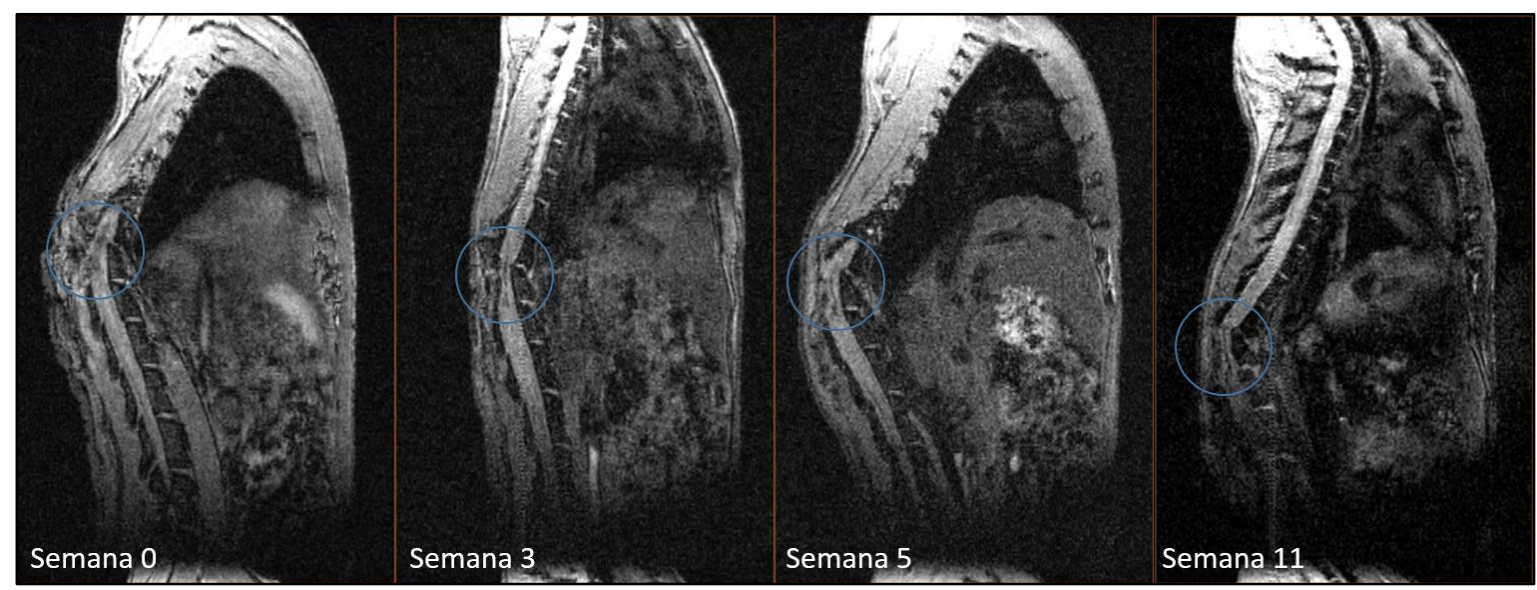

Figura 6.3 Imágenes sagitales, longitudinales, de resonancia magnética, ponderadas en T1, de rata con lesión traumática de médula espinal. Obtenidas con secuencia GE3D. Se remarca la zona de la lesión con un círculo.

En la Figura 6.4 se muestran una serie de imágenes longitudinales, ponderadas en T2, de un sujeto control. En ellas se puede apreciar el avance de la lesión; en la semana 0 se muestra una respuesta hipointensa en la región de interés (encerrada en azul), la cual se podría asociar al proceso de degeneración debido a la LTME.

En la semana 3 se muestra un acinturamiento en la región de interés, el cual también es remarcado en la Figura 6.3 para el mismo estudio. En la semana 5, además del ya mencionado proceso de perdida de la arquitectura de la zona, se comienza a apreciar la generación de voxeles hiperintensos, los cuales estarían asociados a la generación de quistes.

Cercano al término del estudio, durante la semana 11, se muestra un gran aumento en la cantidad de los voxeles hiperintensos; Éstos, además de ser mayor cantidad se muestran más concentrados en algunas zonas centrales, acompañados de la gran pérdida de la arquitectura de la zona lesionada marcada en la Figura 6.3. 


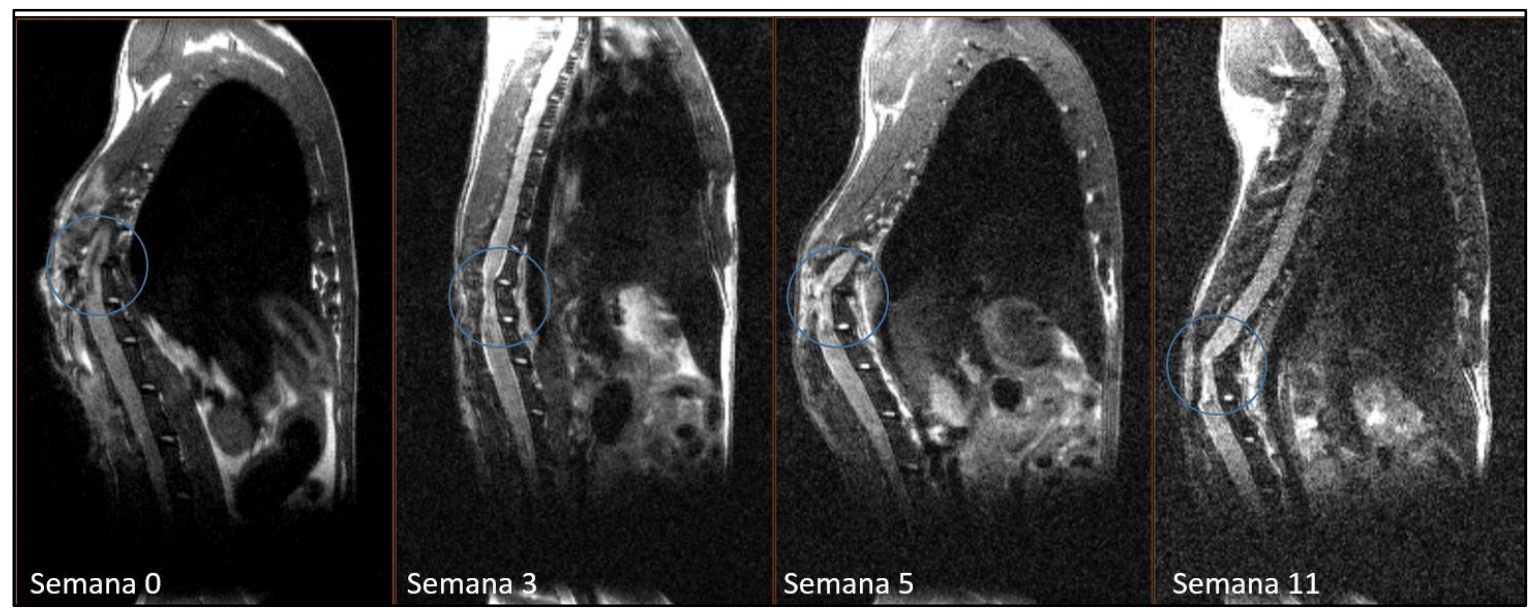

Figura 6.4 Imágenes sagitales, longitudinales, de resonancia magnética, ponderadas en T2, de rata con lesión traumática de médula espinal. Obtenidas con secuencia GE3D. Se remarca la zona de la lesión con un círculo.

Todos los sujetos control presentaron daños similares, en las mismas etapas de estudio, al sujeto mostrado en las Figuras 6.3 y 6.4. Sin embargo, cuando se hizo la comparación con los sujetos implante se mostraron algunas diferencias cualitativas en las imágenes convencionales de T1 y T2.

En la Figura 6.5 se muestra una comparativa de la zona de la lesión, región de interés, en imágenes ponderadas en T1, de un sujeto control contra un sujeto implante. Esta comparativa se muestra en las Semanas 0 y 11, porque son los puntos de mayor relevancia; los cuales indican el comienzo del estudio y el final del mismo.

Se puede apreciar que en la Semana 0 se tiene una respuesta hipointensa similar sobre el centro de la médula y una orilla, correspondiente a la zona donde se realizó la lesión. Al finalizar el estudio, en la Semana 11, se apreció una mejor conservación de la arquitectura de la médula en la zona lesionada, los sujetos implantes sufrieron menor acinturamiento en la región de interés. Sin embargo, con un estudio que se mostrará más adelante, no se apreció un cambio significativo en la cantidad de tejido perdido por parte de los sujetos control. 

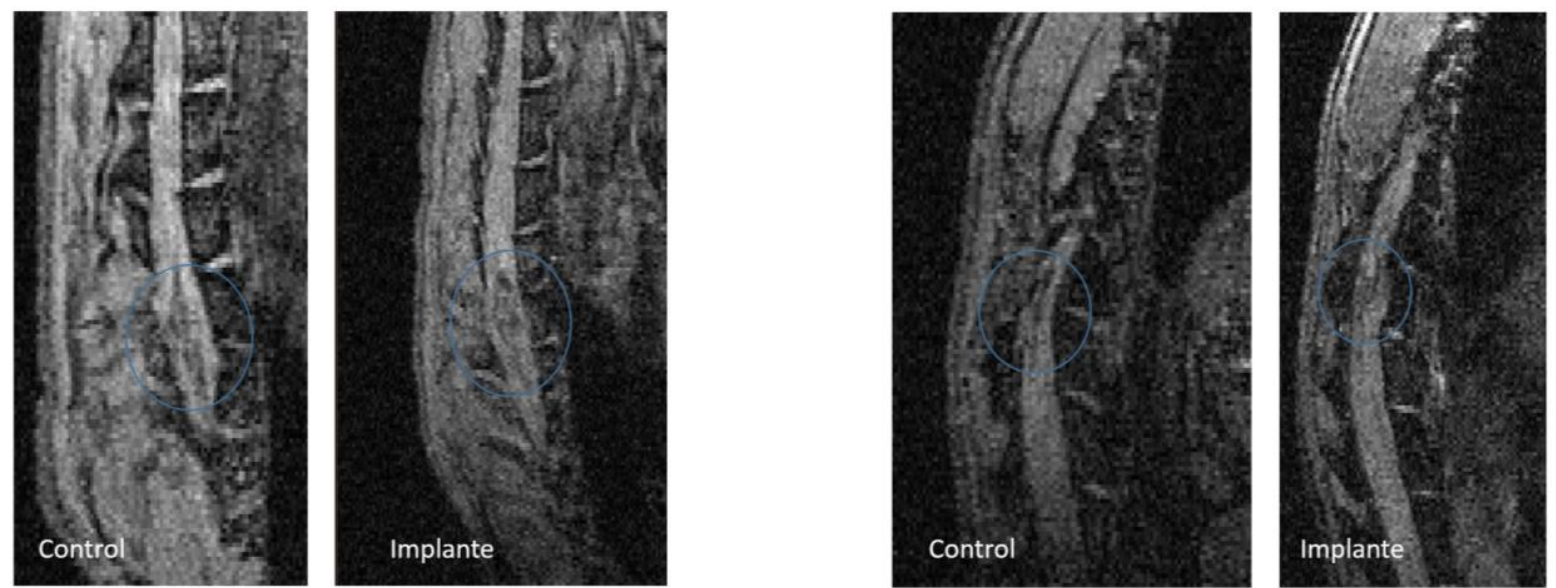

Figura 6.5 Imágenes sagitales de resonancia magnética, ponderadas en T1, de la zona de la lesión traumática de médula espinal en ratas. Se realiza comparativa entre sujeto control y sujeto implante en las semanas 0 y 11, después de la lesión y 7 semanas después del implante, respectivamente.

En la Figura 6.6 se muestra una comparativa de la zona de la lesión, región de interés, en imágenes ponderadas en $\mathrm{T} 2$, de un sujeto control contra un sujeto implante. Nuevamente, se aprecia similitud en la semana 0 de estudio, ambos grupos tuvieron una gran respuesta hipointensa, que probablemente sea asociada al proceso quirúrgico para llevar a cabo la lesión.

El cambio más interesante se muestra a la Semana 11 de estudio, por dos razones principales. Primera, en el grupo implante, mediante evaluación cualitativa, se muestra una mayor preservación de la arquitectura de la zona lesionada, existe menor acinturamiento. Segunda, como se había mencionado anteriormente, la cantidad de quistes se aprecia mayor y mucho más compacto en la zona central de la médula cuando se compara con el sujeto implante, el cual tiene estas regiones hiperintensas más distribuidas por toda la zona de lesión. 
2 días después de la LTME. (Semana 0)

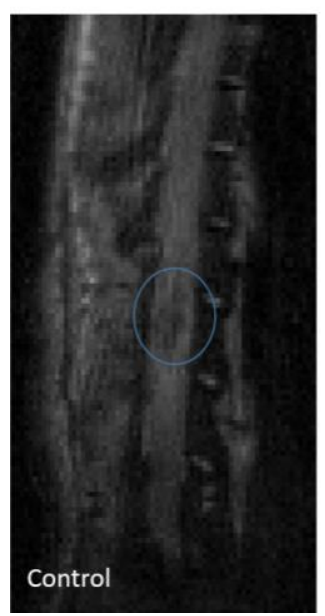

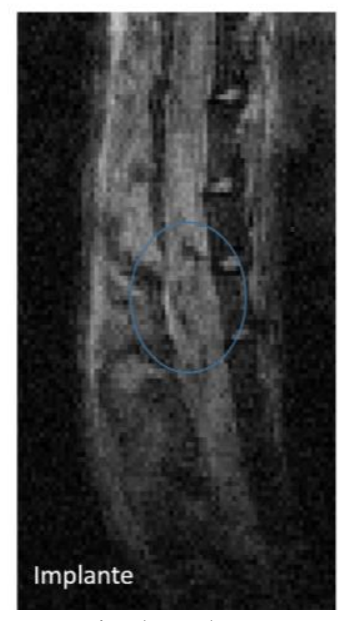

11 semanas después de la LTME. (Semana 11)

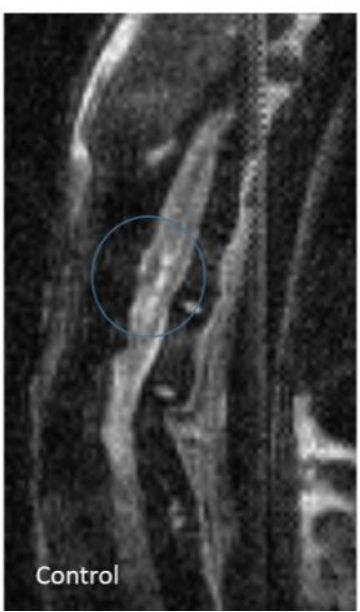

Figura 6.6 Imágenes sagitales de resonancia magnética, ponderadas en T2, de la zona de la lesión traumática de médula espinal en ratas. Se realiza comparativa entre sujeto control y sujeto implante en las semanas 0 y 11, después de la lesión y 7 semanas después del implante, respectivamente.

\subsubsection{Fracción de Anisotropía}

Los valores mostrados en este apartado se obtuvieron con los procesamientos de imágenes detallados en el apartado 5.5 del presente escrito. Con los valores que se generaron de FA, en el epicentro de la lesión, se obtuvo la media de ambos grupos en cada una de las semanas en las cuales se realizaron estudios de resonancia magnética (Semanas 0, 3, 5, 8 y 11). Se encontró que ambos grupos tuvieron una caída a la quinta semana (una semana después del implante) con respecto a la semana 0 (después de la lesión), lo que podría ser una respuesta ante el daño que se sigue generando a partir de la lesión. Sin embargo, ambos grupos incrementaron sus valores de FA para la semana 8, pero con una pendiente más elevada para el caso del grupo implante [Figura 6.7]. 


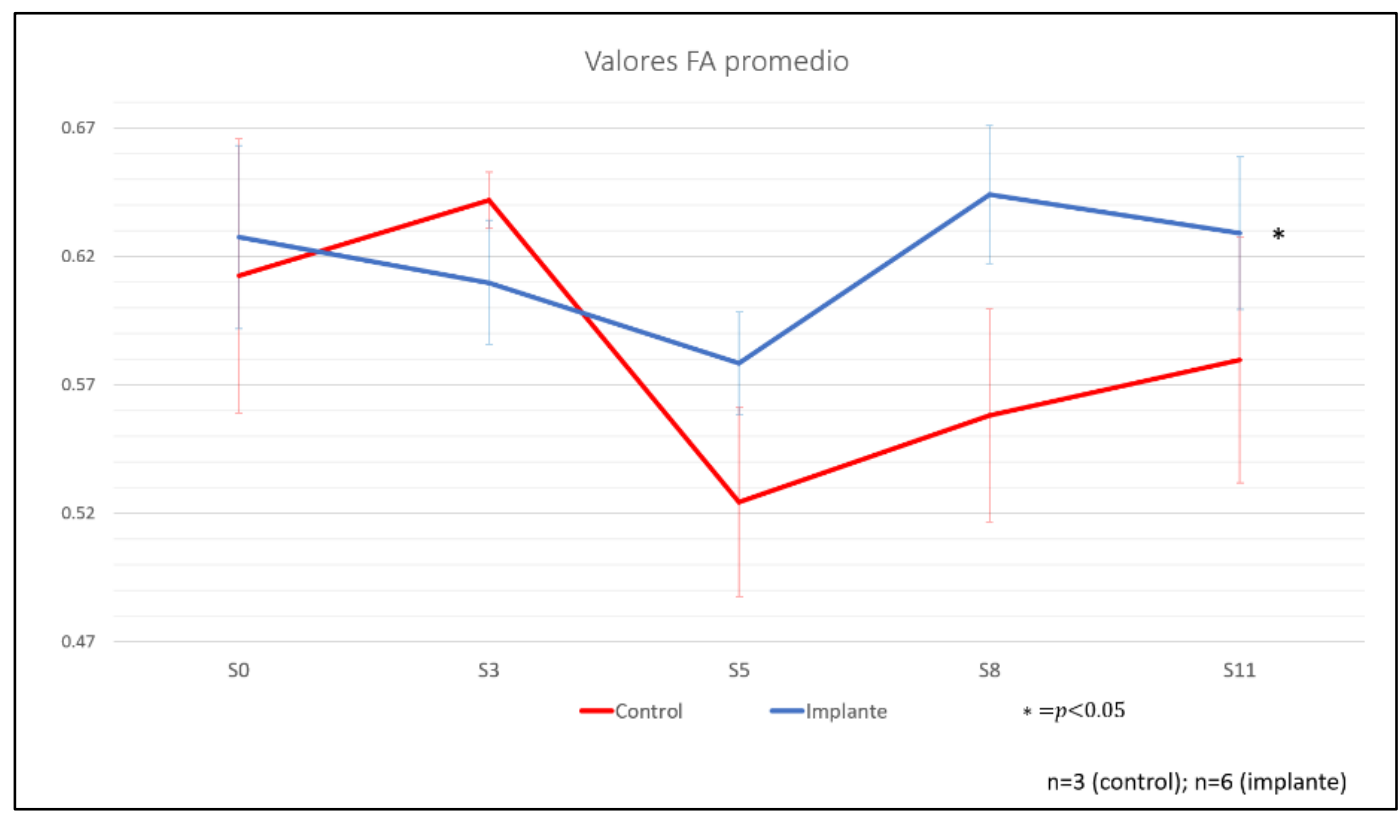

Figura 6.7 Gráfica de valores FA promedio, de los dos diferentes grupos de estudio. Expresado como la media de las evaluaciones por grupo de estudio \pm error estándar $(\mathrm{n}=3$ grupo control; $\mathrm{n}=6$ grupo implante). ANOVA de medidas repetidas. *Diferencia significativa entre grupo implante con respecto al grupo control $(\mathrm{p}<0.05)$

Estos resultados asemejan el movimiento que realizan las evaluaciones BBB, mostradas en la Figura 6.2. En estos valores también se encontró una caída en la Semana 11 con respecto a la Semana 8 para el grupo implante; situación que ya se ha mencionado, se desconoce la causa para un comportamiento de este tipo.

Algo que se debe resaltar es que no se encontraron diferencias estadísticamente significativas entre las semanas de estudio para ambos grupos; los cambios entre un estudio y otro no son relevantes. Sin embargo, sí se encontró una diferencia significativa $(\mathrm{p}<0.05)$ para el comportamiento de los valores promedio de FA para el grupo implante con respecto al grupo control.

\subsubsection{Coeficiente de Difusión Aparente}

Sobre los valores del coeficiente de difusión aparente, ADC, que se obtuvieron del epicentro de la lesión, se realizó una gráfica con los promedios de ambos grupos, para cada una de las 
semanas en las que se les realizó estudio de imagenología por resonancia magnética. [Figura 6.8] Similar a lo ocurrido en FA, hay un aumento de los valores ADC de la semana 5, para ambos grupos de estudio, con respecto a la semana 0. Esto podría indicar un decremento en la organización de la región estudiada.

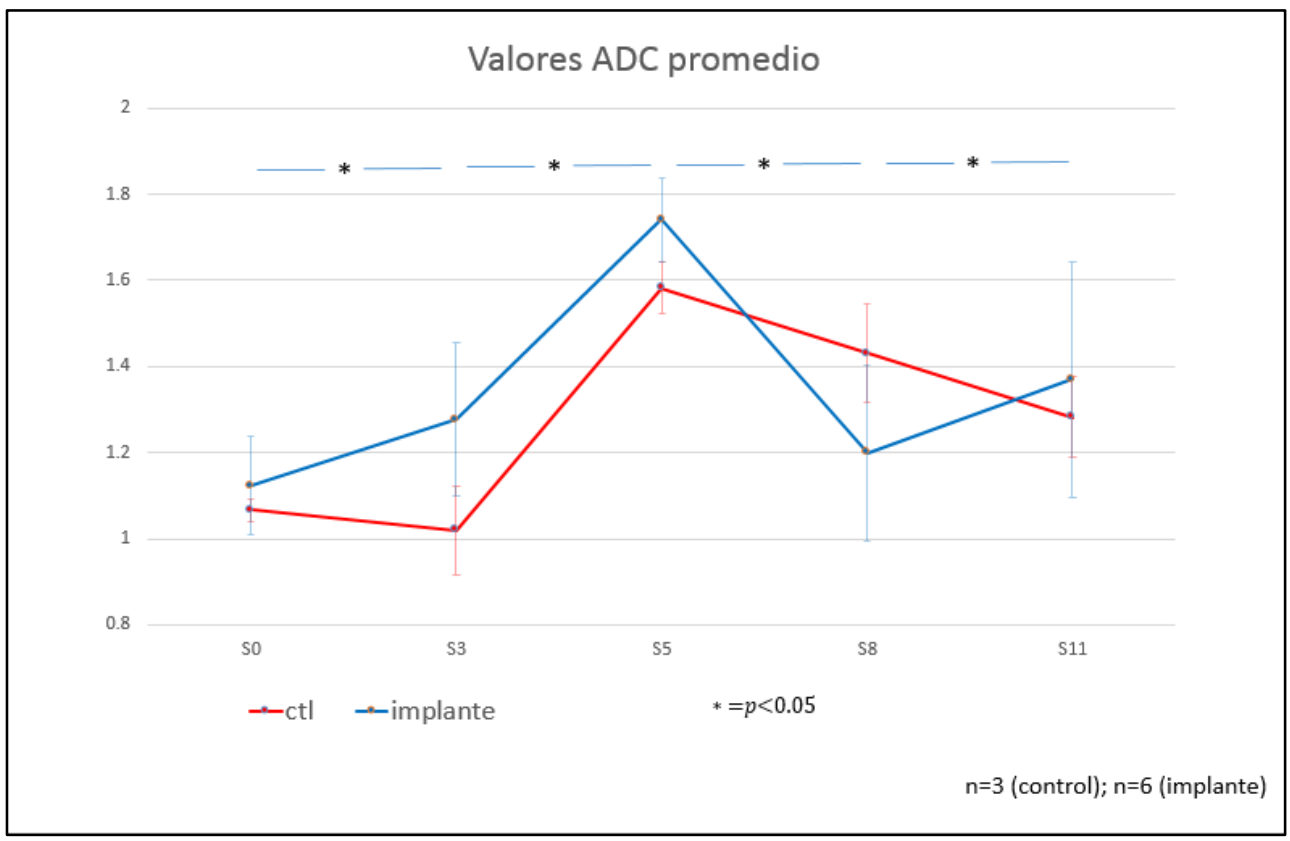

Figura 6.8 Gráfica de valores ADC promedio, de los dos diferentes grupos de estudio. Expresado como la media de las evaluaciones por grupo de estudio \pm error estándar $(\mathrm{n}=3$ grupo control; $\mathrm{n}=6$ grupo implante). ANOVA de medidas repetidas. *Diferencia significativa entre las semanas de estudio para ambos grupos $(\mathrm{p}<0.05)$

Al llegar a la semana 8 se muestra un gran decremento de los valores ADC, más marcado para el grupo implante. Sin embargo, como se ha venido mencionando, este valor vuelve a incrementar para el grupo implante, contrario a lo que realiza el grupo control que continúa disminuyendo hasta la semana 11. Esto es congruente con lo que sucedió en BBB y FA para el grupo implante, hubo una pérdida después de la Semana 9 con respecto a los logros generados hasta la Semana 8.

En este caso no se encontró diferencia estadísticamente significativa $(\mathrm{p}<0.05)$ entre los grupos de estudio, pero sí se logró ésta entre las diferentes semanas de estudio para ambos grupos de sujetos. 


\subsubsection{Morfometría de tejido preservado}

Tal como se mencionó en el capítulo anterior, se segmentó la región correspondiente al epicentro de la lesión, desde T8 hasta T10. En la Figura 6.9 se muestra la comparación entre un sujeto implante contra un sujeto control, en la última semana de estudio; se puede apreciar que las zonas de quistes son mayores $\mathrm{y}$, sobre todo, más concentradas para el grupo control con respecto al grupo implante. Sobre la arquitectura de la médula se muestra que el grupo implante se conservó de mejor manera con respecto a una médula de una rata sana. Además, el tejido hipointenso que se puede relacionar con tejido dañado, respuesta inflamatoria, cicatriz glial o polímero, entre otros se muestra en mayor cantidad para las ratas del grupo control. Siendo la mayoría de estos factores contraproducentes, se puede decir que el tejido hipointenso es perjudicial para la rehabilitación.

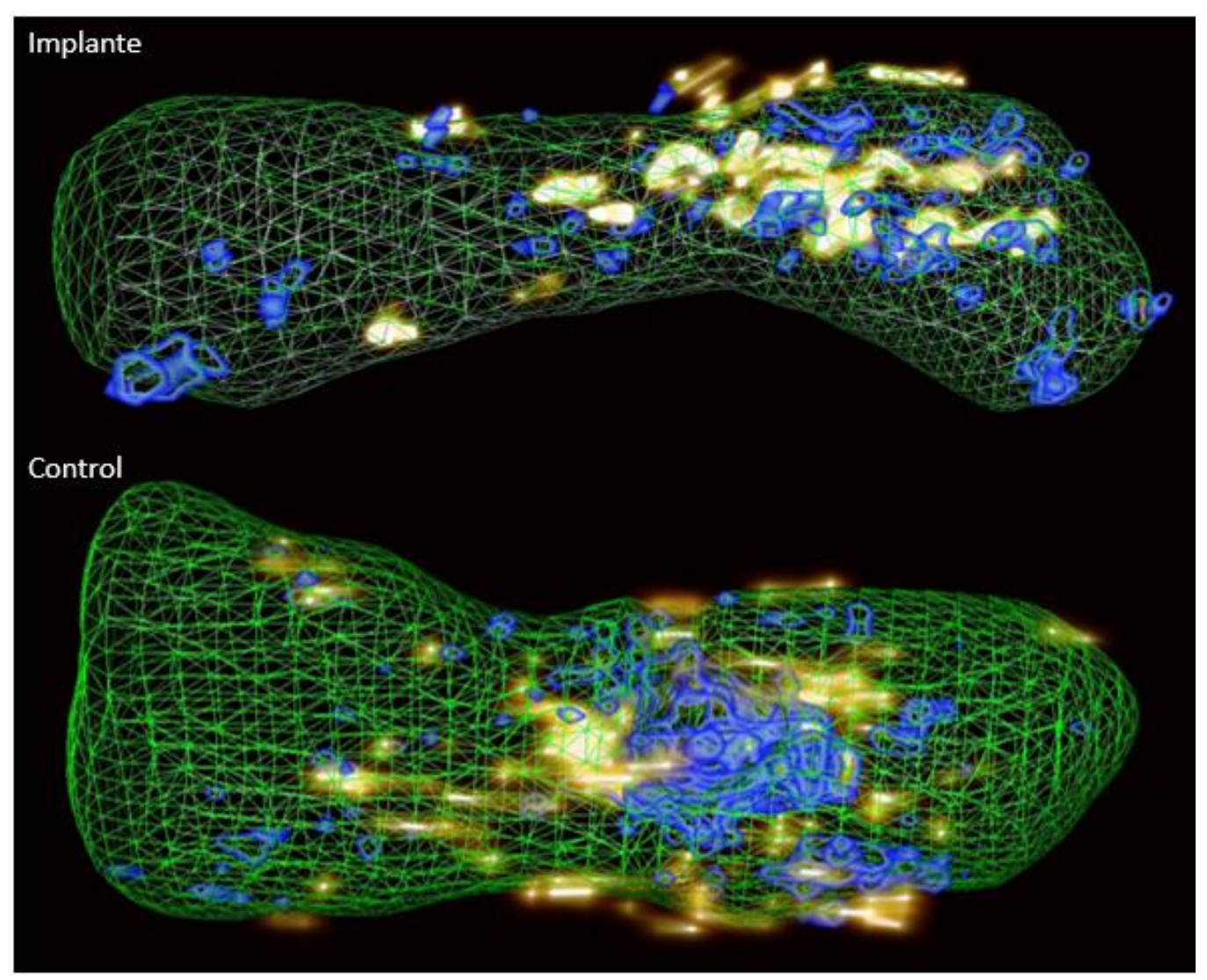

Figura 6.9 Comparativa morfológica entre grupos de investigación. Se muestra la médula segmentada entre T8-T10, para la semana 11 de estudio. En verde se encuentra todo el tejido nervioso, en azul se muestran los quistes y en color amarillo los voxeles hipointesos de la región de interés. 
Todas estas observaciones retrospectivas se corroboraron con la gráfica de la Figura 6.10 y la Tabla 6.2. En la primera de ellas se puede observar como el grupo implante tiene una caída importante para la semana 5 en cuanto a tejido preservado. Sin embargo se recupera para la semana 11 y se encuentra en mayor porcentaje que el grupo control. Lo cual indica que el grupo control pierde mucho más tejido después de 5 semanas del implante con respecto a las ratas implantadas con PPy/I.

También se debe denotar que la cantidad de quiste es mayor para el grupo control sobre el grupo implante para la semana 11, remarcando que durante la semana 5, después del implante, eran prácticamente iguales; lo cual se aprecia de mejor forma en la Tabla 6.2; la cual contiene todos los números correspondientes a la gráfica en cuestión.

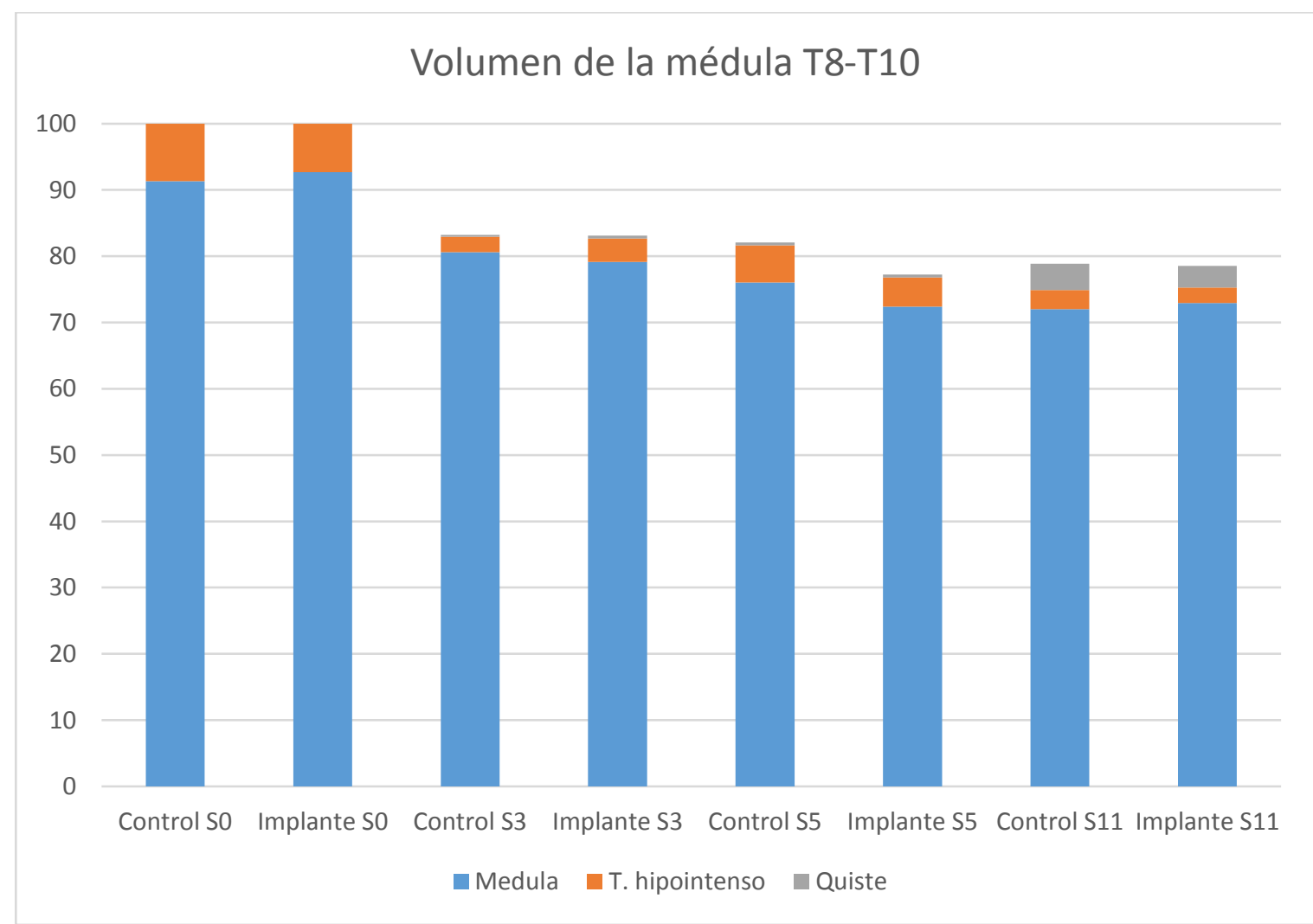

Figura 6.10 Gráfica con los porcentajes de preservación de tejido en la médula espinal para cada uno de los grupos de investigación en las diferentes semanas que fueron evaluadas. 
La cantidad de tejido medular preservado en la última semana de estudio con respecto a la primera semana de estudio, no fue significativamente diferente para ambos grupos de estudio. Sin embargo, existió un cambio importante en la arquitectura de la zona lesionada, tal como se ejemplificó en la Figura 6.9

\begin{tabular}{|c|c|c|c|c|c|c|c|c|}
\hline & $\begin{array}{c}\text { Control } \\
\text { S0 }\end{array}$ & Implante & Control & Implante & Control & Implante & Control & Implante \\
\hline Medula & $\mathbf{9 1 . 3 1}$ & $\mathbf{9 2 . 7 0}$ & $\mathbf{8 0 . 5 8}$ & $\mathbf{7 9 . 1 4}$ & $\mathbf{7 6 . 0 3}$ & $\mathbf{7 2 . 4 1}$ & $\mathbf{7 2 . 0 0}$ & $\mathbf{7 2 . 9 4}$ \\
\hline $\begin{array}{c}\text { Tejido } \\
\text { hipointenso }\end{array}$ & $\mathbf{8 . 6 8}$ & $\mathbf{7 . 2 9}$ & $\mathbf{2 . 3 8}$ & $\mathbf{3 . 5 3}$ & $\mathbf{5 . 6 2}$ & 4.38 & $\mathbf{2 . 8 8}$ & $\mathbf{2 . 3 2}$ \\
\hline Quiste & & & $\mathbf{0 . 2 4}$ & $\mathbf{0 . 4 5}$ & $\mathbf{0 . 4 4}$ & $\mathbf{0 . 4 4}$ & $\mathbf{3 . 9 6}$ & $\mathbf{3 . 2 5}$ \\
\hline
\end{tabular}

Tabla 6.2 Porcentajes de volúmenes de los dos grupos de investigación con respecto al tiempo del experimento en que fueron evaluados.

Finalmente, se debe remarcar que el tejido hipointenso disminuye de la semana 0 a la semana 3 , y aumenta de la semana 3 para la semana 5 . Esto se podría deber a la intervención que implica exponer la médula para realizar el implante en la zona lesionada, generando un edema cercano a la zona de interés. 


\subsection{Correlaciones entre variables cuantificables}

Se realizó el estudio de la correlación, mediante la prueba de Pearson, entre las variables encontradas en la experimentación. La Figura 6.9 nos muestra que existe una relación significativa entre los valores de ADC con respecto a los obtenidos en FA; esto a pesar de que en la revisión de la literatura se encontró que la correlación entre estas dos variables es mayor que lo expuesto aquí.

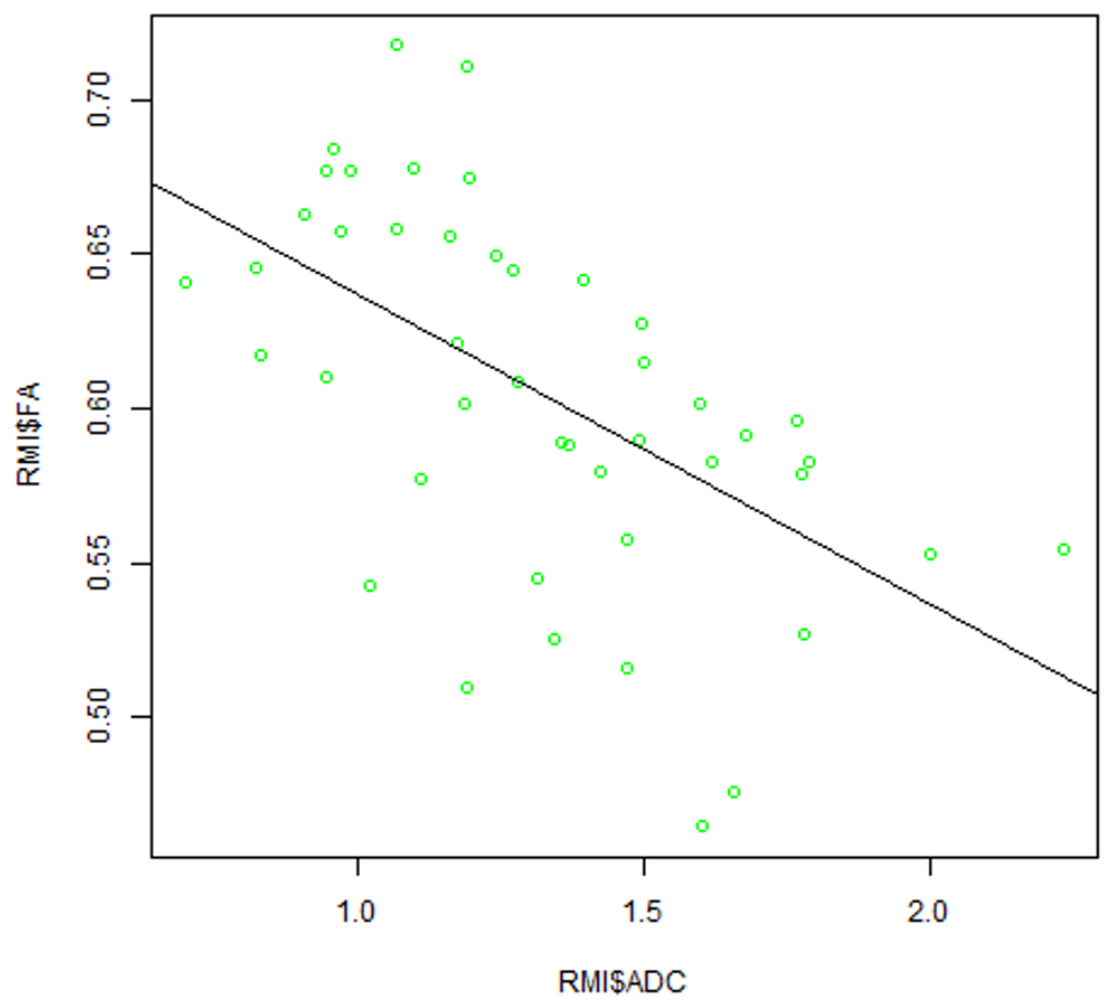

Figura 6.11 Correlación de valores FA con ADC para cada uno de los estudios (5 estudios en total) realizados a cada sujeto experimental $(n=9), 45$ muestras en total. Cálculo del coeficiente de correlación de Pearson, se encontró relación significativa $\left(\mathrm{r}^{2}=0.3153\right.$, $\mathrm{p}<0.01)$

Sin embargo, cuando se realizó el estudio de correlación de las dos variables previamente mencionadas (FA y ADC), con respecto a los valores obtenidos en la escala BBB, durante las semanas que había estudios de resonancia magnética, no se encontró ninguna relación significativa. [Figura 6.10] 

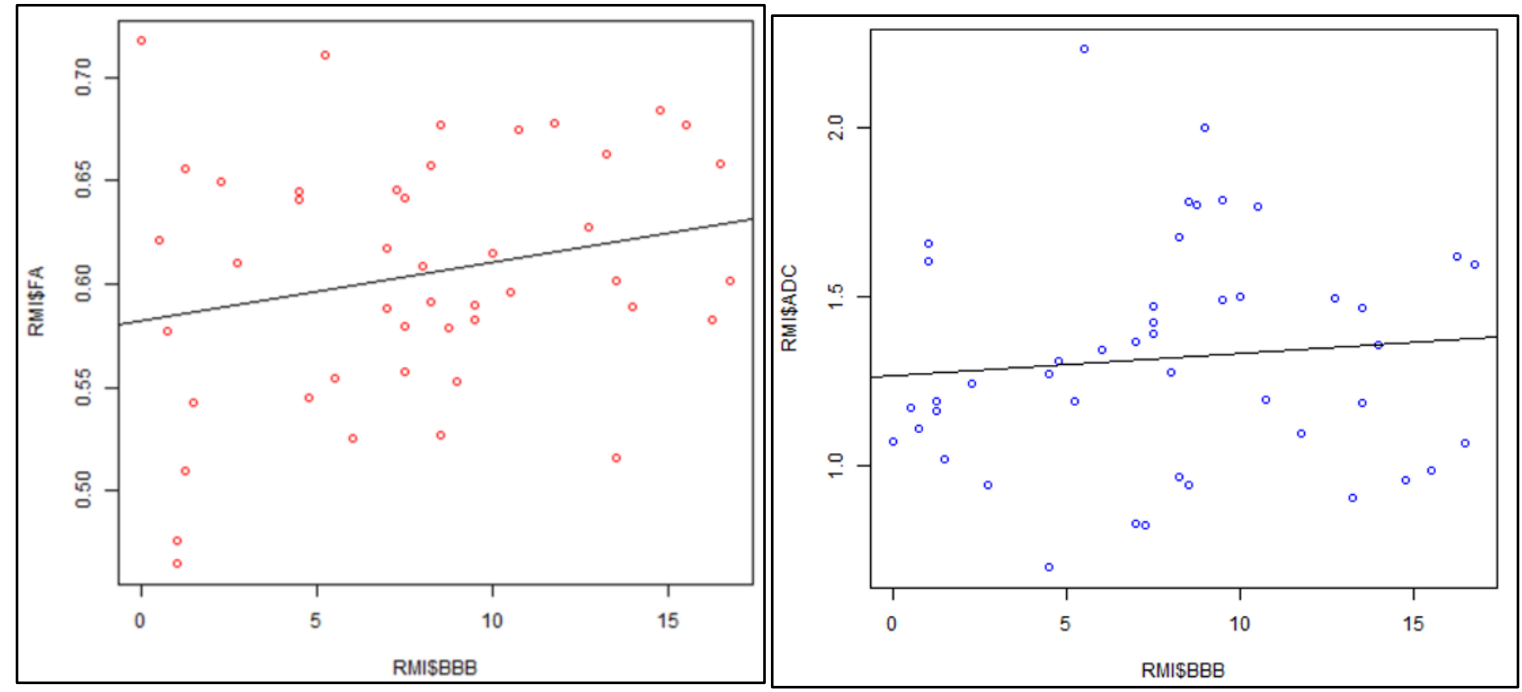

Figura 6.12 Correlación de los puntajes FA (rojo) y ADC (azul), con respecto a las evaluaciones BBB de la semana en la cual se realizó cada estudio de resonancia magnética, 5 estudios en total realizados a cada sujeto experimental $(n=9), 45$ muestras en total. Cálculo del coeficiente de correlación de Pearson, no se encontró relación significativa para $\mathrm{FA}-\mathrm{BBB}\left(\mathrm{r}^{2}=0.0511, \mathrm{p}=0.135\right)$, ni para $\mathrm{ADC}-\mathrm{BBB}\left(\mathrm{r}^{2}=0.026\right.$, $\mathrm{p}=0.208)$ 


\section{Discusión}

"Yo recibo 25 horas por semana de asistencia personal para diferentes tareas.

Tengo pocas personas profesionales (enfermeras) con quienes he tenido una buena química y a quienes les puedo pedir acompañarme cuando veo un viaje por venir. Yo siempre planeo bien los tiempos para disfrutar el curso del viaje, para que mi asistente pueda tener una experiencia positiva cuando me acompaña. Estoy extremadamente complacida con este tipo de asistente personal"

Kjell, Noruega

El material ocupado como implante en este estudio, es similar en composición química con respecto a otros que se han presentado en la misma línea de trabajo. Se muestra que es completamente reproducible en cuanto al método de síntesis; comienza a haber problemas cuando se piensa en el modo de aplicación, ya que no está bien estandarizado cuál es el mejor método, más aún cuando se trabaja con la dosificación para posibles casos futuros en otros animales de experimentación o casos clínicos.

En la evaluación funcional, medida por la escala BBB, se pudo apreciar una mejoría significativa para la media de los valores del grupo implante con respecto a la media del grupo control, un panorama alentador para los casos de LTME. Aunque la mejoría con el implante fue claramente menor, comparada con los estudios realizados en etapas agudas y subagudas, se deben tomar en cuenta los cambios que se pudieron apreciar morfológica y morfométricamente a través de la MRI.

Es evidente que el número de sujetos se debe incrementar en gran medida para poder respaldar de mejor manera los resultados obtenidos en el presente estudio y disminuir la variabilidad de los resultados. Sin embargo, incrementar la cantidad de sujetos representa una gran inversión, a nivel de recursos humanos, infraestructura y financiamiento.

A pesar de ello se considera que es ideal continuar con la línea de investigación en la misma etapa de la LTME, incluso con otras especies animales, ya que se ampliará el conocimiento que se tiene sobre las lesiones y será cada vez más reproducible cada una de las situaciones 
que se presenten; mientras más casos se estudien más conocimiento se tiene de los fenómenos que no se han podido explicar en este documento.

Los resultados obtenidos de las imágenes por resonancia magnética nos muestran que es posible seguir longitudinalmente a los sujetos con lesión traumática de médula espinal; otorgando un posible panorama a la amplificación de su uso en situaciones clínicas. Se considera que es una herramienta con muchísimo potencial a futuro para este tipo de lesiones.

Es relevante mencionar que se requiere una mejora en la calidad de la infraestructura médica de nuestro país, para que se pueda pensar en la resonancia magnética como un método básico en la evaluación de la lesión de médula espinal, ya que, actualmente, no existe la solvencia de equipo necesario para realizar eso con todos los pacientes. Pero, a pesar de ello, se debe comenzar a pensar más en esta herramienta al momento de probar tratamientos, ya que es uno de los métodos que más información puede arrojar sin ser invasivo ni nocivo para la salud de los pacientes.

A pesar de que no se muestran relaciones significativas entre los parámetros obtenidos con resonancia magnética, con respecto al método de evaluación funcional utilizado, escala $\mathrm{BBB}$, hay algunas tendencias comparables entre estas variables. Por ejemplo, en la semana 5 de estudio, después del implante hubo una caída de los valores FA con respecto al inicio, los valores $\mathrm{ADC}$ se incrementaron en gran medida, mientras que la cantidad de tejido preservado disminuía; cuando se les colocó el implante al grupo del mismo nombre, se pudo apreciar un incremento de gran pendiente de la media de los valores FA, un decremento en los valores ADC y la cantidad de tejido preservado comenzó a dejar de disminuir con la tendencia que llevaba. Todos estos factores muestran la misma tendencia que los valores BBB después del implante, la media de estos valores, para el grupo implante, se elevó de manera significativa para las primeras cuatro semanas después del implante.

Posterior a estas semanas de mejoría hubo una disminución de la actividad motriz generalizada en todas las ratas, no se sabe cuál podría ser la causa de esta situación que se encontró en todos los sujetos experimentales. 
Es ideal realizar algunos estudios exvivo a estos mismos sujetos para poder corroborar la información; se prepararon las muestras para realizar estos estudios que se podrían presentar en estudios posteriores con su correspondiente ampliación de número de sujetos, situación que se menciona en el siguiente apartado. 


\section{Conclusiones}

“Tengo 51 años y una lesión completa en T6, paraplejia, causada por la compresión de un coágulo sanguíneo.

Yo estaba impresionado cuando por primera vez estuve paralizado, había recibido el diagnóstico por

parte de un médico en 1984"

Nipapan, Tailandia

Con el presente estudio se mostró que con el uso de un Resonador Magnético de 7T es posible estudiar y establecer el estado de gravedad en los sujetos experimentales, después de una lesión traumática de médula espinal. De igual manera, se puede establecer el efecto longitudinal del polipirrol dopado con yodo en el tejido medular, después de una lesión traumática en fase crónica.

Se mostró que la apreciación cualitativa de las imágenes anatómicas, obtenidas por medio de resonancia magnética, puede dar información sobre el estado de la lesión sin tener que ser invasivo o dañino para los sujetos, permitiendo dar información complementaria a lo observado por otras técnicas experimentales como las evaluaciones funcionales. La MRI otorga información de daños internos que otras técnicas in-vivo son incapaces de proveer.

Además, se muestran opciones cuantitativas y morfométricas, ayudadas por procesamiento de imágenes; tales como FA, ADC y porcentaje de volumen preservado que complementan aún más el pronóstico del estado de la lesión de médula espinal en fase crónica. Resultando en un acercamiento que podría facilitar y ampliar el panorama en el uso de tratamientos clínicos. Sumándose al uso actual de la MRI en el tratamiento de LTME.

En este estudio se mostró una posible viabilidad del uso de PPyI como tratamiento de LTME en fase crónica; la evaluación funcional otorgó una diferencia significativa para el grupo de implante con respecto al grupo control. De igual manera el estudio morfológico de resonancia magnética permitió visualizar cambios relevantes en las ratas del grupo implante, al finalizar el estudio, con respecto al grupo control previo al implante. El estudio 
morfométrico corroboró dicho panorama, ya que presenta ligeros cambios entre los dos grupos de estudio. Debemos recordar que no existe ningún tratamiento capaz de mejorar la funcionalidad en etapa crónica, por lo cual el presente estudio podría convertirse en algo muy representativo para la línea de investigación.

Finalmente, se debe hacer un importante comentario a la continuación de estudios en este rubro, ya que nos encontramos frente a un grave problema de salud mundial; cualquier avance, complemento, ampliación de herramientas o técnicas, puede significar un aporte único a la mejora de la calidad de vida de los pacientes con lesión de médula espinal.

\subsection{Perspectivas}

> Evaluar el efecto del PPy/I después de una lesión de médula espinal, en fase crónica, en otras especies animales que puedan ampliar el panorama experimental.

$>$ Utilizar técnicas histológicas exvivo para comparación con estudios de resonancia magnética a diferentes etapas de la lesión para verificar la precisión y exactitud de esta herramienta.

> Ampliar el número de sujetos experimentales para reducir la dispersión mostrada.

$>$ Establecer parámetros de su uso en los estudios de resonancia magnética, para poder estandarizar una posible aplicación en el diagnóstico clínico.

> Estandarizar las secuencias experimentales de resonancia magnética para reducir posibles errores debidos a la variación entre los sujetos experimentales. 


\section{Anexos}

\section{Anexo A. Escala BBB}

\begin{tabular}{|c|c|}
\hline Score & Operational definitions of categories and attributes \\
\hline 0 & No observable movement of the hindlimbs \\
\hline 1 & Slight (limited) movement of one or two joints, usually hip and/or knee \\
\hline 2 & $\begin{array}{l}\text { Extensive movement of one joint or extensive movement of one joint and slight movement of the } \\
\text { other }\end{array}$ \\
\hline 3 & Extensive movement of two joints \\
\hline 4 & Slight movement of all three joints of the hindlimbs \\
\hline 5 & Slight movement of two joints and extensive movement of the \\
\hline 6 & Extensive movement of two joints and slight movement of the third joint \\
\hline 7 & Extensive movement of the three joints in the hindlimbs \\
\hline 8 & Sweeping without weight bearing or plantar support of the \\
\hline 9 & $\begin{array}{l}\text { Plantar support of the paw with weight bearing only in the support stage (i.e., when } \\
\text { occasional, frequent or inconsistent dorsal stepping with weight bearing and no plantar ste }\end{array}$ \\
\hline 10 & Plantar stepping with occasional weight bearing and no forelimb-hindlimb coordination \\
\hline 11 & Plantar stepping with occasional weight bearing and occasional forelimb-hindlimb coordination \\
\hline 12 & $\begin{array}{l}\text { Plantar stepping with frequent to consistent weight bearing and occasional forelimb-hindlimb } \\
\text { coordination }\end{array}$ \\
\hline 13 & $\begin{array}{l}\text { Plantar stepping with frequent to consistent weight bearing and frequent forelimb-hindlimb } \\
\text { coordination }\end{array}$ \\
\hline 14 & $\begin{array}{l}\text { Plantar stepping with consistent weight support, consistent forelimb-hindlimb coordination and } \\
\text { predominantly rotated paw position (internally or externally) during locomotion both at the instant } \\
\text { of initial contact with the surface as well as before moving the toes at the end of the support stage } \\
\text { or frequent plantar stepping, consistent forelimb-hindlimb coordination and occasional dorsal } \\
\text { stepping. }\end{array}$ \\
\hline 15 & $\begin{array}{l}\text { Consistent plantar stepping, consistent forelimb-hindlimb coordination and no movement of the toes } \\
\text { or occasional movement during forward movement of limb; predominant paw position is parallel to } \\
\text { the body at the time of initial contact. }\end{array}$ \\
\hline 16 & $\begin{array}{l}\text { Consistent plantar stepping and forelimb-hindlimb coordination during gait and movement of the } \\
\text { toes occurs frequently during forward movement of the limb; the predominant paw position is } \\
\text { parallel to the body at the time of initial contact and curved at the instant of movement. }\end{array}$ \\
\hline 17 & $\begin{array}{l}\text { Consistent plantar stepping and forelimb-hindlimb coordination during gait and movement of the } \\
\text { toes occurs frequently during forward movement od limb: the predominant paw position is parallel } \\
\text { to the body at the time of initial contact and at the instant of movement of the toes. }\end{array}$ \\
\hline 18 & $\begin{array}{l}\text { Consistent plantar stepping and forelimb-hindlimb coordination during gait and movement of the } \\
\text { toes occurs consistently during forward movement of limb; the predominant paw position is parallel } \\
\text { to the body at the time of initial contact and curved during movement of the toes. }\end{array}$ \\
\hline 19 & $\begin{array}{l}\text { Consistent plantar stepping and forelimb-hindlimb coordination during gait and movement of the } \\
\text { toes occurs consistently during forward movement of limb; the predominant paw position is parallel } \\
\text { to the body at the instant of contact and at the time of movement of the toes, and the animal presents } \\
\text { a downward tail some or all of the time. }\end{array}$ \\
\hline
\end{tabular}




\begin{tabular}{|c|l|}
\hline 20 & $\begin{array}{l}\text { Consistent plantar stepping and forelimb-hindlimb coordination during gait and movement of the } \\
\text { toes occurs consistently during forward movement of limb; the predominant paw position is parallel } \\
\text { to the body at the instant of contact and at the time of movement of the toes, and the animal presents } \\
\text { consistent elevation of the tail and trunk instability. }\end{array}$ \\
\hline 21 & $\begin{array}{l}\text { Consistent plantar stepping and coordinated gait, consistent movement of the toes; paw position is } \\
\text { predominantly parallel to the body during whole support stage; consistent trunk stability; consistent } \\
\text { tail elevation }\end{array}$ \\
\hline
\end{tabular}




\section{Referencias}

1. Álvarez Mejía, L. Salgado-Ceballos H, Olayo R, Cruz GJ, Olayo MG, Díaz-Ruíz A, Ríos C, Mondragón-Lozano R, Morales-Guadarrama A, Sánchez-Torres S, Morales J. «Effect of Pyrrole Implants Synthesized by Different Methods on Spinal Cord Injuries of Rats.» Revista Mexicana de Ingeniería Biomédica 36, no 1 (2015): 7-21.

2. Álvarez-Mejía, Ana Laura. Tesis para obtener el grado de Maestro en Ciencias (Ingeniería Biomédica): Influencia del campo magnético sobre la regeneración axonal después de un implante de polímero semiconductor en un modelo de lesión por sección completa de la médula espinal. DF: Universidad Autónoma Metropolitana Unidad-Iztapalapa, 2008.

3. Alvarez-Mejía, Laura et al. «Functional recovery in spinal cord injured rats using polypyrrole/iodine implants and treadmill training.» J. Mater Sci: Mater Med 26, $\mathrm{n}^{\circ}$ 209 (2015): 11.

4. Angelova, N. David Hunkeler. «Rationalizing the design of polymeric.» TIBTECH 17 (1999): 409-421.

5. Basser, P.J. et al. «Diffusion-tensor MRI: theory, experimental design and data analysis- a technical review.» NMR Biomed. 15, $\mathrm{n}^{\circ} 7$ (2002): 456-467.

6. Basso D, Beattie M and Bresnahan J. «A sensitive and reliable locomotor rating scale for open field testing in rats.» J. Neurotrauma 21, nº 1 (Feb 1995): 1-21.

7. Bazley, Faith A. «DTI for assessing axonal integrity after contusive spinal cord injury and transplantation of oligodendrocyte progenitor cells.» 34th Annual International Conference of the IEEE EMBS. San Diego, California, USA: IEEE, 2012. 82-85.

8. Bickenbach, J. et al. [eds]. International perspectives on Spinal Cord Injury. Malta: World Health Organization, 2013.

9. Blesch, A. and Tuszynski. «Spinal cord injury: plasticity, regeneration and the challenge of translational drug development.» Trends in Neuroscience 32 (2008): 41-47.

10. Brennan, FH. Kurniawan ND, Vukovic J, et al. «IVIg attenuates complement and improves spinal cord injury outcomes in mice.» Ann Clin Transl Neurol 3, $\mathrm{n}^{\circ} 7$ (2016): 495-511. 
11. Cao, W. Lu X, Cheng Z. «The advancement of human serum albumin-based molecular probes for molecular imaging.» Curr Pharm Des 21, no 14 (2015): 19081915.

12. Chandra, J, F Sheerin, L Lopez de Heredia, T Meagher, D King, M Belci and RJ Hughes. «MRI in acute and subacute post-traumatic spinal cord injury: pictorial review.» Spinal Cord, 2011: 1-6.

13. Chiu, W. et al. «Epidemiology of Traumatic Spinal Cord Injury: Comparisons between developed and developing countries.» Asia-Pacific Journal of Public Health 22, no 1 (January 2010): 9-18.

14. Choi, SY. Kwak BK, Shim HJ, Lee J, Hong SU, Kim KA. «MRI traceability of superparamagnetic iron oxide nanoparticle-embedded chitosan microspheres as an embolic material in rabbit uterus.» Diagn Intery Radiol 21, nº 1 (2015): 47-53.

15. Cruz, GJ, Olayo González MG, Salgado Ceballos H, Díaz Ruíz A, Rios Castañeda C, Olayo González R, Morales Corona J, Álvarez Mejía AL, Mondragón Lozano R, Morales Guadarrama A. Contribuciones del Instituto Nacional de Investigaciones Nucleares al avance de la Ciencia y la Tecnología en México [Chapter 1: Strategy for the Treatment of Spinal Cord Injuries after Complete Section Using Polymeric Implants Synthesized by Plasma]. México, D.F., 2010.

16. Cruz, Guillermo J. Mondragón-Lozano R. Díaz-Ruiz A. Manjarrez J. Olayo R. Salgado-Ceballos H. Olayo MG, Morales J, Alvarez-Mejía L, Morales A, MéndezArmenta M, Plascencia N, Fernández MC, Ríos C. «Plasma polypirrole implants recover motor function in rats after spinal cord transection.»J Mater Sci: Mater Med 23 (2012): 2583-2592.

17. DeVivo, M. et al. «International Spinal Cord Injury Core Data Set.» Spinal Cord 44, no 9 (2006): 535-540.

18. DeVivo, MJ. «Estimating Life Expectancy for Use in Determining Lifetime Costs of Care.» Top Spinal Cord Inj Rehabil 7, nº 4 (2002): 49-58.

19. Díaz-Ruíz, A. «MECANISMOS DE DAÑO Y NEUROPROTECCIÓN EN LA LESIÓN.» MENSAJE BIOQUÍMICO, VOL. XXXVII. México, D.F: Butanda A, Guevara Flores A, Guevara Fonseca J, Matuz Mares D, Rendón E y Vázquez Meza H (eds.), 2013. 69-108.

20. Diaz-Ruiz, A. salgado-Ceballos H, Montes S, Guizar-Sahagun G, Gelista-Herrera N, Mendez-Armenta M, Diaz-Cintra S, Ríos C. «Delayed administration of dapsone protects from tissue damage and improves recovery after spinal cord injury.» $J$ Neurosci Res 89, nº 3 (2011): 373-380. 
21. Dong, Y. and Benveniste E. «Immune function of astrocytes.» Glia 36 (2001): 180190.

22. Doran, M. et al. «Normal and abnormal white matter tracts shown by MR imaging using directional diffusion weighted sequences.» Journal computational assist tomography 66, no 1 (1990): 865-873.

23. Dryden, DM et al. «Direct health care costs after traumatic spinal cord injury.» The Journal of Trauma 59 (2005): 443-449.

24. Fan, H. Hui J, Duan Z, Fan D, Mi Y, Deng J, Li H. «Novel scaffolds fabricated using oleuropein for bone tissue engineering.» Biomed Res Int, 2014.

25. Fitch, M. et al. «Cellular and molecular mechanisms of glial scarring and progressive cavitation: in vivo and in vitro analysis of inflammation-induced secondary injury after CNS trauma.» J. Neurosci. 19 (1999): 8182-8198.

26. Flores, Herrera Daniela, Morales Cozzi Carolina y Ladislao Flores Alvis. «Siringomielia asociado a malformación de Chiari tipo I.»Rev Cient Cienc Med 15, $\mathrm{n}^{\mathbf{o}} 2$ (2012): 49-52.

27. Garzón, T. y Magda Elizabeth. «Trauma raquimedular: factores predictivos de recuperación neurológica a largo plazo.» Repertorio de Medicina y Cirugía 14, no 2 (2005): 74-78.

28. Grossman, RG. Fehlings MG, Frankowski RF, et al. «A prospective, multicenter, phase I matched-comparison group trial of safety, pharmacokinetics, and preliminary efficacy of riluzole in patients with traumatic spinal cord injury.» $J$ Neurotrauma 31, no 3 (2014): 239-255.

29. Grover, Vijay P.B. et al. «Magnetic Resonance Imaging Principles and Techniques: Lessons for Clinicians.» Jorunal of Clinical and Experimental Hepatology 5, $\mathrm{n}^{\mathrm{o}} 3$ (September 2015): 246-255.

30. Grundy D., Swain A. ABC of spinal cord injury. 4th edn. London: BMJ Books, 2002.

31. Guyton, Arthur C. and John E. Hall. Tratado de fisiología médica: Unidad IX El sistema nervioso: A. Principios generales y fisiología de la sensibilidad. 12. Barcelona: Elsevier, 2011.

32. Guyton, Arthur C. Tratado de fisiología médica. México, D.F.: Nueva editorial interamericana, 1984.

33. Hall, Edward D. and Joe E. Springer. «Neuroprotection and Acute Spinal Cord Injury: A Reappraisal.» NeuroRx 1, n⿳0 1 (2004): 80-100. 
34. Hegemann, Dirk. «Plasma polymerization and its applications in textiles.» Indian Journal of Fibre \& Textile Research 31 (2006): 99-115.

35. Hejcl, A, Lesny P, Pradny M, Michalek J, Jendelova P, Stulik J, Sykova E. «Biocompatible hydrogels in Spinal Cord Injury Repair.»Physiological research, 2008: 121-132.

36. Henao-Lema, C. y Pérez-Parra, J. «Lesiones medulares y discapacidad: revisión bibliográfica.» Aquichan 10, nº 2 (2010): 157-172.

37. Holanda, Ledycnarf J. Patricia M M Silva, Thiago C Amorim, Matheus O. Lacerda, Camila R. Simao and Edgard Morya. «Robotic assisted gait as a tool for rehabilitation of individuals with spinal cord injury: a systematic review.» Journal of NeuroEngineering and Rehabilitation 14, $\mathrm{n}^{\circ} 126$ (2017): 7.

38. Jablonska, Anna, Kozlowska H, Markiewicz I, Domanska-Janik K. and Barbara Lukomska. «Transplantation of neural stem cells derived from human cord.» Acta Neurobiol Exp 70 (2010): 337-350.

39. Lammertse, Daniel, David Dungan, James Dreisbach, Scott Falci, Adam Flanders, Ralph Marino, Eric Schwartz. «Neuroimaging in Traumatic Spinal Cord Injury: An evidence-based Review for Clinical Practice and Research.» J Spinal Cord Med. 30, no 3 (2007): 205-214.

40. Liang, Yingkai. Linqing Li, Scott Rebecca A, Kiick Kristi L. «50th Anniversary Perspective: Polymeric Biomaterials: Diverse Functions Enabled by Advances in Macromolecular Chemistry.» Macromolecules 50 (2017): 483-502.

41. Martínez, M et al. «Fisiología cerebral por imágenes: Difusión por tensióntractografía.» Revista Argentina de neurocirugía, 2007: 21,22.

42. Mazaira, J. et al. «Epidemiología de la lesión medular y otros aspectos.» Rehabilitación 32, nº 6 (Junio 1998): 365-372.

43. McIntyre A, Thompson S, Janzen S, Mehta S, Sequeira K, Boyd M, Teasell RW. Syringomyelia Following Spinal Cord Injury. 5. Spinal Cord Injury Rehabilitation Evidence, 2014.

44. McMahon, SS, Albermann S, Rooney GE, Moran C, Hynes J, García Y, Dockery P, O'Brien T, Winderbank AJ, Barry FP. «Effect of cyclosporin A on functional recovery in the spinal cord following contusion injury.» J Anat 215, nº 3 (2009): 267-279.

45. Molina A, et al. «A computerized system for the application of Basso Beattie and Bresnahan scale in Wistar rats.» Acta Ortop Bras 23, no 4 (2015): 179-183. 
46. Mondragón-Lozano R, Ríos C, Roldán-Valadez E, Cruz GJ, Olayo MG, Olayo R, Salgado-Ceballos h, Morales J, Mendez-Armenta M, Álvarez-Mejía L, Fabela O, Morales-Guadarrama A, Sánchez-Torres S, Díaz-Ruíz A,. «Delayed injection of polypyrrole doped with iodine particle suspension after spinal cord injury in rats improves functional recovery and decreased tissue damage evaluated by 3.0 Tesla in vivo magnetic resonance imaging.» The Spine Journal 17, $\mathrm{n}^{\circ} 4$ (2017): 562-573.

47. Mondragon-Lozano, R. et al. «Feasibility of in vivo quantitative magnetic resonance imaging with diffusion weighted imaging, T2-weighted relaxometry and diffusion tensor imaging in a clinical 3-tesla magnetic resonance scanner for the acute traumatic spinal cord injury of rats.» Tech. Spine 38 (2013): 1242-1249.

48. Mondragón-Lozano, Rodrigo. Tesis para obtener el grado de Doctor en Ciencias: Efecto del Polipirrol/Yodo como tratamiento de la lesión de médula espinal de ratas evaluado mediante imágenes de difusión por resonancia magnética in vivo. Ciudad de México: Universidad Autónoma Metropolitana, 2014.

49. Montoto, A. et al. Manual SERMEF de Rehabilitación y Medicina Física. Madrid: Médica Panamericana, 2006.

50. Morales, A. et al. «Estudio de implante de polímero semiconductor en lesión de médula espinal en rata mediante análisis de imágenes.» IFMBE Proc. 18 (2008): 650-653.

51. Morales, J et al. «Synthesis by plasma and characterization of bi-layer anilinepyrrole thin films doped with iodine.» J. Polym Sci Part B 40 (2002): 1850-1856.

52. Morales-Guadarrama, A, Salgado-Ceballos H, Morales J, Ríos C, Cruz GJ, DíazRuíz A, Olayo MG, Álvarez-Mejía L, Mondragón-Lozano R, Olayo R,. «CAT and MRI Studies of Spinal Cord Injured Rats Implanted with PPy/I.»Revista Mexicana de Ingeniería Biomédica 34, no 2 (2013): 145-155.

53. Morales-Guadarrama, A. Salgado Ceballos H, Grijalva I, Morales J, Ríos C, Cruz GJ, Díaz-Ruíz A, Olayo MG, Álvarez-Mejía L, Mondragón-Lozano R, IbañezContreras A, Hernández-Godínez B, Olayo R. «Spinal Cord Injury of Rhesus Monkey Implanted with PPy/I Plasma Polymer, MRI Study.» Editado por A. Braidot and A. Hadad. IFMBE Proceedings 49 (2015): 174-177.

54. Morsi, YS. «Bioengineering strategies for polymeric scaffold for tissue engineering an aortic heart valve: an update.» Int J Artig Organs 37, nº 9 (2014): 651-667.

55. Nacher, Pierre-Jean. «Magnetic Resonance Imaging: From Spin Physics to Medical Diagnosis.» Quantum Spaces, 2007: 1-35. 
56. National Spinal Cord Injury Statistical Center. Annual Statistical Report for the Spinal Cord Injury Model System Public Version. Birmingham, Alabama: University of Alabama at Birmingham, 2016.

57. National Spinal Cord Injury Statistical Center. Facts and Figures at a Glance. Birmingham: AL: University of Alabama at Birmingham, 2016.

58. Nguyen, D.H. Newton Cho, Kajana Satkunendrarajah, James W Austin, Jian Wang and Michael G Fehlings. «Immunoglobulin G (IgG) attenuates neuroinflammation and improves neurobehavioral recovery after cervical spinal cord injury.» Journal of Neuroinflammation 9, $\mathrm{n}^{\circ} 224$ (2012): 1-14.

59. Oakden, W., Meaghan A. O'Reilly, Margarete K. Akens, Isabelle Aubert, Cari Whyne, Kullervo Hynynen, Greg J. Stanisz. «Quantitative MRI in a non-surgical model of cervical spinal cord injury.» NMR Biomed. 28, $\mathrm{n}^{\circ} 8$ (2015): 925-936.

60. Oyinbo, C.A. «Secondary injury mechanisms in traumatic spinal cord injury: a nugget of this multiply cascade.» Acta Neurobiol Exp 71 (2011): 281-299.

61. Papastefanaki, F. Chen J, Lavdas AA, Thomaidou D, Schachner. «Grafts of Schwann cells engineered to express PSA-NCAM promote functional recovery after spinal cord injury.» Brain 130 (2007): 2159-2174.

62. Pérez, Ramiro. et al. «Aspectos epidemiológicos de la lesión medular de la población del Centro Nacional de Rehabilitación.» Revista Mexicana de Medicina Física y Rehabilitación 20 (2008): 74-82.

63. Pooley, Robert A. «AAPM/RSNA Physics Tutorial for Residents: Fundamental Physics of MR Imaging.» RadioGraphics 25 (2005): 1087-1099.

64. Popovich, P. et al. «Cellular inflammatory response after spinal cord injury in sprague-dawley and lewis rats.» Journal of Comparative Neurology 377 (1997): 443-464.

65. Recio Rodríguez, M. et al. «Imagen de tractografía 3T: anatomía y aplicaciones clínicas.» Radiología 55 (2013): 57-68.

66. Rodríguez, A.O. «Principles of magnetic resonance imaging.» Revista mexicana de física 50, nº 3 (2004): 272-286.

67. Royal College of Physicians, British Society of Rehabilitation Medicine, Multidisciplinary Association of Spinal Cord Injury Professionals, British Association of Spinal Cord Injury Specialists, Spinal Injuries Association. «Chronic spinal cord injury: management of patients in acute hospital settings: national guidelines.»Concise guidance to good practice: A series of evidence-based guidelines for clinical management, $\mathrm{n}^{\circ} 9$ (2008): 1-15. 
68. Salgado-Ceballos, H. Guizar-Sahagun G. Feria-Velasco A. Grijalva I, Espitia L. Ibarra A, Madrazo I. «Spontaneous long-term remyelination after traumatic spinal cord injury in rats.» Brain Res. 782 (1998): 126-135.

69. Saremi, F. «Post-traumatic chronic spinal cord injury: assessment with MRI.» Medical Journal of the Islamic Republic of Iran 9, no 2 (1995): 83-89.

70. Satkunendrarajah, K. Nassiri F, Karadimas SK, et al. «Riluzole promotes motor and respiratory recovery associated with enhanced neuronal survival and function following high cervical spinal hemisection.» Exp Neurol 276 (2016): 59-71.

71. Scherzinger, Ann L. and William R. Hendee. «Basic principles of magnetic resonance imaging.»High-tech medicine 143, nº 6 (1985): 782-792.

72. Scholpa, Natalie E. and Rick G. Schnellmann. «Mitochondrial-Based Therapeutics for the Treatment of Spinal Cord Injury: Mitochondrial Biogenesis as a Potential Pharmacological Target.» J Pharmacol Exp Ther 363, no 3 (2017): 303-313.

73. Simard JM, Tsymbalyuk O, Ivanov A, et al. «Endothelial sulfonylurea receptor 1regulated NC Ca-ATP channels mediate progressive hemorrhagic necrosis following spinal cord injury.» J Clin Invest 117, nº 8 (2007): 2105-2113.

74. Stehling, Michael K., Robert Turner, y Peter Mansfield. «Echo-Planar Imaging: Magnetic Resonance Imaging in a Fraction of a Second.» Science 254, $\mathrm{n}^{\circ} 5028$ (1991): 43-50.

75. Tahara, Y. Nakashi K, Ji K, Ikeda A. Toko K. «Development of a portable taste sensor with a lipid/polymer membrane.» Sensors (Basel) 13, nº 1 (2013): 1076-1084.

76. Tanhoffer AR, Yamazaki KR , Nunes AE, Pchevozniki IA, Pchevozniki MA, Nogata C Aikawa J, Bonatto JS, Brito G, Lissa DM, Fernandes CL. «Glutamine concentration and inmune response of spinal cord-injured rats.» J Spinal Cord Med 30 (2007): 140-146.

77. Thottappillil, Neelima and Prabha D Nair. «Scaffolds in vascular regeneration: current status.» Vasc Health Risk Manag 11 (2015): 79-91.

78. Thuret S, Moon LD and Gage FH. «Therapeutic interventions after spinal cord injury.» Nat Rev Neuroscience 7 (2006): 628-643.

79. Tortosa, A. «Infermera Virtual.» Infermera Virtual. 2009. https://www.infermeravirtual.com/files/media/file/99/Sistema\%20nervioso.pdf?13 58605492 (último acceso: 22 de agosto de 2017).

80. Tran, NM. Dufresne M, Helle F, Hoffmann TW, Francois C, Brochot E, Paulier P, Legallais C, Duverlie G, Castelain S. «Alginate hydrogel protects encapsulated 
hepatic $\mathrm{HuH}-7$ cells against hepatitis $\mathrm{C}$ virus and other viral infections.» PLoS One 9, no 10 (2014): e109969.

81. Ulndreaj, Antigona, Anna Badner and Michael G. Fehlings. «Promising neuroprotective strategies for traumatic spinal cord injury with a focus on the differential effects among anatomical levels of injury.» F1000Res 6 (2017): 1907.

82. Varoqui, D. Xun Niu, Mehdi M. Mirbagheri. "Ankle voluntary movement enhancement following robotic-assisted locomotor training in spinal cord injury.» Journal of NeuroEngineering and Rehabilitation 46 (2014): 11.

83. Vedantam, Aditya et al. «Diffusion tendor imaging of the spinal cord: A review.» Coluna 12, no 1 (2013): 64-69.

84. Wang, S and Volk T. «Composite biopolymer scaffolds shape muscle nucleus: Insights and perspectives from Drosophila.» Bioarchitecture 5, no 3-4 (2015): 3543.

85. Warden, P. et al. «Delayed glial cell death following wallerian degeneration in white matter tracts after spinal cord doral column cordotomy in adult rats.» Exp. Neurol. 168 (2001): 213-224.

86. WHO. International perspectives on Spinal Cord Injury. Malta: World Health Organization, 2013.

87. Wydeven, T. and R. Kubacki. «Antireflection coating prepared by plasma polymerization of perfluorobutene-2.» Appl. Opt. 15 (1976): 132-136.

88. Xiong, Yiqin. Doctoral Dissertation: ROLE OF REACTIVE OXYGEN SPECIES PEROXYNITRITE IN TRAUMATIC SPINAL CORD INJURY. Kentucky: University of Kentucky UKnowledge, 2008.

89. Zhang, Cuo. et al. «Feasibility of $3.0 \mathrm{~T}$ diffusion-weighted nuclear magnetic resonance imaging in the evaluation of functional recovery of rats with complete spinal cord injury.» Neural Regeneration Research 10, ${ }^{\circ} 3$ (2015): 412-418. 
BETODIO DEL EFECTO DEL

POSTPIRROL DOPNDO CON YODO, SINETIZADO DOR PLASMA, BK Butas con Lesido ClóntCA de NEDOLA ESPTKRL, POR MEDIO DE Mat.
In la Ciudad de Mexico, se presestaron a 1as 10:00 horas del dia 16 del men de abril del ano 2018 en la llaidad Iztapalapa de la Univerafdad Autónena Metropolitana, 105 auscritos nienbros del jurado:

DR, JOSE BFBEN ISGAEL, CRIJALVR OTERO

DR, JUAN CRRLOS NXOYACAYL MCQALES GUABAORANR

DE. JoEr TOAOUTA AZPIRCQ IBERAN

Bajo la Presidencia del primero y con cardoter de seoretario el ditino, se zeanieron para proceder al Exomen de Grado euys denoninacion aparece al aloger, para th cbtencion del grado te:

vaEsTho rn CTENCTAS (TNOBHIBATA BICAEDICA)

DET RRTURO HERMAMDES MEDINA

7 de acuerdo con el articuto 78 fracoión III del Beglarento de Ratudita superiorea de la Vniversidad Autbnona Metropolitana, los afanbroa del fursdo resotvieron:

ARTURO HERNANDEZ MEDINA ALUMNO

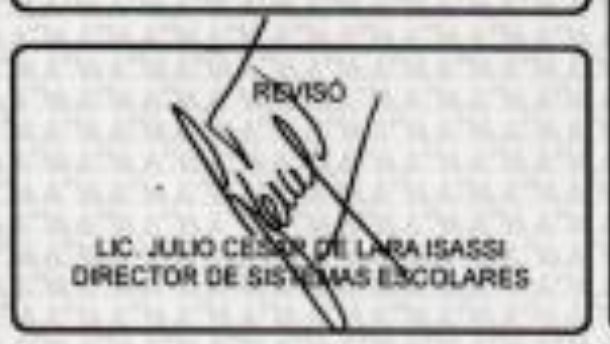

DRECTOR DE LADMSION OE CBI

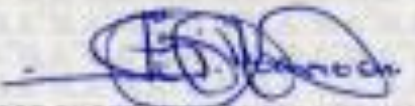

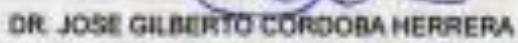

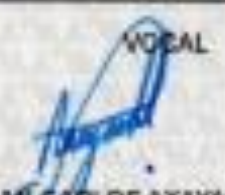

DR. JUAC CARLOS NATKCATL MORALES GUAOARRAMA

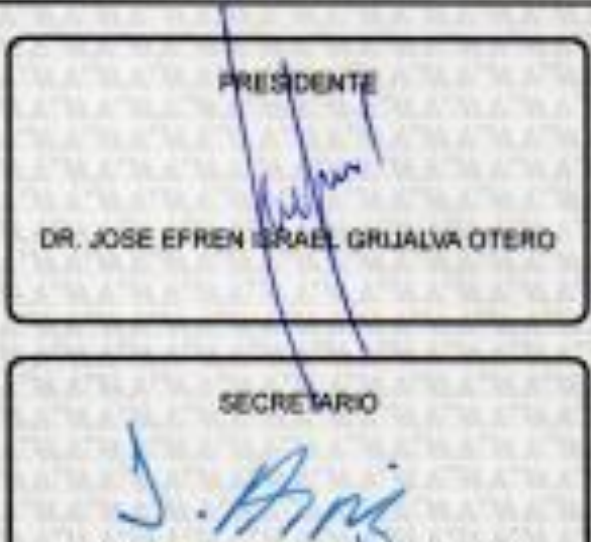

Dit JOSE JOAOUN AzPhOZ LEEHAN 